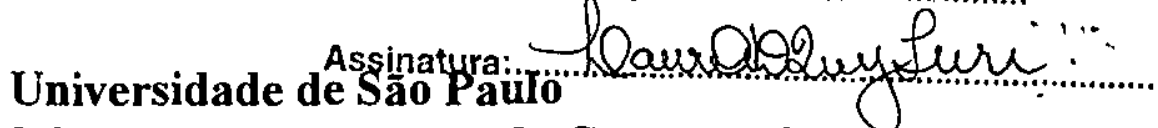
Data de Depósito $2,5,99$ Instituto de Ciências Matemáticas e de Computação Departamento de Ciências de Computação e Estatística

\title{
Algoritmos para Indexação de Dados Espaciais Pontuais em Gerenciadores de Objetos ${ }^{1}$
}

\author{
Roberto Figueira Santos Filho
}

Orientação:

Profa. Dra. Agma Juci Machado Traina

Dissertação apresentada ao Instituto de Ciências Matemáticas e de Computação - ICMCUSP - como parte dos requisitos para obtenção do título de Mestre em Ciências de Computação e Matemática Computacional

ICMC-USP, São Carlos.

Maio de 1999

\footnotetext{
${ }^{1}$ Este trabalho teve apoio financeiro da FAPESP.
} 
Dedico este trabalho a meus pais,

Maria Amélia e Roberto. 


\section{AGRADECIMENTOS}

À Profa. Dra. Agma Juci Machado Traina, sempre presente e atenciosa, pelo apoio e confiança que dispensou durante a elaboração deste trabalho.

Ao Prof. Dr. Caetano Traina Júnior, pela amizade e pelas valiosas contribuições que muito contribuiram para o aprimoramento deste trabalho.

À Profa. Dra. Maria Cristina Ferreira de Oliveira pelo apoio como Orientadora Acadêmica.

A Beth, Laura e Marília, Seção de Pós-Graduação, e a Adriana e Sandrinha, Seção de Convênios, pela simpatia e atenção com que sempre me atenderam.

A Rose e Gláucia, Biblioteca, pela grande ajuda com as referências bibliográficas.

A Paulinho, Audiovisual, pela atenção com que sempre me atendeu.

A meus irmãos pela amizade e pelo incentivo que sempre me deram. Em especial, a Maria Carmen e Patrícia.

Ao pessoal do Grupo de Base de Dados e Imagens - ICMC-USP, pela atenção nas prévias, pelas constantes sugestões e, principalmente, pela amizade. Em especial, aos amigos Carlos Roberto Valêncio, Marisa Beck, Mauro Biajiz e Rildo Ribeiro dos Santos.

Aos amigos que, direta ou indiretamente, contribuíram com seu apoio. Em especial, a todo o pessoal da Jbe, a meu primo Octaviano Menezes e ao amigo Marcos André Kutova.

À FAPESP, pelo apoio financeiro dado para o desenvolvimento deste trabalho. 


\section{Resumo}

$\mathrm{O}$ armazenamento e a recuperação de imagens podem fazer-se pela indexação de características extraidas, automaticamente, por algum procedimento computacional. Estas características são muitas vezes constituídas por valores numéricos sob a forma de vetores, representando coordenadas de pontos no espaço cuja dimensão é determinada pela quantidade destes valores. Diversos métodos de indexação voltados para este tipo de dados têm sido estudados e desenvolvidos no contexto de Sistema Gerenciadores de Banco de Dados, tidos como Métodos de Indexação Espacial, com o intuito de melhorar o desempenho do acesso às informações

O presente trabalho se inicia pela exposição de como o Modelo de Dados SIRIUS define "Imagem" como tipo de dados abstrato, visando o desenvolvimento de aplicações na área médica, e como algoritmos de extração de características são associados a este tipo. Em seguida, fez-se o estudo sobre dados espaciais envolvendo: definições, propriedades, aplicações e métodos de indexação espacial, onde os métodos R-Tree e TV-Tree são descritos. Por fim, discutiu-se o resultado de testes feitos com esses métodos, utilizando conjuntos de pontos entre as dimensões 2 e 255, o que aponta o segundo (TV-Tree) como o mais adequado a aplicações que trabalham com pontos em dimensões distintas e elevadas. Dessa forma, pôde-se definir qual o método mais preferencial a ser incorporado ao Gerenciador de Objetos do SIRIUS, afim de efetuar a indexação do tipo de dados "Imagem" nesse ambiente. 


\section{Abstract}

The retrieval of images from databases using features automatically extracted from the stored material takes advantage of all information contained in the images, and it precludes human analysis. The features extracted are typically arrays of numbers that are used by index structures as points in an $n$-dimensional space, where $n$ is the size of the feature array. Recently, many indexing methods for the image data type have been studied and developed on the context of Data Base Management Systems. Such methods are known as Spatial Data Structures or Multidimensional Access Methods.

This work briefly introduces how "Images" are defined as an abstract data type in the SIRIUS Data Model, and how feature extraction algorithms can be associated to this data type. The approach is aimed toward a medical domain application context. Therefore, the most important spatial data types are studied, describing their properties, common applications and indexing methods. The methods R-Tree and TV-Tree are described in detail. Finally, the results of the tests performed using these methods for point data sets within the dimensions 2 and 255 are presented. It was seen that the TV-Tree method is better suited for applications that need to work with point data in distinct and high dimensions. Thus, the TV-tree method can be used in the SIRIUS/GO Object Manager. 


\section{Sumário}

1. INTRODUÇÃO 1

1.1 Considerações Iniciais 2

1.2 Definição do Problema 4

1.3 Organização do Trabalho 5

2. TIPO dE DAdOS IMAgEM NO MOdELO SIRIUS 7

2.1 Introdução $\quad 8$

2.2 TAD Imagem no Modelo SIRIUS 9

2.2.1 Constante-Imagem 10

2.2.2 Sumarizadores 11

2.2.3 Parâmetros das Imagens 13

2.3 Meta-Esquema do TAD Imagem em SIRIUS $\quad 14$

2.4 Conclusão 16

3. Dados Espacials 17

$\begin{array}{lll}3.1 & \text { Introdução } & 18\end{array}$

3.2 Representação de Dados Espaciais 20

3.3 Consultas Espaciais $\quad 25$

3.3.1 Definições preliminares $\quad 25$

3.3.2 Operadores espaciais 26

3.4 Métodos de Indexação Espacial 30

3.4.1 Definições preliminares 30

3.4.2 R-Tree $\quad 33$

3.4.2.1 Introdução 34

3.4.2.2 Estrutura de dados 34

3.4.2.3 Consulta 36

3.4.2.4 Inserção 36

3.4.2.5 Remoção 38

3.4.2.6 Particionamento 39

3.4.3 TV-Tree 41

3.4.3.1 Introdução $\quad 41$

3.4.3.2 Estrutura de Dados $\quad 43$

3.4.3.3 Consulta 45

3.4.3.4 Inserção 46

3.4.3.5 Particionamento 47

3.4.3.6 Remoção 48

3.5 Exemplos de Aplicação e Trabalhos Relacionados 48

3.6 Conclusão $\quad 50$

4. AVALIANDO os MIEs R-TREE TV-TREE

4.1 Introdução 53

4.2 Descrição das Simulações

4.3 R-Tree $\quad 57$

4.3.1 Resultados $\quad 59$ 
4.3.2 Discussão $\quad 66$

$\begin{array}{lll}4.4 & \text { TV-Tree } & 68\end{array}$

4.4.1 Resultados $\quad 69$

4.4.2 Discussão $\quad 74$

4.5 R-Tree X TV-Tree $\quad 76$

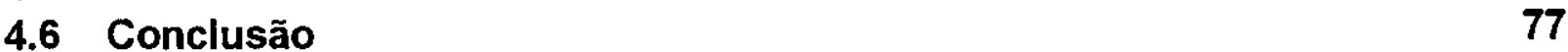

5. CONClusões $\quad 79$

5.1 Considerações Iniciais $\quad 80$

$\begin{array}{lll}5.2 & \text { Principais Contribuições } & 82\end{array}$

5.3 Propostas de Trabalhos Futuros $\quad 83$

REFERÊNCIAS BIBLIOGRÁFICAS $\quad 85$ 


\section{Lista de Figuras}

Figura 1: Meta-esquema de definição de uma aplicação com o TAD imagem em

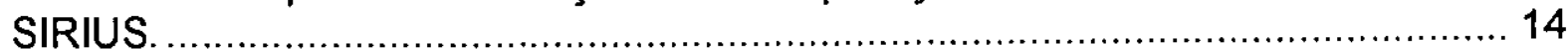

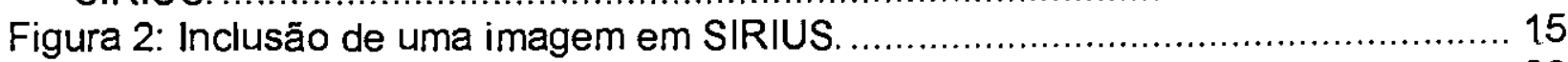

Figura 3: Etapas de uma consulta espacial............................................................ 26

Figura 4: Exemplo de uma operação Point Query. ................................................. 27

Figura 5: Exemplo de uma operação Window Query................................................ 27

Figura 6: Exemplo de uma operação Intersection Query. ........................................... 28

Figura 7: Exemplo de uma operação Enclosure Query................................................ 28

Figura 8: Exemplo de uma operação Containment Query ............................................. 28

Figura 9: Exemplo de uma operação Adjacency Query. ............................................. 29

Figura 10: Evolução dos Métodos de Indexação Espacial [Gaede \& Günther, 98]...... 31

Figura 11: Exemplo de uma R-Tree. a) Representação em memória; b) Representação

espacial com os MBRs. ......................................................................... 35

Figura 12: Exemplo de um particionamento. a) Particionamento ruim; b)

Particionamento bom.

Figura 13: Exemplos de TMBRs (em forma de Diamantes e Esferas). a) $\alpha=1$; b) $\alpha=2$;

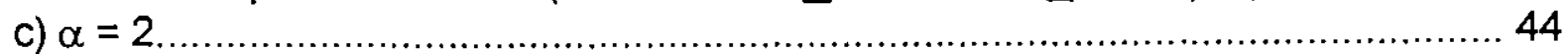

Figura 14: Exemplo de uma $T V-1$ (MBRs em forma de diamantes)............................ 45

Figura 15: Exemplo de uma TV-2 (MBRs em forma de esferas).............................. 45

Figura 16: Exemplo de inserção. O TMBR $D 1$ é ajustado para incluir o ponto $P$......... 46

Figura 17: $R$-Tree - Altura após 10.000 inserções. .................................................. 59

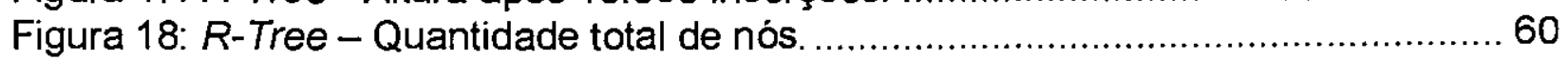

Figura 19: Variância (em escala logarítmica) das 256 coordenadas dos 10.000 pontos

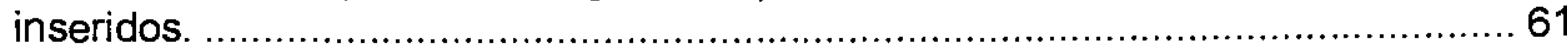

Figura 20: $R$-Tree-Nós particionados por ponto inserido, considerando as 1.000

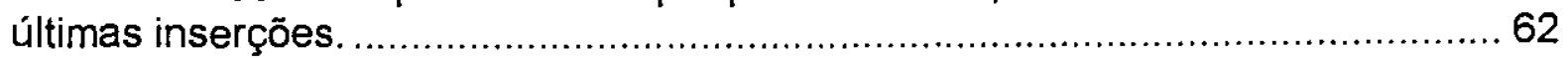

Figura 21: $R$-Tree - Tempo total de inserção para os últimos 1.000 pontos. ............... 63

Figura 22: $R$-Tree - Número de nós acessados por ponto consultado vs. dimensão. . 65

Figura 23: $R$-Tree - Tempo médio de processamento de um nó em função da

dimensão, durante a fase de consulta.............................................................6

Figura 24: TV-Tree - Altura da árvore após 10.000 inserções. .................................. 69

Figura 25: TV-Tree - Quantidade total de nós após 10.000 inserçöes...................... 70

Figura 26: TV-Tree - Taxa de ocupação após 10.000 inserções. ............................. 70

Figura 27: TV-Tree - Nós acessados por inserção para os últimos 1.000 pontos....... 71

Figura 28: TV-Tree - Tempo total de inserção dos últimos 1.000 pontos .................... 72

Figura 29: TV-Tree - Número de nós acessados por ponto consultado vs. dimensão. 73

Figura 30: TV-Tree - Tempo total de 1.000 consultas vs. dimensão. ........................ 73

Figura 31: TV-Tree - Tempo médio de processamento de um nó em função da

dimensão, durante a fase de consulta............................................................... 74

Figura 32: R-Tree X TV-Tree - Nós particionados por inserção, considerando os

últimos 1.000 pontos. 


\section{Lista de Tabelas}

Tabela 1: Quantidades máxima e minima de entradas por nó da $R$-Tree em função da dimensăo em teste.

Tabela 2: Simulações utilizando a $R$-Tree terminadas com sucesso. ......................... 58

Tabela 3: $R$-Tree - Configuraçăo após a inserção de 10.000 pontos ......................... 59

Tabela 4: $R$-Tree - Desempenho da inserção. Foram considerados apenas os últimos 1.000 pontos.

Tabela 5: $R$-Tree - Desempenho obtido com 1.000 consultas por coincidência exata. 64

Tabela 6: Faixa de valores correspondente ao número máximo de entradas por nó em funçăo das dimensōes de teste da $T v$-Tree. Esta faixa corresponde ao intervalo encontrado nos diferentes niveis dos respectivos indices.

Tabela 7: TV-Tree - Configuração após a inserção de 10.000 pontos. 69

Tabela 8: TV-Tree - Desempenho da inserção. Foram considerados apenas os últimos 1.000 pontos.

Tabela 9: TV-Tree - Desempenho obtido com 1.000 consultas por coincidência exata. 72 


\section{Abreviaturas}

BD

Base de Dados

BI

Base de Imagens

MBR

Minimum Bounding Rectangle (mínimo retângulo externo a um objeto espacial)

MIE Método de Indexação Espacial

PACS Picture Archiving and Communication System (Sistema de Armazenamento e Comunicação de Imagens)

PAM Point Access Methods (Métodos de Acesso Pontual)

SGBD Sistema de Gerenciamento de Base de Dados

SIRIUS/GO Gerenciador de Objetos para o modelo de dados SIRIUS

TAD Tipo Abstrato de Dados

TMBR Telescopic Minimum Bounding Region (mínimo retângulo externo a um objeto espacial) 
1. INTRODUÇÃO 


\section{INTRODUÇÃO}

\subsection{Considerações Iniciais}

O uso de estruturas de indexação para auxiliar o armazenamento e a recuperação eficientes de dados textuais ou numéricos tem sido muito estudado. Diversas estruturas foram desenvolvidas para atender a múltiplas necessidades [Elmasri \& Navathe, 94] [Folk et al., 98], tais como: tamanho do conjunto de dados (armazenamento em memória principal X memória secundária), possibilidade de inclusão e exclusão de dados após a construção do índice (conjunto de dados dinâmicos $\mathrm{X}$ conjunto de dados estáticos), formas de consulta e de acesso (acesso direto $\mathrm{X}$ acesso seqüencial), dentre outras.

Torna-se possível a indexação desses tipos de dados, principalmente, porque existe uma relação de ordem entre seus elementos. Porém, os Sistemas de Gerenciamento de Bases de Dados (SGBDs) têm sido cada vez mais utilizados para aplicações "não tradicionais", tais como: áudio digitalizado, partituras musicais [Beck, 97], circuitos eletrônicos, hipertextos, imagens diversas [Petrakis \& Faloutsos, 97] [Schneider, 97] [Traina et al., 98], etc. Em geral, não é possível identificar uma relação de ordem entre os elementos que compõem estes conjuntos. A dificuldade está na definição de um critério que permita estruturá-los [Gudivada \& Raghavan, 95]. Em outras palavras, não é possível dizer que uma imagem é "menor" (está antes) ou é "maior" (está depois) do que outra com base, apenas, em seu conteúdo pictórico.

Com o intuito de preencher esta lacuna novas técnicas de indexação têm sido desenvolvidas Dentre elas, está a extração (automática ou não) de características dos dados a serem indexados, as quais podem estar sob diferentes formas, como vetores [LinK et al., 94] [Berchtold et al., 96] [Chakrabarti \& Mehrotra, 99] ou conjuntos de atributos [Petrakis \& Faloutsos, 97]. Supõe-se que as características sejam definidas e geradas de maneira a estarem em um domínio que possa ser ordenado, tornando possível, então, a criação de estruturas de indexação que fazem o mapeamento entre o que foi extraído e seus respectivos dados de origem. Exemplos de características são: grafos relacionais de atributos (Attributed Relational Graphs - ARGs) [Petrakis \& Faloutsos, 97], descritores de formatos (shape descriptors) [Jagadish, 91], 
histogramas de cores [Santos et al., 96], descritores de Fourier (Fourier descriptors) [Berchtold et al., 96], etc.

Mais especificamente, os elementos que compõem as características geradas sob a forma de vetores (também conhecidas por vetores de caracteristicas, ou feature vectors), podem ser vistos como coordenadas de pontos no espaço. Desta forma, a noção de semelhança entre os vetores passa a equivaler à noção de proximidade entre os pontos. Equivalendo, conseqüentemente, à semelhança entre os objetos de origem.

Outras características, cuja representação é mais complexa do que um simples ponto, são geralmente vistas como regiões intervalares ou outra forma geométrica, envolvendo, ainda, noções do tipo interseção, fronteira, continência, etc. Devido à associação com objetos no espaço, as estruturas que indexam estes tipos de dados são conhecidas como Métodos de Indexação Multidimensionais ou Métodos de Indexação Espaciais. E os objetos assim definidos são conhecidos por Dados Espaciais.

O presente trabalho refere-se ao estudo e à comparação de estruturas de indexação que suportam a armazenagem e a recuperação de dados espaciais, tendo como aplicação principal a indexação de características extraídas automaticamente de imagens em bancos de dados. Sua motivação tem origem em um projeto maior, chamado CAMS/SIRIUS, que objetiva o desenvolvimento de um ambiente de apoio voltado para a Medicina (Computer-Aided Medical Systems - CAMS), utilizando o Modelo de Dados SIRIUS [Biajiz, 96]. Em complemento a este ambiente, está sendo desenvolvido, também, um Sistema de Arquivamento e Comunicação de Imagens (Picture Archiving and Communication Systems - PACS) para auxiliar o diagnóstico médico.

Fazem parte deste projeto o Grupo de Base de Dados e Imagens (GBdI) do Instituto de Ciências Matemáticas e de Computação da USP em São Carlos (ICMC-USP); o Instituto de Biociências, Letras e Ciências Exatas da Universidade Estadual Paulista Júlio de Mesquita Filho em S. J. Rio Preto - IBILCE-UNESP; o Centro de Ciências das Imagens e Física Médica do Hospital das Clínicas da Faculdade de Medicina de Ribeirão Preto - HC-FMRP-USP; e os grupos de Instrumentação Eletrônica e de Ressonância Magnética do Instituto de Física de São Carlos - 
IFSC-USP, sendo que este último mantém, ainda, um intercâmbio de cooperação com a Santa Casa de Misericórdia de São Carlos.

Será apresentada, inicialmente, uma breve descrição do modelo de dados SIRIUS [Biajiz, 96], o qual está sendo utilizado para o desenvolvimento do ambiente $C A M S$, e de como o tipo de dados imagem é tratado neste modelo. Será feita, em seguida, uma revisão bibliográfica em torno de Dados Espaciais, abrangendo: conceitos, propriedades, exemplos de métodos de indexação e aplicações.

Em seguida, serão discutidos dois métodos de indexação espaciais visando o problema apresentado na seção 1.2. Estes métodos foram testados e avaliados com vetores de características gerados artificialmente, simulando o algoritmo de extração de histograma de cores. Os passos que envolvem a simulação, o processo de criação do conjunto de teste, os resultados obtidos e as respectivas conclusões são apresentados, indicando o método de indexação mais adequado à solução do problema.

\subsection{Definição do Problema}

Conforme dito na seção anterior, este trabalho envolve a indexação de imagens a partir de vetores de características, os quais podem ser tratados como pontos no espaço cuja dimensão é definida pela quantidade de elementos que compõem os vetores. Como exemplo de características foram citados: histogramas de cores, descritores de Fourier e outros.

Como diferentes tipos de características geram vetores com quantidades diferentes de elementos, os conjuntos de pontos, relativos a cada característica, se encontram em espaços de dimensões diferentes. Espera-se, então, que seja criado um índice para cada tipo de característica que possa vir a ser extraída das imagens. Porém, o algoritmo de indexação utilizado para manipular estes índices deve ser o mesmo, visto que os objetos que serão indexados, independente da característica, correspondem a pontos. Ou seja, um único método de indexação deve ser aplicado aos diferentes tipos de características gerando índices diferentes. 
Observa-se, ainda, que a quantidade de elementos que podem compor estes vetores varia muito com relação aos diferentes tipos de características. Por exemplo, uma característica pode ter até mais que 200 elementos: um histograma de cores de imagens digitais de 8 bits, em tons de cinza, pode ter 256 tons diferentes [Santos et al., 96].

O capitulo 2, a seguir, detalha a solução apresentada pelo Modelo SIRIUS para esta diversidade de tipos de características e como as estruturas de indexação são incorporadas. Por enquanto, será apenas comentada a necessidade da existência de índices diferentes para tipos de características $^{2}$ distintos, sem aprofundar a questão de como os indices são usados para armazenar e recuperar as imagens.

A proposta deste trabalho é estudar os diversos métodos de indexação espaciais existentes e identificar aquele que melhor atenda aos seguintes requisitos:

- suportar conjuntos distintos de pontos em espaços com dimensões variadas, podendo atingir valores na ordem das centenas;

- suportar armazenamento secundário;

- ser dinâmico (possibilidade de incluir e excluir dados ao longo do tempo).

\subsection{Organização do Trabalho}

Este trabalho apresenta a seguinte organização:

- capítulo 1: são apresentadas as idéias que motivaram o desenvolvimento do presente trabalho e sua organização;

- capítulo 2: é apresentada a forma como o Modelo SIRIUS trata o tipo de dados "imagem", mostrando a importância deste trabalho dentro do projeto que envolve o desenvolvimento do ambiente CAMS. É apresentado, ainda, onde o método aqui indicado se incorpora a este ambiente;

\footnotetext{
${ }^{2}$ A partir deste ponto, o termo "tipos de características" será tratado por "classes de características".
} 
- capítulo 3: é apresentada uma revisão bibliográfica sobre dados espaciais, abrangendo: definições, exemplos de consultas, exemplos de métodos de indexação espaciais, exemplos de aplicações, etc.;

- capítulo 4: são apresentados resultados de simulações com os métodos apresentados na seção 3.4 , assim como as conclusões em torno destes resultados, indicando o método que atende aos requisitos comentados anteriormente (seção 1.2);

- capítulo 5: são apresentadas as conclusões finais e propostas para futuras pesquisas;

- Referências Bibliográficas. 
2. Tipo de Dados Imagem no Modelo SIRIUS 


\section{TIPO DE DADOS IMAGEM NO MODELO SIRIUS}

\subsection{Introdução}

Os exames médicos podem gerar uma grande quantidade de dados em formato digital provenientes dos diversos equipamentos computadorizados [Dutton, 90] (TRM, radiografias, ultra-sonografia, eletrocardiograma, etc.). Observa-se que boa parte desses instrumentos é voltada à geração de imagens gráficas. Para organizar e divulgar informações de um centro de aquisição de imagens médicas estão sendo desenvolvidos, cada vez mais, os chamados Sistemas de Arquivamento e Comunicação de Imagens (Picture Archiving and Communication Systems PACS) [Dutton, 90] [Alcocer et al., 96] [Sclabassi et al., 96] [Marsh, 97].

Aplicados à área médica, esses sistemas devem organizar todas as informações relevantes (textuais ou pictóricas) dos pacientes em análise [Gennip et al., 92] [Ratib, 92] [Crudele et al., 97]. Significando, portanto, um grande impulso para o auxílio ao diagnóstico médico, pois possibilitam a recuperação e o cruzamento de informações de forma muito mais eficiente e conforme a especificação do usuário, neste caso o médico.

Os sistemas $P A C S$ que utilizam SGBDs tradicionais baseiam-se na recuperação de' imagens através de atributos numéricos ou textuais previamente associados, sobre os quais as buscas são efetuadas [Cardenas et al., 93] [Flickner et al., 95]. Isto se dá, resumidamente, por não ser imediata a definição de um critério que permita estruturar uma coleção de imagens [Gudivada \& Raghavan, 95]. Esses atributos são usualmente obtidos pela descrição do conteúdo das imagens (por exemplo, um diagnóstico feito por um médico), ou por outros dados externos relacionados (por exemplo, os parâmetros utilizados no equipamento de coleta) [Brown, 92].

Porém, a recuperação baseada em informações pictóricas propicia um potencial de auxílio muito maior para o diagnóstico. Com esse recurso, torna-se possível, por exemplo, solicitar de um banco de imagens aquelas que possuem um determinado objeto (visto como imagem de busca) [Grosky \& Mehrotra, 89] [Tchounikine et al., 97] [Zaniolo et al., 97]. 
A recuperação de imagens calcada em informações extraídas do seu conteúdo tem sido muito estudada [Tamura \& Yokoya, 84] [White \& Jain, 96b] [Petrakis \& Faloutsos, 97] e está fundamentada na extração de características (features) que possam ser indexadas. Os índices gerados são usados para restringir drasticamente o tamanho do conjunto de imagens resultante de uma consulta, de maneira que apenas algumas (relativamente) poucas precisem ser, de fato, comparadas. Cada índice corresponde a uma determinada característica que tende a ser independente das demais. $\mathrm{E}$ cada consulta vincula um determinado conjunto de características, estabelecendo um inter-relacionamento entre elas.

O GBdI vem desenvolvendo um Sistema de Gerenciamento de Base de Dados Orientada a Objetos (SGBDOO), fundamentado no Modelo de Dados SIRIUS [Biajiz, 96], conhecido por SIRIUS/GO. Este modelo corresponde a uma evolução do MRO - Modelo de Representação de Objetos, apresentado originalmente em 1986 em [Traina, 86], o qual gerou o Gerenciador de Objetos - GEO/MRO.

Dentre as novas características do Modelo SIRIUS, encontra-se a representação de imagens como um tipo abstrato de dados (TAD) [Santos, 97] [Traina et al., 98], definido de maneira a permitir a indexação e a recuperação de imagens baseadas em seu conteúdo. A próxima seção apresenta um resumo de como este TAD é tratado pelo Modelo SIRIUS, procurando mostrar onde o presente trabalho se insere dentro dos projetos do referido grupo de pesquisa, a sua importância e principal motivação.

\subsection{TAD Imagem no Modelo SIRIUS}

As imagens no SIRIUS/GO são definidas no seu meta-modelo como uma especialização do conceito de Atributo associado a Objetos. Este meta-modelo considera que cada atributo tem uma Característica, definida como uma especialização do conceito de atributo de objetos, o qual, por sua vez, é uma especialização do conceito de TAD. Desta forma, a associação de uma característica a um atributo determina o conjunto de operações em que o mesmo está envolvido.

Por exemplo, número é uma característica de atributo que define as seguintes operações: soma, multiplicação, etc. Cadeia de caracteres, que é outra característica de atributo, engloba as 
seguintes operações: busca, concatenação, extração, etc. O conjunto de operações definidas por uma certa característica é independente do tipo de dados usado para representar, em meio computacional, o atributo a que se refere. Sendo assim, não há diferença se um número está sendo representado como inteiro, real ou dupla precisão.

Resumindo, a imagem passa a ser tratada como uma característica de atributo, permitindo que diversos formatos de representação e diversos algoritmos de processamento especializados sejam associados aos objetos que a possuem.

A seguir será apresentado um conjunto de conceitos usados para definir o TAD imagem dentro do meta-modelo do Modelo SIRIUS (os conceitos que serão apresentados foram obtidos em [Santos, 97] [Traina et al., 98]).

\subsubsection{Constante-Imagem}

Nas linguagens de programação as constantes representam informações com um determinado valor fixo e com uma semântica bem definida, que não pode sofrer alterações além de sua criação e eliminação. Constantes podem ser definidas para representar valores numéricos, tais como: 5 (cinco), 3,141592 (representação do número PI); ou que simbolizam seqüências de caracteres, tais como: "Endereço Comercial". A utilização de constantes é feita com o objetivo de facilitar futuras operações de comparação ou manipulação envolvendo os valores por elas representados.

Da mesma forma, uma constante-imagem consiste em uma imagem qualquer, indicada como padrão para futuras operações. Essas constantes são consideradas significativas para a descrição do conjunto a ser manipulado, ou das imagens presentes em um domínio de aplicação. Por exemplo, o médico pode obter uma tomografia do coração que seja significativa para a descrição de uma determinada patologia, passando a utilizá-la como parâmetro para futuras buscas de exames com características semelhantes. Em outras palavras, essa constante pode ser definida no sistema como um padrão de comparação para as tomografias que venham a ser, posteriormente, inseridas no SGBD. 
Observa-se que é necessário definir diferentes constantes-imagem para categorias diferentes de exames. No exemplo anterior, se as consultas fossem referentes a exames de tomografia da região craniana, uma constante referente ao coração não poderia ser vista como significativa para descrever as possiveis patologias que se espera encontrar na região em questão. Torna-se necessária, então, a indicação de outras para caracterizar este novo domínio.

Com o conceito de constante-imagem definem-se duas categorias em SGBDs, a saber: (a) as imagens pertencentes ao domínio da aplicação, representando o Banco de Imagens (BI), e (b) as constantes-imagem, consistindo em um subconjunto do BI composto pelos elementos básicos para comparação com as demais. Este subconjunto passa a ser utilizado para recuperar imagens semelhantes (em algum aspecto) com base no seu conteúdo pictórico e não mais em função de atributos associados.

\subsubsection{Sumarizadores}

Os dados são inseridos em uma base de dados (BD) com o objetivo de poderem ser manipulados posteriormente, seja através de uma consulta para a sua recuperação, ou através de alguma outra operação. Com as imagens ocorre o mesmo, ou seja, supõe-se que serão manipuladas e tratadas de forma semelhante aos demais tipos de dados, obedecendo aos aspectos que lhes sejam particulares.

Para afirmar que uma determinada imagem pode ser comparada a alguma das constantes-imagem definidas no BI, é necessário definir aspectos relacionados, especificamente, com as características gráficas das mesmas, tais como: forma, textura, histograma, etc. Com estas definições, torna-se possível extrair parâmetros necessários para realizar operações de comparação.

Estes aspectos são vistos como operadores que podem ser aplicados sobre o domínio das imagens do $\mathrm{BI}$, os quais representam o conjunto de manipulações válidas para um determinado conjunto, $\mathrm{e}$ cujo resultado pode ser utilizado como argumento na definição de comparações entre as mesmas. Operações de convolução, tratamento de histogramas, pseudo-côr, etc. representam funções que, 
ao serem aplicadas, produzem como resultado um valor mensurável sobre o qual é possível definir uma operação de comparação.

Em outras palavras, os operadores representam características que permitem a comparação entre duas imagens. Por exemplo, a forma ou padrão dos objetos contidos em uma imagem correspondem a características que podem ser extraidas, onde esta representa o operador e as imagens, os seus argumentos.

$\mathrm{O}$ tratamento de uma imagem por um operador pode retornar um ou mais valores, a depender do processamento realizado. Por exemplo, considere um operador que represente a busca de padrões para o qual são fornecidos dois argumentos: um indicando o padrão a ser procurado e outro onde a busca será feita. Esta operação pode retornar, além da informação indicando se o padrão foi ou não encontrado, a sua localização (em termos de coordenadas) na imagem processada e a porcentagem de semelhança do trecho encontrado com o padrão de busca. Outro exemplo seria a operação para determinar o histograma com a distribuição de cores. Esta operação poderia ser definida de forma a retornar, além do próprio histograma, a variância e o desvio padrão da distribuição de tons.

Cada operador definido representa um processamento que retorna uma série de valores (parâmetros), a depender de como o mesmo foi especificado. Portanto, os parâmetros ou variáveis descritoras de um operador representam o conjunto de valores obtidos a partir da sua aplicação sobre uma determinada imagem. Estes elementos descrevem o operador em seu aspecto estrutural, através do conjunto de informações que pode ser por ele extraído. As informações são representadas através de elementos numéricos, portanto mensuráveis. Isto permite definir, com precisão, operações de recuperação através da comparação de seus valores. Ainda, o valor representado pelo parâmetro indica o nível de similaridade das imagens envolvidas com os argumentos na operação.

A comparação e a definição da relação de ordem entre imagens, para um determinado operador, serão possíveis se este representar uma característica gráfica que possa ser descrita através de valores mensuráveis. As características como: forma, textura, histograma, etc., se enquadram nesta categoria. Assim, ao se descrever o conteúdo de uma imagem, utilizando-se uma das 
características para a recuperação a partir do BI, esta operação será avaliada, comparando-se os valores resultantes da aplicação dos operadores correspondentes. Portanto, as operações de comparação são realizadas indiretamente, através dos valores que descrevem de forma mensurável o grau de semelhança de cada imagem, presentes no BI, com relação às constantesimagens.

Considerando o jargão utilizado pelo Modelo SIRIUS, estes operadores são conhecidos por sumarizadores das imagens.

\subsubsection{Parâmetros das Imagens}

A aplicação de um sumarizador, como dito na seção anterior, resulta em elementos numéricos que definem a instância da variável de descrição (parâmetro) de uma imagem. Uma variável de descrição assume valores que podem ser estruturalmente diferentes, a saber: um elemento numérico, um par ordenado, uma tripla ou um conjunto ordenado de valores.

A semântica associada a cada um destes diferentes tipos é determinada através da constanteimagem e da característica representada pelo sumarizador quando de uma inclusão na BI. Os parâmetros, como será visto adiante, constituem informações muito úteis para o processo de seleção e recuperação das imagens.

Quando se usa o sumarizador associado a uma determinada constante-imagem, o resultado gerado (conjunto de parâmetros) é único. Considerando imagens diferentes, é intuitivo esperar que se os resultados obtidos com um mesmo sumarizador são semelhantes, elas devem ser, sob o aspecto definido pelo sumarizador, também semelhantes. Portanto, para identificar semelhanças em relação a um determinado aspecto, basta comparar o grau de semelhança entre os parâmetros retornados pelo sumarizador utilizado na extração das características.

Porém, processar (aplicar o sumarizador) todas as imagens a cada consulta pode ser uma tarefa muito custosa. A solução proposta no SIRIUS é de armazenar não apenas a imagem em si, como também o resultado dos sumarizadores a ela relacionados na medida em que as inserções são 
feitas no BI. Com isso, as consultas são realizadas diretamente nos parâmetros armazenados, sem a necessidade de reprocessar todo o BI.

Visto que os parâmetros apresentam uma relação de ordem, pois são constituídos de valores mensuráveis, podem ser organizados e manipulados através de estruturas de indexação apropriadas, tornando as consultas mais eficientes. Estas estruturas devem levar em consideração, sobretudo, a grande variedade de operadores que podem ser definidos para uma determinada BI, o que gera conjuntos de parâmetros com quantidades distintas de valores.

\subsection{Meta-Esquema do TAD Imagem em SIRIUS}

Fundamentado nestes conceitos, o armazenamento das imagens pode ser feito em associação com objetos na base de dados (BD), onde são tratadas como características de atributos de objetos de um determinado tipo. Para o SIRIUS, a associação entre uma constante-imagem e um sumarizador caracteriza um domínio, o qual define um grupo com aspectos semelhantes. Para cada constante-imagem, vários operadores podem ser associados, definindo domínios diferentes. Em contra partida, um mesmo operador pode ser associado a constantes-imagem diferentes, definido, também, outros dominios.

Ao ser armazenada, a imagem é submetida a um conjunto de pares <sumarizador, constante-imagem> significativos à aplicação da qual faz parte, gerando os parâmetros como resultado. A Figura I apresenta de forma simplificada o meta-esquema do TAD imagem em SIRIUS (uma

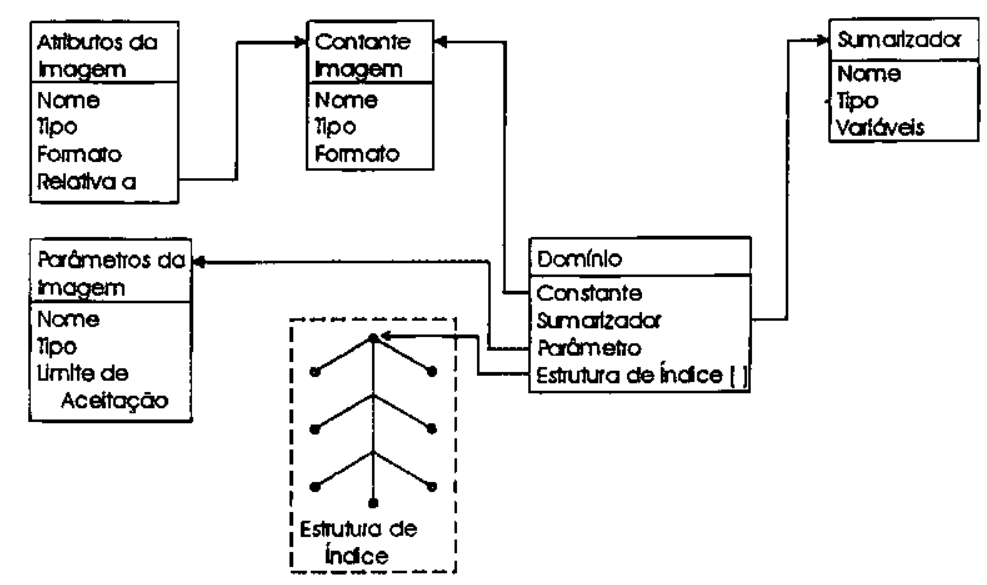

Figura 1: Meta-esquema de definiçāo de uma aplicação com o TAD imagem em SIRIUS.

explicação e representação mais detalhada podem ser obtidas em [Santos, 97]).

Quando uma aplicação é construída, conjuntos de constantes-imagem e conjuntos de sumarizadores são definidos e associados, definindo domínios diferentes. Esses domínios correspondem a atributos que podem ser associados a outros objetos da BD. Com isso, na medida 
em que são feitas inserções na BI, calculam-se apenas os parâmetros relativos aos pares <sumarizador, constante-imagem>, aos quais as imagens inseridas se aplicam.

Cada um dos parâmetros resultantes é, então, usado para a criação de estruturas de índices, sendo uma para cada domínio definido pela aplicação. Cada imagem armazenada pode pertencer a várias estruturas de índices

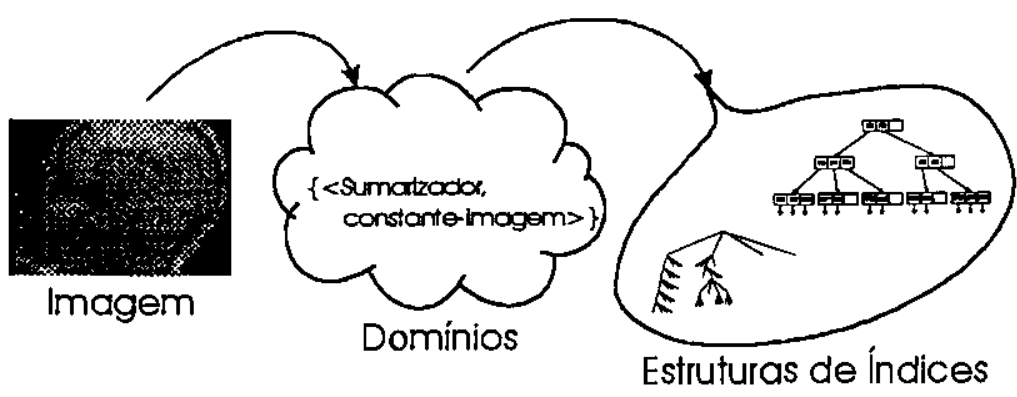

Figura 2: Inclusão de uma imagem em SIRIUS. simultaneamente, uma para cada domínio definido para os atributos de objeto que a tem como valor. A Figura 2 ilustra a inclusão em uma BI, destacando a etapa de indexação.

Como dito anteriormente, os parâmetros são apresentados sob a forma de conjuntos ordenados compostos por um, dois, três ou vários elementos de valor numérico. Esses conjuntos podem ser vistos como vetores (também chamados vetores de características - feature vectors). A utilização de estruturas de indexação tradicionais desenvolvidas para manipular dados numéricos ou textuais, como as B-Trees e suas derivadas [Comer, 79], não são muito apropriadas para tratar dados multivalorados [Jagadish, 91]. Para tanto, a solução apresentada é a de tratar os elementos destes vetores como coordenadas de um ponto situado em um espaço de dimensão $n$, onde $n$ corresponde ao número de elementos do respectivo vetor, e utilizar estruturas de indexação voltadas para o armazenamento de dados espaciais [Jagadish, 91] [Berchtold et al., 96] [Chakrabarti \& Mehrotra, 99].

Uma revisão bibliográfica sobre este tipo de dados, dados espaciais, é apresentada no capítulo 3 abrangendo: definições, exemplos de consultas, exemplos de estruturas de indexação voltadas para dados espaciais, aplicações, etc.

O objetivo deste trabalho é estudar estruturas de indexação apropriadas para o armazenamento e a recuperação de vetores de características extraidos de imagens médicas e identificar a que melhor se adapta ao gerenciador SIRIUS/GO, considerando, principalmente, os seguintes requisitos: 
- suportar vetores com quantidades variadas de elementos. Em outras palavras, pontos em espaços que podem ser bidimensionais, tridimensionais ou maiores, podendo atingir dimensões na ordem das centenas. Por exemplo: o sumarizador que faz a busca de um determinado padrão em uma imagem pode ser definido de forma a retornar três elementos, ou seja, duas coordenadas (indicando a posição na imagem aonde o padrão foi encontrado) e o grau de semelhança com o padrão de busca; já o histograma de cores para tons de cinza e pixels de 8 bits pode ser definido de forma a retornar 256 elementos;

- suportar armazenamento secundário. É inviável a utilização de índices em memória principal, considerando o volume de informações gerado por um centro de aquisição e armazenamento de imagens médicas;

- ser dinâmico (possibilidade de incluir e excluir dados ao longo do tempo). Estruturas de indexação estáticas podem gerar índices mais eficientes (considerando o tempo de resposta em uma consulta), porém, quando um novo dado está para ser inserido, todo (ou quase todo) o indice deve ser refeito. A cada momento, novas imagens estarão sendo geradas pelo centro de aquisição. Não será interessante, portanto, que a cada nova inserção o índice seja refeito, pois implicará em perda de tempo. Espera-se que a estrutura de indexação para tais situações possua mecanismos para garantir sua eficiência.

\subsection{Conclusão}

Este capítulo apresentou um breve histórico do Modelo de Dados SIRIUS, seguido de um resumo dos conceitos usados para definir "Imagem" como tipo abstrato de dados neste modelo. A partir destes conceitos, o meta-esquema do TAD imagem foi discutido. Foi comentando o que ocorre quando da criação de uma aplicação e da inserção das imagens. Finalizando, o trabalho aqui proposto foi apresentado no contexto do meta-esquema, mostrando sua motivação principal e sua relevância dentro do projeto CAMS/SIRIUS. 
3. DADOS ESPACIAIS 


\section{DADOS EsPaCIAIS}

\subsection{Introdução}

Os SGBDs convencionais têm sido desenvolvidos e aplicados, predominantemente, na organização de grandes volumes de dados relacionados a aplicações financeiras e administrativas, também chamadas "tradicionais" (standard). Porém, as recentes pesquisas na área de gerenciamento de dados têm se voltado cada vez mais para aplicações de âmbito técnico- científicas, também citadas como "não tradicionais" (non-standard).

Esta nova abordagem trouxe a necessidade de se adaptar os modelos de dados e os SGBDs convencionais às novas exigências impostas por aplicações não tradicionais, tais como: projeto auxiliado por computador (CAD - Computer Aided Design), processamento de imagens, sistemas multimídia, sistemas de informações geográficas (GIS - Geographic Information Systems), projeto de circuitos integrados auxiliado por computador e outras nas áreas médica e biológica [Schneider, 97].

Dentre estas diversas exigências feitas aos SGBDs, uma que tem se tornado cada vez mais necessária, devido à grande variedade de aplicações, é a capacidade de gerenciar dados geométricos ou espaciais ${ }^{3}$ (também citados como dados multidimensionais), ou seja, relacionados com o espaço geométrico onde são representados [Schneider, 97]. Estes dados consistem de objetos espaciais compostos por pontos, linhas, regiōes do espaço, retângulos, superficies, volumes, hipercubos e outros de dimensões maiores que envolvem, inclusive, a noção de tempo [Aref \& Samet, 97].

\footnotetext{
${ }^{3}$ O termo "espaço" tem sido muito usado para referenciar o espaço em terceira dimensão. Daqui para frente, os termos relacionados ao espaço de representação dos dados ("espaço", "espacial", outros) não limitam a ordem de sua dimensão (a menos que isso seja colocado de forma explícita), fazendo referência a espaços $n$-dimensionais, sendo " $n$ " um número natural diferente de zero. Será considerado, também, como definido o significado da expressão " $n$-dimensional" para indicar uma dimensão qualquer (incógnita) diferente de zero.
} 
Exemplos de dados espaciais (ou objetos espaciais) incluem a representação para: rios, estradas, municípios, estados, acidentes geográficos, circuitos eletrônicos, tumores, transações financeiras, seqüências encadeadas como DNA e caracteres alfanuméricos, etc. Exemplos de propriedades relativas a estes dados incluem: extensão e localização geográfica de um rio, limites de um município, variações financeiras ao longo de um intervalo de tempo, histograma de cores de uma tomografia, etc. [LinK et al., 94] [Samet, 95] [Berchtold et al., 96] [Aref \& Samet, 97]. São exemplos de consultas feitas em BDs espaciais: "obter as ultra-sonografias nas quais os valores dos índices do histograma de cores variam em torno de $15 \%$ com relação aos respectivos índices da ultra-sonografia de fulano...", "indicar as ruas de uma cidade que são cortadas por determinada linha do metrô...", etc.

Gaede e Günther em [Gaede \& Günther, 98] relacionam algumas propriedades de dados espaciais que permitem um melhor entendimento dos requisitos de uma $\mathrm{BD}$ espacial:

1. Complexidade estrutural: dados espaciais podem ser compostos por um simples ponto ou por diversos milhares de polígonos distribuídos arbitrariamente no espaço. Geralmente, não é possível armazenar coleções de objetos deste tipo em uma tupla de tamanho fixo, referente a uma simples tabela de BDs relacionais;

2. Dinamismo: dados espaciais são, geralmente, dinâmicos. Inserções, remoções e alterações são comuns ao longo do tempo e, conseqüentemente, as estruturas de dados utilizadas para suportar dados deste tipo têm que ser projetadas prevendo este dinamismo, para evitar uma deterioração;

3. Quantidade: BDs espaciais tendem a ser muito grandes (possuir grande volume de informações), o que torna necessária uma perfeita integração entre o armazenamento de dados em memória primária (armazenamento primário) e o feito em memória secundária (armazenamento secundário);

4. Inexistência de uma álgebra padronizada: apesar da existência de diversas propostas, ainda não existe uma álgebra padronizada para dados espaciais. Ou seja, não existe um conjunto padrão de operadores básicos próprios de dados espaciais. $O$ conjunto de operadores (que serão tratados por operadores/operações espaciais) é 
estritamente dependente do dominio da aplicação em uso, embora alguns operadores (como interseção) sejam mais comuns que outros;

5. Muitos operadores espaciais são não fechados: a intercessão de dois polígonos, por exemplo, pode resultar em um número qualquer de pontos, arestas, ou polígonos disjuntos. Esta propriedade é particularmente importante quando esses operadores são aplicados consecutivamente;

6. Custo computacional: embora o custo computacional varie entre os operadores espaciais, geralmente estes operadores são mais "caros" que os relacionais.

Após esta breve apresentação sobre dados espaciais, abrangendo seu significado, sua importância e sua complexidade, serão abordados alguns conceitos em torno de como são representados em meio computacional e algumas formas comuns de consulta.

\subsection{Representação de Dados Espaciais}

A forma elementar de representar objetos espaciais em um meio computacional é tratá-los de forma explícita, ou seja, simplesmente definir seus atributos e relacionamentos com outros objetos e armazená-los em algum SGBD convencional.

Por exemplo, em uma base contendo dados sobre estradas de rodagem de um estado, uma opção seria atribuir, explicitamente, os campos: nome, extensão, tipo de capeamento (asfalto, barro, brita, etc.) e outros. E, quanto à sua posição no espaço, simplesmente acrescentar registros (possivelmente vários) indicando as coordenadas (longitude e latitude) de início e fim de cada trecho (que podem ser limitados pelas cidades atravessadas pela estrada).

Esta visão pode ser facilmente implementada em BDs convencionais e é muito prática quando as consultas são simples e podem ser previstas com antecedência. Porém, há motivos que a tornam indesejável, como, por exemplo, os dois a seguir:

1. as consultas teriam que ser conhecidas a priori para que fossem feitos ajustes na representação dos dados de forma a suportá-las. Supondo a base definida com os atributos acima, uma consulta interessante seria: dada uma estrada, encontrar as 
estradas que a cruzam. Ora, a não ser que o cruzamento ocorra em uma cidade, a base como foi definida acima não pode responder a esta pergunta de forma rápida. Uma solução seria armazenar, adicionalmente, os cruzamentos existentes. Porém,

2. esta solução levaria o usuário a cadastrar uma quantidade de dados imprevisível, levando a uma quantidade de informações absurdamente grande e desnecessária (supondo a existência de outra forma de representação), acarretando um alto custo de processamento para a recuperação dos dados armazenados.

Em outras palavras, o problema é que as consultas feitas em BDs espaciais (ou consultas espaciais) tendem a focalizar a localização dos objetos no espaço ou, dependendo do tipo de objeto (linhas, retângulos, cubos, etc.), suas medidas (comprimento, área, volume).

A habilidade em responder a consultas espaciais de maneira flexível está diretamente relacionada à forma como estes dados estão representados nas BDs. Além disto, para se obter um desempenho razoável, os dados devem estar ordenados de alguma forma [Samet, 95].

A dificuldade em representar e ordenar os dados espaciais está em que "não existe uma ordenação total entre objetos espaciais que preserve a proximidade ${ }^{4}$ existente no espaço" [Schneider, 97]. Ou seja, não há como fazer um mapeamento de um espaço $n$-dimensional ( $\operatorname{com} n$ maior que um) em um espaço unidimensional de forma que dois objetos quaisquer tidos como próximos no espaço original estejam próximos entre si na seqüência gerada pela ordenação.

A ordenação de dados espaciais deve, então, ser fundamentada em todas as informações que os mesmos apresentam inerentes ao espaço. Ou seja, a ordenação é feita sob a porção do espaço ocupada pelo dado. Técnicas que utilizam esta forma de ordenação são conhecidas como Métodos de Indexação Espacial ou Métodos de Indexação Multidimensional (por questões de padronização e simplificação, será usado neste trabalho a abreviação da primeira denominação, ou seja, Método de Indexação Espacial - MIE).

\footnotetext{
${ }^{4}$ As considerações feitas em todo este trabalho supõem o espaço Euclideano como base de representação. A noção adotada para distância (e proximidade) é relativa à distância Euclideana.
} 
Uma forma bastante usual de implementar busca em BDs espaciais usando sistemas convencionais corresponde à utilização de estruturas de indexação unidimensionais (B-Tree [Comer, 79] e suas variantes) repetidamente, uma para cada dimensão. Este método tem se mostrado insatisfatório, pois não é possivel decidir com total segurança, a partir de uma dimensão, o que pode ou não ser excluído (do conjunto resposta) sem antes ter consultado os dados relativos às outras dimensões (não necessariamente todas). Em outras palavras, o conjunto de dados a ser verificado durante uma consulta não pode ser reduzido gradualmente de forma satisfatória.

Gaede e Günther em [Gaede \& Günther, 98] relacionam alguns requisitos básicos que os MIEs devem possuir em função das propriedades apresentadas pelos dados espaciais (ver seção 3.1) e suas aplicações:

1. Dinamismo: os dados são inseridos e removidos da $\mathrm{BD}$ de forma aleatória. Os MIEs devem tratar estas mudanças continuamente;

2. Suportar armazenamento secundário: tendo em vista o grande volume de dados, os MIEs devem prover formas de armazenamento secundário;

\section{Suporte a grande número de operações espaciais;}

4. Independência quanto à seqüiência de inserção dos dados e quanto à sua distribuição no espaço: o desempenho dos MIEs não pode ser debilitado se a ordem de inserção for modificada, ou se os dados não estiverem uniformemente distribuídos no espaço;

5. Simplicidade: MIEs intricados mostram-se, em geral, passíveis de erro de implementação e, desta forma, não são suficientemente confiáveis para aplicações em larga escala;

6. Possibilidade de crescimento da BD: os MIEs devem se adaptar facilmente ao crescimento da $\mathrm{BD}$;

7. Eficiência quanto ao tempo (eficiência temporal): consultas espaciais devem ser rápidas. $O$ principal objetivo é alcançar as características de desempenho proporcionadas por uma $B$-Tree [Comer, 79]: os MIEs devem garantir um desempenho com complexidade de ordem logarítmica em relação a operações de busca, 
independentemente da distribuição dos dados e da ordem de inserção. Este desempenho deve ser mantido para qualquer combinação dos parâmetros relativos à sua dimensionalidade (ordem da dimensão espacial);

8. Eficiência quanto ao número de bytes necessários para armazenamento (eficiência de armazenamento): um indice deve ser armazenado de forma a gastar uma quantidade de bytes menor do que aquela gasta com os atributos dos dados a serem indexados. Em muitos MIEs, o tamanho do índice é diretamente proporcional (em alguns casos até em ordem exponencial) à dimensão do espaço [LinK et al., 94];

9. Concorrência e confiabilidade: os SGBDs atuais permitem que os dados sejam acessados, inseridos e alterados por vários usuários ao mesmo tempo (de forma concorrente). Os MIEs devem estar preparados para lidar com o acesso concorrente aos dados sem implicar em grande perda de desempenho. Além disso, devem fornecer recursos para recuperar índices danificados por eventuais falhas no sistema (confiabilidade);

10.Impacto mínimo: por fim, a integração de um MIE a um sistema de gerenciamento de banco de dados deve gerar o menor impacto possivel nas partes já existentes do mesmo.

Em acréscimo, Samet em [Samet, 90] comenta que é comum a ocorrência de colisão em algumas aplicações envolvendo dados espaciais, ou seja, dois objetos espaciais podem ter a mesma coordenada no espaço. Por exemplo: algumas cidades possuem elevados em algumas de suas ruas (ruas elevadas ao longo de outras ruas como se fossem pontes, porém percorrendo o mesmo caminho). Uma $\mathrm{BD}$ espacial que considere apenas os aspectos relativos à localização bidimensional das ruas (coordenadas - latitude e longitude - de início e fim de seus segmentos) teria que permitir que dois objetos ocupassem o mesmo ponto no espaço.

Conseqüentemente, uma análise detalhada da distribuição espacial dos dados deve ser feita para verificar a possibilidade da existência de colisões e tomar as devidas providências com relação ao MIE a ser implementado. Samet propõe, ainda, que os registros de índices tenham um ponteiro a mais, direcionado para uma lista de colisões. Esta proposta, apesar de implicar um campo extra 
para uma situação que pode ser considerada rara, é justificada pela possibilidade de tornar necessários procedimentos de inclusão mais complicados, caso não seja implementada.

Porém, White e Jain em [White \& Jain, 96b] colocam que em algumas aplicações (principalmente as voltadas para informações visuais que indexam vetores de características - feature vectors), em que o domínio dos dados em cada dimensão corresponde ao dos números reais, as chances de ocorrerem colisões são muito raras e diminuem à medida que a ordem da dimensão aumenta. Logo, cabe ao projetista do MIE decidir como abordar este problema.

Outra sugestão interessante apresentada por Samet, agora em [Samet, 95], diz respeito à separação estrutural dos dados espaciais em dois subconjuntos: um subconjunto de atributos espaciais, relativos às características espaciais do objeto (coordenadas, por exemplo), e um subconjunto de atributos não-espaciais, relativos às demais características (nomes - o nome de uma rua, por exemplo), mantendo uma ligação entre os dois subconjuntos (possivelmente por ponteiros). Com este recurso, procura-se obter um desempenho melhor nas consultas espaciais devido a ter-se, num certo momento, uma quantidade maior de chaves de indexação (atributos espaciais dos objetos) na memória principal, visto que a porção desta memória que era ocupada pelo segundo subconjunto de atributos está agora ocupada por outras chaves.

Para finalizar, existe ainda uma subdivisão dos MIEs, citada em [Kriegel et al., 90] [Sellis et al., 97] [Gaede \& Günther, 98], que será utilizada nas demais seções:

1. Métodos de acesso pontual (ou "point access methods" - PAM): métodos desenvolvidos para acessar dados que correspondem a pontos no espaço, conhecidos por dados pontuais. Em outras palavras, dados situados em um espaço $n$-dimensional sem nenhuma extensão (dados espaciais gerados a partir de vetores de características são um exemplo de dados pontuais);

2. Métodos de acesso espacial (ou "spatial access methods" - $S A M M^{5}$ ): métodos desenvolvidos para acessar dados que correspondem a objetos complexos (que

\footnotetext{
${ }^{5}$ Para manter uma correlação com o termo original em inglês, neste texto serão utilizadas as siglas originais. $P A M$ e $S A M$, apenas mudando a fonte para itálico.
} 
precisam de vários pontos distintos para ser representados), conhecidos por dados espaciais, tais como linhas, polígonos, regiões do espaço, cubos, hipercubos, etc.

\subsection{Consultas Espaciais}

Como foi dito anteriormente, não existe um conjunto básico padrão de operadores espaciais. Porém, diversos autores têm sugerido possíveis conjuntos padrão [Friedman et al., 77] [Orenstein, 86] [Kriegel et al., 92] [Roussopoulus et al., 95] [White \& Jain, 96b]. Em especial, Gaede e Günther em [Gaede \& Günther, 98] relacionam um conjunto bastante abrangente (com relação aos exemplos encontrados na literatura) de operadores espaciais, que será apresentado adiante com suas respectivas definições formais.

\subsubsection{Definições preliminares}

Os exemplos a seguir supõem o espaço Euclideano como base de representação dos objetos espaciais, o qual será tratado simplesmente por $E^{d}$, em que $d$ indica a ordem da dimensão do mesmo. Os objetos armazenados em uma $\mathrm{BD}$ espacial possuem apenas uma localização no espaço, expressa por suas $d$ coordenadas. No entanto, vale lembrar que uma mesma localização espacial pode ser “ocupada” por vários objetos armazenados na BD.

A "porção" do espaço "ocupada" por um objeto, $0 . G$, é descrita através dos seus atributos espaciais. Esta "porção" corresponde à geometria, formato ou extensão espacial do objeto. É válido observar que objetos espaciais podem conter "buracos", a literatura apresenta uma analogia desta propriedade a um queijo suíço.

Diversos MIEs fazem uma aproximação do formato do objeto para um formato mais simples, como um retângulo ou uma esfera, por facilitar seu manuseio. Esta aproximação é feita considerando o retângulo minimo ou a esfera mínima externa ao objeto, que enclausura toda a sua extensão espacial, de forma a obter a menor área ou volume possível. Este trabalho irá tratar apenas da aproximação para retângulos, por ser esta a mais comum encontrada nos MIEs. 
Considerando o menor intervalo $I(o)=\left[a_{i,} b_{i}\right]\left(a_{i .} b_{i} \in E^{\mathrm{l}}\right)$ que limita e descreve a extensão do objeto $o$ ao longo da dimensão $i(0<i<n)$ em um espaço $n$-dimensional, o retângulo mínimo limítrofe a este objeto é definido por $I^{d}(o)=I_{1}(o) \times I_{2}(o) \times \ldots \times I_{\mathrm{d}}(o)$. O termo utilizado na literatura inglesa para designar este retângulo é minimum bounding rectangle $(M B R)$ ou minimum bounding box $(M B B)$, sendo que a sigla $M B R$, do termo em inglês, será utilizada no decorrer deste trabalho por já ser de uso bastante difundido.

Com a utilização do $M B R$ para representar os dados, uma consulta espacial pode ser feita em duas etapas (ver Figura 3), visando um melhor desempenho [Patel \& DeWitt, 96]:

1. Filtragem: nesta etapa, a consulta é feita sobre os $M B R$ s dos objetos para gerar um conjunto de objetos candidatos, ou conjunto candidato, de tamanho reduzido. Porém, esta abordagem é passível de erro por não ter sido utilizado o formato real dos objetos.

2. Refinamento: nesta etapa, o formato real do objeto é utilizado para gerar o conjunto final de resposta, ou conjunto resultado. Esta análise pode ser computacionalmente muito custosa a depender do operador usado na consulta, da complexidade dos objetos e da dimensão do espaço, justificando a etapa de filtragem.

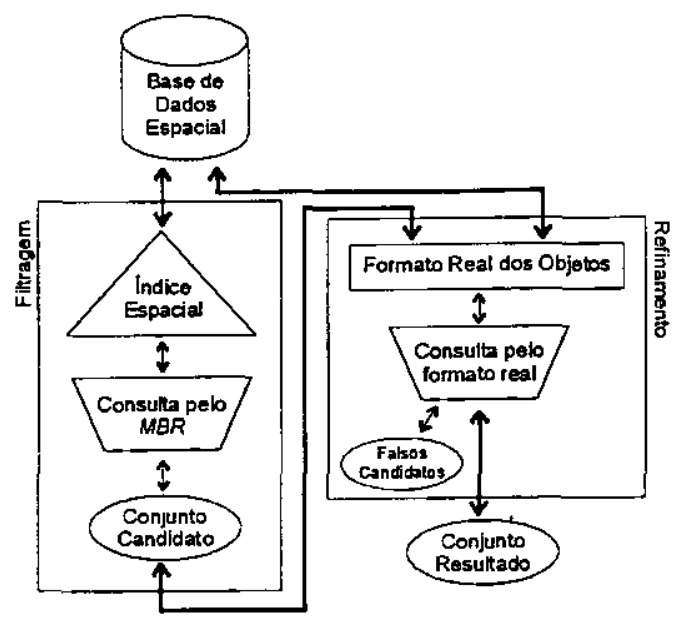

Figura 3: Etapas de uma consulta espacial.

\subsubsection{Operadores espaciais}

Os nomes das operações serão apresentados em inglês para manter o padrão encontrado na literatura. As figuras (da Figura 4 até a Figura 9) que ilustram estas operações foram obtidas em [Gaede \& Günther, 98]. 


\section{Exact Match Query/EMQ ou Object Query}

Considere-se um objeto $o^{\prime}$ com extensão espacial $o^{\prime} . G \subseteq E^{d}$. Esta operação resulta em um subconjunto com todos os objetos $o$ que ocupam a mesma extensão espacial que $o^{\prime}$.

$$
\operatorname{EQM}\left(o^{\prime}\right)=\left\{o \mid o^{\prime} . G=o . G\right\}
$$

\section{Point Query/PQ}

Considere-se um ponto $p \in E^{d}$. Esta operação resulta em um subconjunto com todos os objetos $o$ que contém $p$ (Figura 4).

$$
P Q(p)=\{o \mid(p \cap o . G)=p\}
$$

Esta operação pode ser considerada como um caso especial das operações: Window Query, Intersection Query, ou Enclosure Query, descritas a seguir.

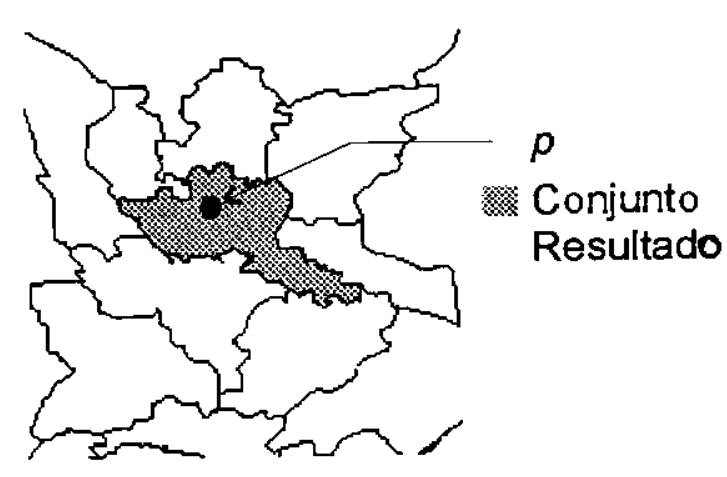

Figura 4: Exemplo de uma operação Point Query.

\section{Window Query/WQ ou Range Query}

Considere-se o intervalo $d$-dimensional $I^{d}=\left[a_{l}, b_{l}\right] \mathrm{X}$ $\left[a_{2}, b_{2}\right] \times \ldots \times\left[a_{d}, b_{d}\right]$. Esta operação resulta em um subconjunto com todos os objetos $o$ que fazem interseção com pelo menos um ponto de $I^{d}$ (Figura 5).

$$
W Q\left(I^{d}\right)=\left\{o \mid\left(I^{d} \cap o . G\right) \neq \varnothing\right\}
$$

Esta operação força que o intervalo seja limitado por retas paralelas aos eixos de coordenadas espaciais.

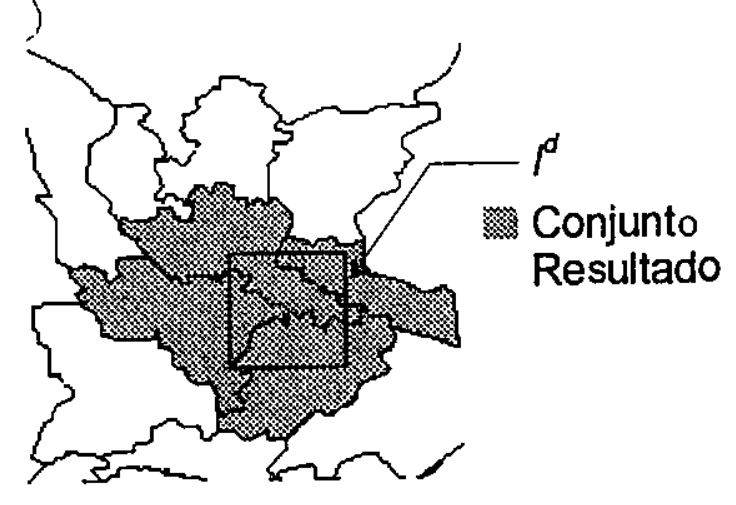

Figura 5: Exemplo de uma operação Window Query. 
Intersection Query/IQ, ou Region Query, ou Overlap Query

Considere-se um objeto $o^{\prime}$ com extensão espacial $o^{\prime} . G$ $\subseteq E^{d}$. Esta operação resulta em um subconjunto com todos os objetos $o$ que fazem interseção com pelo menos um ponto de $o^{\prime}$ (Figura 6).

$$
I Q\left(o^{\prime}\right)=\left\{o \mid\left(o^{\prime} . G \cap o . G\right) \neq \varnothing\right\}
$$

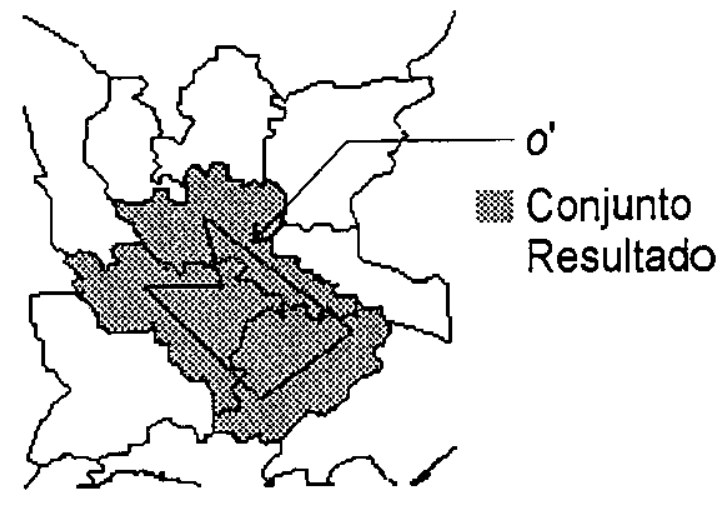

Figura 6: Exemplo de uma operação Intersection Query.

Esta operação é uma generalização da operação Window Query de forma a permitir que o intervalo, ou melhor, que a região espacial, tenha formato e orientação quaisquer.

\section{Enclosure Query/EQ}

Considere-se um objeto $o^{\prime}$ com extensão espacial $o^{\prime} \cdot G \subseteq E^{d}$. Esta operação resulta em um subconjunto com todos os objetos $o$ que englobam $o^{\prime}$ (Figura 7).

$$
E Q\left(o^{\prime}\right)=\left\{o \mid\left(o^{\prime} . G \cap o \cdot G\right)=o^{\prime} \cdot G\right\}
$$

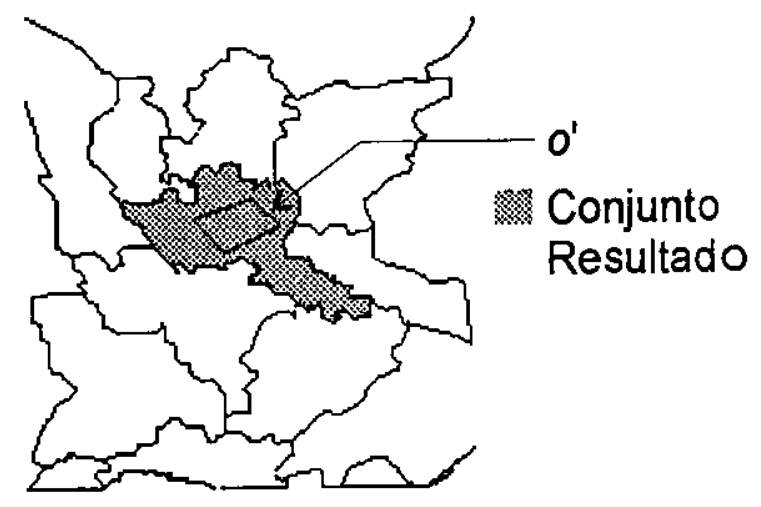

Figura 7: Exemplo de uma operação Enclosure Query.

\section{Containment Query/CQ}

Considere-se um objeto $o^{\prime}$ com extensão espacial $o^{\prime} . G \subseteq E^{d}$, esta operação resulta em um subconjunto com todos os objetos o que são englobados por $o^{\prime}$ (Figura 8).

$$
C Q\left(o^{\prime}\right)=\left\{o \mid\left(o^{\prime} . G \cap o . G\right)=o . G\right\}
$$

\section{Adjacency Query/AQ}

Considere-se um objeto $o^{\prime}$ com extensão espacial $o^{\prime} . G \subseteq E^{d}$, esta operação resulta em um subconjunto

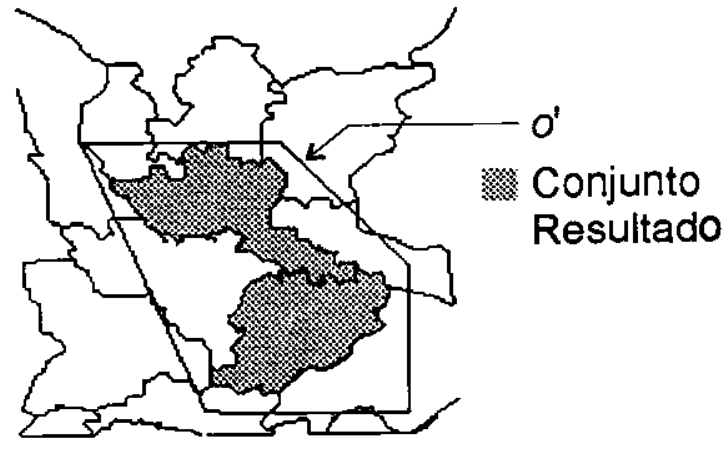

Figura 8: Exemplo de uma operaçäo Containment Query. 
com todos os objetos $o$ adjacentes a (que fazem fronteira com) $o^{\prime}$ (Figura 9).

$$
\begin{gathered}
A Q\left(o^{\prime}\right)=\left\{o \mid\left(\left(o^{\prime} . G \cap o . G\right) \neq \varnothing\right) \wedge\right. \\
\left.\left(o^{\prime} . G^{\circ} \cap o . G^{9}\right)=\varnothing\right\}
\end{gathered}
$$

Sendo que $o^{\prime} \cdot G^{o}$ e $o \cdot G^{o}$ correspondem à região interior às extensões espaciais $o^{\prime} . G$ e $o . G$.

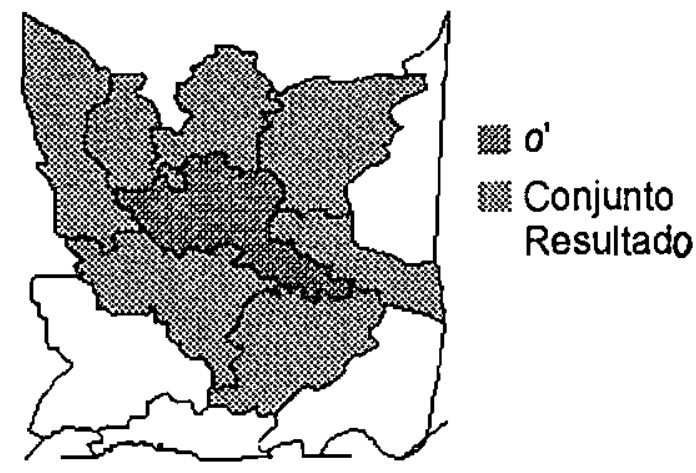

Figura 9: Exemplo de uma operaçäo Adjacency Query.

\section{Nearest Neighbor Query/NNQ}

Considere-se um objeto $o^{\prime}$ com extensão espacial $o^{\prime} . G \subseteq E^{d}$. Esta operação resulta em um subconjunto com todos os objetos $o$ que possuem a menor distância em relação a $o^{\prime}$. É interessante lembrar que vários objetos podem estar ocupando uma posição ou porção do espaço (colisão), daí a possibilidade de existirem mais de um com distância mínima.

$$
N N Q\left(o^{\prime}\right)=\left\{o \mid \forall o^{\prime \prime}: \operatorname{dist}\left(o^{\prime} . G, o . G\right) \leq \operatorname{dist}\left(o^{\prime} . G, o^{\prime \prime} . G\right)\right\}
$$

A distância entre dois objetos complexos é geralmente definida como sendo a distância entre seus pontos mais próximos. A função distância entre dois objetos espaciais $\operatorname{dist}\left(o^{\prime} . G, o^{\prime \prime} . G\right)$ corresponde, normalmente, à distância Euclideana. Algumas vezes é utilizada a função distância Manhattan ${ }^{6}$ (conhecida como "city block").

Uma variação desta operação corresponde a obter um subconjunto com os $k$ objetos mais próximos a um certo objeto $o^{\prime}$.

\section{Spatial Join}

Considerem-se duas coleções, $R$ e $S$, de objetos espaciais e um predicado $\theta$. Esta operação resulta em um subconjunto com todos os pares de objetos $\left(o, o^{\prime}\right) \in R \mathrm{X} S$ em que $\theta\left(o, G, o^{\prime} . G\right)$ tem valor verdadeiro.

\footnotetext{
${ }^{6}$ A distância Manhattan entre dois pontos $\left(x_{1}, y_{1}\right)$ e $\left(x_{2}, y_{2}\right) \dot{e}\left|x_{1}-x_{2}\right|+\left|y_{1}-y_{2}\right|$ [Samet, 90].
} 


$$
R \triangleright \triangleleft_{\theta} S=\left\{\left(o, o^{\prime}\right) \mid(o \in R) \wedge\left(o^{\prime} \in S\right) \wedge \theta\left(o . G, o^{\prime} . G\right)\right\}
$$

Gaede e Günther [Gaede \& Günther, 98] relacionam, como exemplo, as seguintes possibilidades para o predicado $\theta$.

- faz_interseção_com $\left(o . G, o^{\prime} . G\right)$

- $\operatorname{contém}\left(o . G, o^{\prime} . G\right)$

- é englobado_por(o.G, o'.G)

- $\operatorname{distância}\left(o . G, o^{\prime} . G\right) \Theta \mathrm{q}, \operatorname{com} \Theta \in\{=, \leq,<, \geq,>\}$ e q $\in E^{\prime}$

- está_a noroeste $\left(o . G, o^{\prime} . G\right)$

- é_adjacente $\left(o . G, o^{\prime} . G\right)$

O predicado espacial faz_interseção_com, $R \triangleright_{\text {faz_interseção_com }} S$, merece um destaque especial por melhorar o desempenho computacional de diversos outros predicados. Por exemplo: para os predicados contém, é_englobado_por e é_adjacente, o predicado faz_interseção_com pode ser usado na etapa de filtragem de uma consulta espacial para gerar um conjunto candidato tipicamente muito menor que o produto Cartesiano $R$ X $S$ [Gaede \& Günther, 98]. Algoritmos para a execução da operação Spatial Join podem ser encontrados em [Kriegel et al., 92] [Brinkhoff et al., 94] [Patel \& DeWitt, 96] [Zhou et al., 97].

A seguir serão apresentados alguns conceitos relacionados a métodos de indexação espacial e serão exemplificados dois destes métodos.

\subsection{Métodos de Indexação Espacial}

\subsubsection{Definições preliminares}

Devido à crescente necessidade de indexar dados espaciais, diversos métodos têm sido desenvolvidos e aperfeiçoados. A Figura 10 apresenta sua evolução ao longo de trinta anos de pesquisas, mostrando os métodos originais e suas derivações em ordem cronológica: 


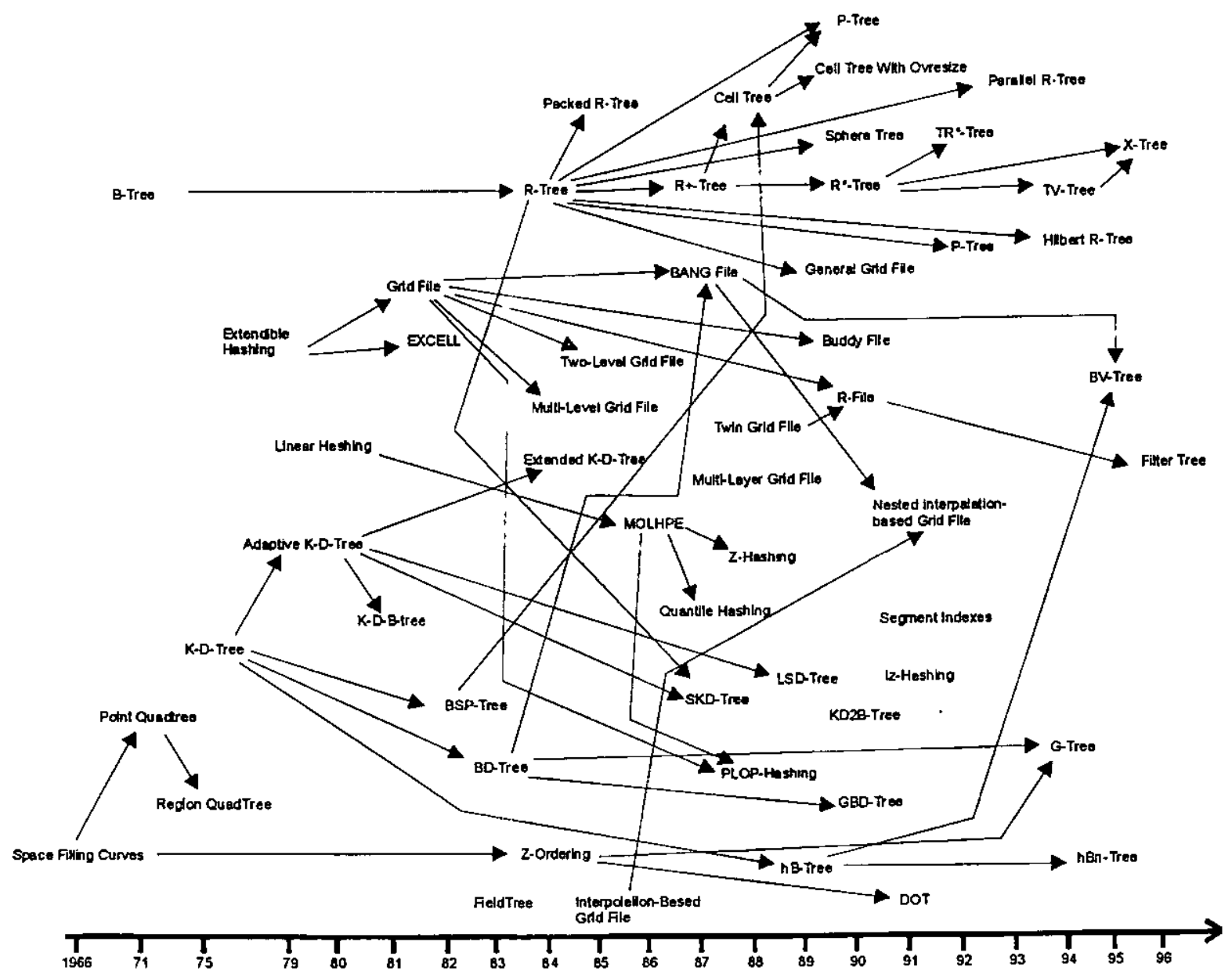

Figura 10: Evolução dos Métodos de Indexação Espacial [Gaede \& Günther, 98]

De forma geral, estes MIEs podem ser diferenciados considerando as seguintes características:

- O tipo de dados para o qual são utilizados: pontuais ou espaciais. Para lidar com dados espaciais, alguns dos MIEs aplicam operações de transformação aos mesmos gerando pontos representados em um espaço cuja dimensão pode ser igual, maior, ou até menor do que a do original [Samet, 95]. Este procedimento é, geralmente, aplicado quando um $P A M$ é utilizado.

- A forma como o espaço é representado:

- O espaço multidimensional pode ser mapeado para um espaço unidimensional [Jagadish, 90]. Este processo será tratado aqui por transformação do espaço;

- Alternativamente, é mantida a dimensão original do espaço. Neste caso, o mesmo é dividido em regiões (ou porções) e a indexação é feita em função destas regiões. A este processo é dado o nome de decomposição do espaço 
[Samet, 90]. Existe, ainda, uma classificação deste processo em função dos princípios que determinam como a decomposição é feita:

- em regiōes iguais, sendo conhecida como decomposição regular do espaço [Samet, 90] (ou, decomposição espacial regular); ou pode ser feita em função da distribuição espacial dos dados, sendo tratada, aqui, por decomposição irregular do espaço (ou, decomposição espacial irregular). Este processo pode ser aplicado mais do que uma vez (dito em vários níveis), o que significa que as regiões geradas em um nível serão subdividas no nível seguinte utilizando o mesmo critério (em regiōes iguais ou não);

- o número de vezes que este processo é aplicado, conhecido por resolução da decomposição [Samet, 90], pode ser fixo (predeterminado, indicado simplesmente por resolução fixa) ou não (por ser o caso mais comum, apenas a resolução fixa é indicada). Quando este princípio é utilizado mais do que uma vez, o processo passa a ser denominado decomposição [fixa] recursiva do espaço (ou decomposição espacial [fixa] recursiva). Pode, então, ser feita uma decomposição espacial regular recursiva, ou seja, a decomposição espacial é feita em regiões iguais e aplicada mais do que uma vez;

- Kriegel, Schiwietz, Schneider e Seeger, em [Kriegel et al., 90], fazem, ainda, as seguintes distinções: as regiões geradas pela decomposição podem ser mutuamente disjuntas duas a duas, ou não disjuntas; essas regiões podem ser intervalares, em que o espaço é dividido por hiperplanos ortogonais aos seus eixos, ou não intervalares (o termo usado originalmente é retangular, mas aqui será usado intervalar por ser mais abrangente quanto à dimensionalidade) e o particionamento pode ser completo ou incompleto, ou seja, a união de todas as regiões geradas pelo particionamento regenera o espaço original, ou apenas as porções onde se encontram os dados, respectivamente. 
- A estrutura de dados básica [Knuth, 73] [Samet, 90]: para organizar esses dados podem ser utilizadas estruturas baseadas em árvores, ditas hierárquicas, ou estruturas lineares, como vetores por exemplo, ditas não hierárquicas.

- Quantidade de dados por unidade de armazenamento (nó de uma árvore, posição de um vetor, etc.): quando uma unidade de armazenamento das estruturas de dados agrupa mais do que um dado (entrada do nó), elas são tratadas por bucket (em português significa balde, cesto ou caçamba) e as estruturas por estrutura bucket (ou seja, estruturas que indexam buckets) [Nievergelt et al., 84] [Freeston, 87] [Samet, 90]. Aquelas estruturas cuja unidade de armazenamento contém apenas um dado são tratadas aqui por estruturas não bucket. Os métodos de indexação, em função destas estruturas, são chamados, respectivamente, métodos bucket e métodos não bucket. É comum, ainda, usar o termo diretório [Freeston, 87] [Samet, 90] para indicar as estruturas bucket. Geralmente, quando se trata de uma estrutura deste tipo, presume-se que a mesma é organizada de forma a permitir armazenamento secundário, em que uma página de disco (ou bloco) corresponde a um bucket ${ }^{7}$.

Como pode ser visto na Figura 10, uma grande quantidade de MIEs já foi desenvolvida. Portanto, por questões didáticas ${ }^{8}$, apenas dois métodos serão apresentados aqui, a saber: a $R$-Tree, por sua importância na literatura, sendo o mais referenciado e muito usado como base de comparação; e a $T V$-Tree, por ser, dentre os estudados, o mais indicado para tratar do problema descrito ao final da seção 2.3. Outros exemplos podem ser obtidos em [Samet, 90] [Gaede \& Günther, 98].

\subsubsection{R-Tree}

Esta seção foi baseada em [Guttman, 84] e apresenta o funcionamento e a estrutura de dados do MIE R-Tree. A notação utilizada pelo autor será mantida.

\footnotetext{
${ }^{7}$ Segundo Freeston, em [Freeston, 87], o termo bucket é usado ao invés de bloco para enfatizar que o seu conteúdo não está, necessariamente, ordenado.

${ }^{8}$ Outras estruturas foram discutidas em [Santos Filho et al., 99a] e [Santos Filho et al., 99b], complementando este trabalho. Dentre elas estão as principais derivadas da $R$-Tree: a $R^{*}$-Tree [Beckmann et al., 90] e a $R+-$ Tree [Beckmann et al., 90].
} 


\subsubsection{Introdução}

O MIE $R$-Tree é, sem sombra de dúvidas, o $S A M$ mais referenciado na literatura, sendo o mais importante entre os que aplicam o conceito de $M B R$. Consiste basicamente de um $S A M$ que faz decomposição espacial irregular recursiva, organizada em diretórios hierárquicos.

\subsubsection{Estrutura de dados}

A R-Tree é uma árvore balanceada em função da altura, sendo que as folhas contêm ponteiros para os atributos não espaciais dos objetos. Os nós correspondem a páginas de disco, com as seguintes características (ver Figura 11, obtida em [Guttman, 84]):

- cada folha contém entradas do tipo (I, Tid), em que Tid se refere (pode ser um ponteiro) a uma tupla na base de dados, contendo os atributos não espaciais do objeto. E I corresponde ao $M B R$ deste objeto;

- cada nó interno contém entradas do tipo $(I, C i d)$, em que Cid é um ponteiro para algum filho. Ao passo que $I$ corresponde ao $M B R$ que cobre todas as regiões descritas pelos $M B R$ dos nós inferiores;

- Considere-se $M$ o número máximo de entradas em um nó. Assuma-se, então, $m \leq M / 2$ o parâmetro que especifica o número mínimo de entradas em um nó.

A $R$-Tree apresenta as seguintes propriedades:

- Toda folha contém entre $m$ e $M$ entradas, exceto a raiz;

- Para cada entrada do tipo ( $I, T i d)$ em uma folha, $I$ é o $M B R$ que contém o objeto descrito por Tid,

- Todo nó interno tem entre $m$ e $M$ filhos, a menos que seja a raiz;

- Para cada entrada do tipo $(I, C i d)$ em um nó interno, $I$ é o $M B R$ que engloba todos os $M B R s$ de seus filhos;

- A raiz tem no mínimo dois filhos, a menos que seja uma folha;

- Todas as folhas aparecem no mesmo nivel. 


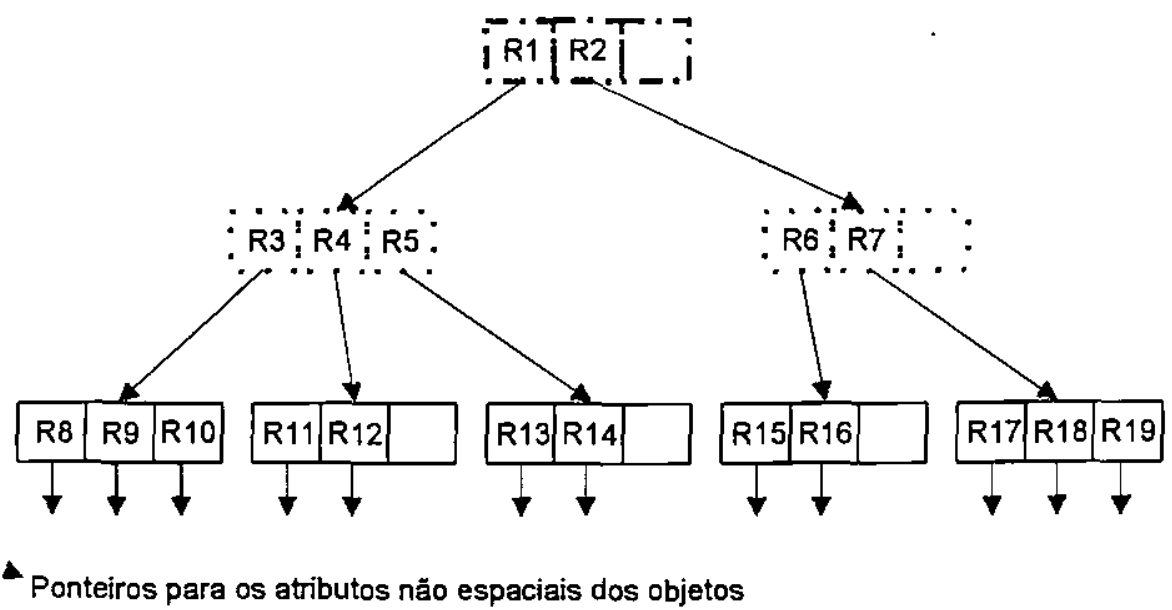

(a)

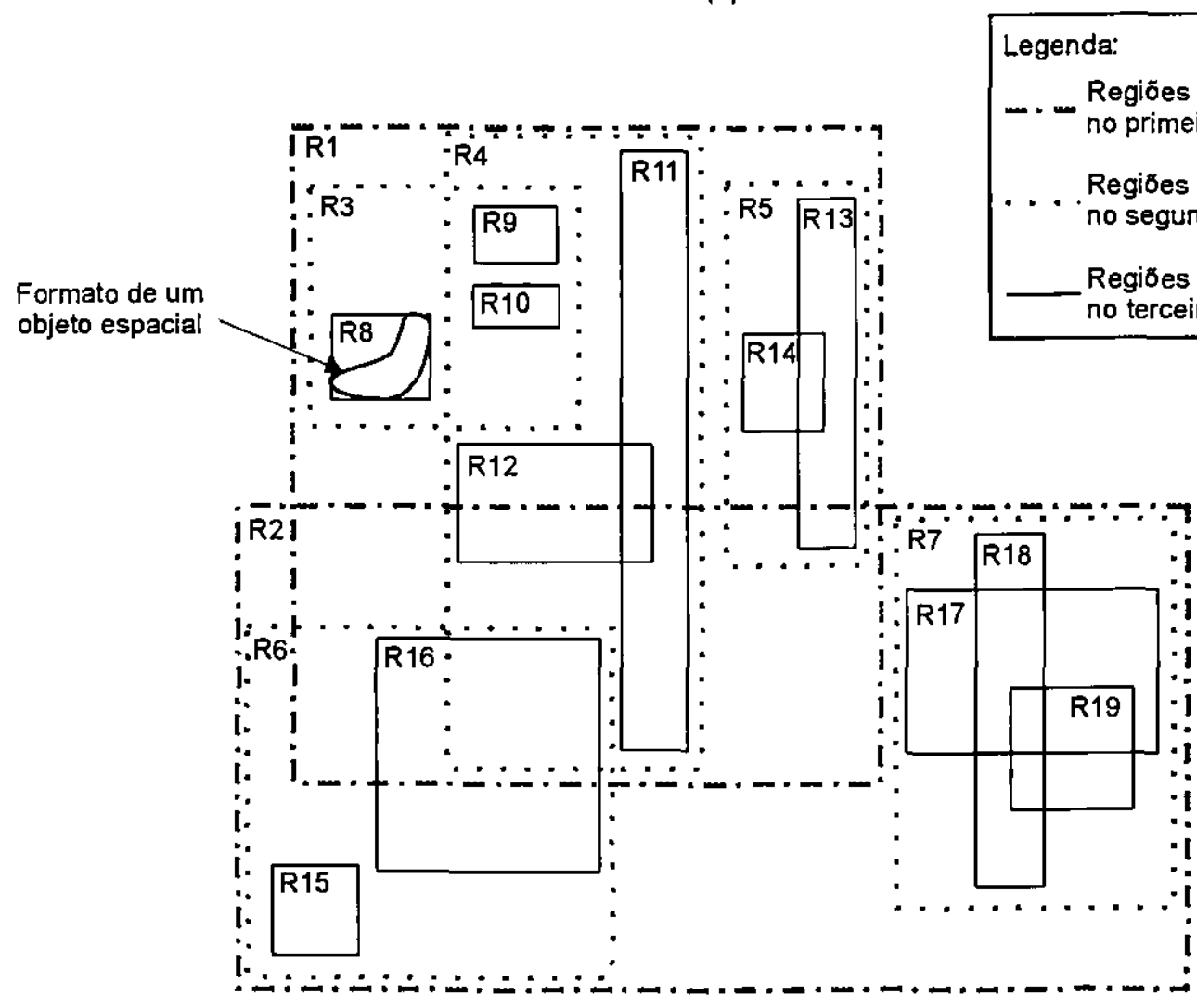

(b)

Figura 11: Exempio de uma $R-T r e e$. a) Representação em memória; b) Representação espacial com os MBRs.

A altura de uma $R$-Tree com $N$ registros é no máximo $\left|\log _{m} N\right|-1$, porque o número mínimo de entradas por nó é $m$. O número máximo de nós é $[N / m]+\left[N / m^{2}\right]+\ldots+1$. A pior taxa de ocupação para todos os nós, exceto para raiz, è $m / M$. Os nós tendem a ter mais do que $m$ entradas, o que irá diminuir a altura da árvore e melhorar a taxa de ocupação. 


\subsubsection{Consulta}

A consulta na $R$-Tree é similar à feita na $B$-Tree. Pode ser necessário percorrer mais do que uma subárvore de um determinado nó, aumentando o custo da consulta. Os algoritmos de inserção e particionamento devem ser projetados de forma a minimizar este aumento.

Considere-se $E . I$ como sendo o $M B R$ referente à entrada $E$, e E.p como sendo um Tid ou Cid. O seguinte algoritmo descreve uma consulta:

Algoritmo 1: Consulta

Encontra todas as entradas cujos $M B R$ s coincidem com um intervalo espacial de consulta $S$, a partir da $R$-Tree cuja raiz é indicada por $T$ :

1. Se $T$ é um nó interno, percorra todas as suas entradas $E$ para verificar se $E . I$ faz interseção com $S$. Para todas as entradas que fazem interseção, execute este passo novamente, considerando $T$ como sendo a subárvore apontada por E.p;

2. Se $T$ é uma folha, percorra todas as entradas $E$ para verificar se $E . I$ faz interseção com $S$. Se as entradas fazem interseção, então compõem o conjunto resposta.

\subsubsection{Inserção}

Inserção na $R$-Tree é similar à feita na $B$-Tree, sendo que novas entradas são acrescentadas nas folhas, e os nós que ultrapassam a capacidade máxima de entradas, $M$, são particionados. $O$ particionamento é, então, propagado para os pais.

Os seguintes algoritmos descrevem a inserção:

Algoritmo 2: Inserção

Insere uma nova entrada $E$ em uma $R$-Tree:

1. Use EscolheFolha para obter a folha $L$ onde $E$ deve ser incluído;

2. Se $L$ tem espaço para mais uma entrada, insira $E$. Caso contrário, use ParticionaNo para obter $L$ e $L L$ contendo $E$ e as antigas entradas de $L$; 
3. Use AjustarÁrvore passando $L$ como parâmetro para propagar as mudanças necessárias árvore acima. Se $L$ foi particionado, passe $L L$ também;

4. Se a propagação do particionamento ao longo da árvore provocou o particionamento da raiz, crie uma nova raiz tendo os dois nós gerados como filhos.

\section{Algoritmo 3: EscolheFolha}

Seleciona a folha em que $E$ será inserida:

1. Faça $N$ corresponder à raiz;

2. Se $N$ é uma folha, retorne $N$;

3. Senão, faça $F$ corresponder à entrada de $N$ cujo $M B R F . I$ necessita de menor expansão para englobar E.I. No caso de empate, escolha a entrada com $M B R$ de menor área;

4. Faça $N$ corresponder ao filho de $F$ referenciado por $F . p$. Retorne ao passo 2 .

\section{Algoritmo 4: Ajustarárvore}

Percorre árvore acima, a partir de uma folha, ajustando os $M B R$ s e propagando os particionamentos:

1. Faça $N=L$. Se $L$ foi particionado anteriormente, faça $N N$ corresponder ao nó resultante do particionamento;

2. Se $N$ é a raiz, encerre;

3. Considere $P$ como sendo o pai de $N$ e $E_{N}$ como sendo a entrada de $P$ referente a $N$. Ajuste $E_{N} I$ de forma a englobar todos os $M B R$ s de $N$;

4. Se $N N$ foi gerado, crie uma nova entrada $E_{N N}$, com $E_{N N} . p$ referenciando $N N$ e $E_{N N} . I$ englobando todos os $M B R$ s de $N N$. Se houver espaço em $P$, insira $E_{N N}$. Caso contrário, use ParticionaNo para obter $P$ e $P P$ contendo $E_{N N}$ e as antigas entradas de $P$;

5. Faça $N=P$. Se $N$ foi particionado, faça $N N=P P$. Retorne ao passo 2 .

O algoritmo ParticionaNo será descrito mais adiante. 


\subsubsection{Remoção}

Os seguintes passos são executados para se remover a entrada $E$ :

\section{Algoritmo 5: Remove}

Remove uma entrada $E$ de uma $R$-Tree:

1. Use EncontraFolha para obter a folha $L$ que contém $E$. Se a entrada $E$ não foi encontrada, encerre;

2. Remova $E$ de $L$;

3. Execute CondensaÁrvore, passando L como parâmetro;

4. Se a raiz ficou com apenas um filho após o passo anterior, transforme este filho na nova raiz.

Hilgoritmo 6: EncontraFolha

Encontra a folha que contém a entrada $E$, a partir da $R$-Tree cuja raiz é indicada por $T$ :

1. Se $T$ é um nó interno, percorra todas as suas entradas $F$ para verificar se $F . I$ faz interseção com F.I. Para cada entrada que faz interseção, execute este passo novamente considerando $T$ como sendo a subárvore apontada por $F . p$, até que $E$ seja encontrado ou que todas as subárvores tenham sido checadas;

2. Se $T$ é uma folha, percorra cada entrada para verificar se corresponde à entrada $E$. Se $E$ for encontrado, retorne $\mathrm{T}$.

Algoritmo 7: CondensaÁrvore

Dada uma folha $L$, da qual uma entrada foi removida, eliminar esta folha caso tenha um número de entradas menor do que o mínimo $m$, e inserir novamente suas entradas. Propagar a eliminação desta folha, se necessário. Ajustar todos os $M B R$ s árvore acima:

1. Faça $N=L$. Considere $Q$ como sendo um conjunto que irá conter os nós eliminados, inicialmente vazio;

2. Se $N$ é a raiz, vá para o passo 6. Caso contrário, considere $P$ como sendo o pai de $N$ e $E_{N}$ como sendo a entrada a entrada de $P$ referente a $N$. 
3. Se $N$ tem menos do que $m$ entradas, elimine $E_{N}$ de $P$ e insira em $Q$;

4. Se $N$ não foi eliminado, ajuste $E_{N} \cdot I$ de forma a englobar todos os $M B R \operatorname{s~de~} N$;

5. Faça $N=P$. Retorne ao passo 2 .

6. Reinsira todas as entradas existentes em $Q$. As entradas que faziam parte de folhas são reinseridas em folhas, da mesma forma que no Algoritmo 2 (Inserção). Mas, entradas que faziam parte de nós internos têm que ser reinseridas no mesmo nível em que se encontravam, de forma que as folhas das subárvores referentes às suas entradas fiquem no mesmo nível que as outras folhas da árvore principal.

\subsubsection{Particionamento}

O particionamento deve ser feito de forma a evitar que os dois nós gerados tenham sempre de ser percorridos quando da execução de uma consulta. Um nó deve ou não ser percorrido conforme o seu $M B R$ total faça ou não interseção com o intervalo

a)

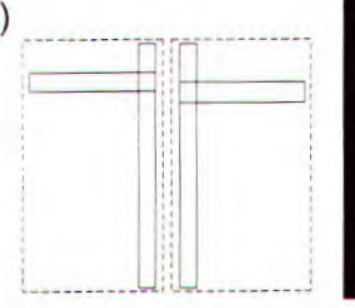

Figura 12: Exemplo de um particionamento. a) Particionamento ruim; b) Particionamento bom. de consulta. Para tanto, a área total dos MBRs de cada um dos nós gerados a partir do particionamento deve ser a menor possível. Como pode ser 'servado, as áreas dos MBRs (linhas tracejadas) na Figura 12a (particionamento ruim) são 1aiores do que as dos $M B R \mathrm{~s}$ da Figura $12 \mathrm{~b}$ (particionamento bom).

A seguir, serão resumidas três propostas para executar o particionamento de um nó, com $M+1$ entradas, de forma a gerar dois outros nós com $M B R$ s de áreas minimas:

\section{Algoritmo Exaustivo}

A forma mais direta de se encontrar os dois nós de áreas mínimas é testar todas as possibilidades de agrupamento das $M+1$ entradas e escolher a melhor. Porém, o número de possibilidades é aproximadamente $2^{M-1}$. Desde que um valor razoável para $M$ é 50 [Guttman, 84], o número de agrupamentos possiveis é consideravelmente grande. 


\section{Algoritmo Quadrático}

A proposta aqui é encontrar uma combinação de entradas com área pequena. Não se garante, porém, que seja esta a melhor combinação possível. O custo é quadrático em relação a $M$ e linear em relação ao número de dimensões.

O primeiro passo consiste em obter duas entradas, dentre as $M+1$, como sementes (primeira entrada) para compor os dois grupos que serão gerados após o particionamento. Estas sementes correspondem às entradas que iriam gerar a maior área, quando comparadas duas a duas, caso fossem colocadas no mesmo nó. Ou seja, subtraindo a área do $M B R$ que engloba estas duas entradas, da soma das áreas das próprias entradas, o valor seria maior do que o resultante do mesmo cálculo aplicado aos outros pares de entradas. As entradas restantes são escolhidas e inseridas como descrito a seguir:

Algoritmo 8: ParticionamentoQuadrático

Dividir um grupo de $M+1$ entradas em dois grupos:

1. Execute ObtémSementes para escolher as duas primeiras entradas e inclua uma em cada grupo;

2. Se todas as entradas já foram inseridas, encerre. Se um dos grupos possui tão poucas entradas, de forma que todas as outras tenham que ser nele inseridas afim de que passe a ter o número mínimo $m$ de entradas, insira todas e encerre;

3. Execute ObtémPróximaEntrada para obter a próxima entrada a ser inserida. Insira esta entrada no grupo que cujo $M B R$ total terá que ser menos expandido após a inserção. $\mathrm{Na}$ ocorrência de empate, a inserção é feita naquele de menor área total. Depois, naquele com menor número de entradas e por fim, no que apresenta os dois casos. Retorne ao passo 2 .

\section{Algoritmo 9: ObtémSementes}

Seleciona duas entradas para serem as primeiras de cada grupo:

1. Para cada par de entradas, $E_{1}$ e $E_{2}$, componha um $M B R J$ que engloba $E_{1}$.I e $E_{2}$.I. Calcule: $d=\operatorname{área}(\mathrm{J})$ - área $\left(E_{1} . \mathrm{I}\right)$ - área $\left(E_{2} . \mathrm{I}\right)$; 
2. Escolha o nó que apresenta o maior valor de $d$.

\section{Algoritmo 10: ObtémPróximaEntrada}

Escolhe uma entrada, dentre as que restam, para ser testada em um grupo:

1. Para cada entrada $E$ que ainda não foi inserida em um dos grupos, calcule $d_{1}=$ aumento necessário à área do $M B R$ total do primeiro grupo para incluir E.I. Considerando, agora, o segundo grupo, calcule $d_{2}$ da mesma forma;

2. Escolha qualquer entrada que apresente a máxima diferença entre $d_{1}$ e $d_{2}$.

\section{Algoritmo Linear}

Este algoritmo apresenta custo linear em relação a $M$ e ao número de dimensões. É basicamente idêntico ao anterior, mas usa uma versão diferente do Algoritmo 9 (ObtémSementes). Além disto, o Algoritmo 10 (ObtémPróximaEntrada) escolhe qualquer entrada dentre as que ainda restam.

\section{Algoritmo 11: ObtémSementesLinear}

Seleciona duas entradas para serem as primeiras de cada grupo:

1. Ao longo de cada dimensão, encontre a entrada cujo $M B R$ tem o lado inferior mais alto e a que tem o lado superior mais baixo. Armazene a distância entre eles;

2. Normalize as distâncias dividindo pelo tamanho de todo o conjunto ao longo da dimensão correspondente;

3. Escolha o par com a maior distância normalizada, dentre todas as dimensões.

\subsubsection{TV-Tree}

Esta seção foi baseada em [LinK et al., 94] e apresenta o funcionamento e a estrutura de dados do MIE TV-Tree. A notação utilizada pelo autor será mantida.

\subsubsection{Introdução}

A $T V$-Tree é um PAM que trabalha com o conceito de $M B R$ armazenando os dados apenas em nós folhas e os seus respectivos $M B R$ s em nós internos de uma árvore. Esta estrutura propõe 
contrair e estender dinamicamente o vetor de características (coordenadas do ponto). Em outras palavras, ao invés de usar um número fixo de coordenadas do ponto, a $T V$-Tree procura usar, em niveis mais altos da árvore, uma quantidade menor de coordenadas, tidas como mais relevantes.

Quando novos objetos são inseridos na árvore, pode vir a ser necessário o uso de outras coordenadas para discriminá-los melhor. A idéia principal é acrescentar novas coordenadas apenas quando são realmente necessárias, suavizando, assim, os efeitos relativos à dimensionalidade do espaço. Um dos beneficios adquiridos é o de tornar possível uma quantidade maior de entradas nos nós situados em níveis mais altos da estrutura.

A sigla $T V$ vem de Telescopic-Vector tree (ou, árvore de vetores telescópicos), fazendo uma analogia ao movimento de contrair e estender um telescópio. Ainda com esta idéia, a TV-Tree chama de "função telescópica" a função utilizada para contrair e estender as coordenadas dos pontos.

Esta função é definida da seguinte maneira:

- dado um vetor $\vec{x}, n \times 1$, e uma matriz $A_{m}, m \times n(\mathrm{~m} \leq \mathrm{n})$, chamada de matriz de contração, o vetor $A_{m} \vec{x}, m \times 1$, é uma $m$-contração de $\vec{x}$. Uma seqüencia de tais matrizes, com $m=1,2, \ldots$, descreve uma função telescópica, desde que a seguinte condição seja satisfeita: se as $m_{1}$-contrações de dois vetores, $\vec{x}$ e $\vec{y}$, são iguais, então, também são iguais as respectivas $m_{2}$-contracões, para qualquer $m_{2} \leq m_{1}$.

O exemplo mais natural, segundo os autores, para esta função, é a que simplesmente trunca o vetor $\vec{x}$. Ou seja, o vetor $A_{m} \vec{x}$ gerado pela aplicação da função telescópica possui os $m$ primeiros elementos do vetor de entrada. Essa função é definida da seguinte forma: para cada matriz $A_{m}, a_{i,}$ $=1$, com $i=j$; e $a_{i j}=0$, caso contrário. Esta função foi usada para gerar os exemplos descritos neste capítulo. Em [LinK et al., 94] podem ser encontrados outros exemplos.

Para a $T V$-Tree o termo $M B R$ não se refere a retângulos, mas sim a regiões do espaço, pois podem ser usadas regiões como: (hiper)esferas, (hiper)retângulos, (hiper)cubos, regiões limitadas em algumas dimensões e em outras não, etc. O termo $M B R$ fica, então, com o seguinte significado: $M B R$ - Minimum Bounding Region (ou, região limítrofe mínima). 
Dentre os formatos para estas regiões o de representação mais fácil é a esfera, pois exige que apenas o centro e o raio sejam armazenados. Uma esfera de raio $r$ é definida como o conjunto de pontos cuja distância Euclideana ao centro da esfera é menor ou igual a $r$. Vale notar que a distância Euclideana é um caso especial da métrica $L_{p}, \operatorname{com} p=2$ :

$$
L_{p}(\vec{x}, \vec{y})=\left[\sum_{i}\left(x_{i}-y_{i}\right)^{p}\right]^{1 / p}
$$

Para a $L_{1}$ (ou distância Manhattan, ou distância city-block), o formato gerado equivale a um diamante; para $L_{\infty}$, o formato gerado equivale a um cubo.

Uma esfera $L_{p}$ de centro $\vec{c}$ e raio $r$, é definida pelo conjunto de pontos cuja distância $L_{p}$ ao centro $\vec{c}$ é menor ou igual a $r$. Os algoritmos apresentados adiante suportam qualquer métrica $L_{p}$, sem necessitar alterações. $\mathrm{O}$ único algoritmo que depende do formato utilizado é o que calcula o $M B R$ de um conjunto de pontos.

\subsubsection{Estrutura de Dados}

O nó da $T V$-Tree representa o $M B R$ dos nós descendentes. Cada região é representada por um centro, que é definido por um vetor telescópico (gerado pela função telescópica), e um valor escalar correspondente ao raio. Um $M B R$ cujo centro é um vetor telescópico é designado por $T M B R$ - Telescopic Minimum Bounding Region.

Uma esfera telescópica $L_{p}$ com centro $\vec{c}$, raio $r$ e dimensionalidade $d$, das quais $\alpha$ estão ativas, é definida pelo conjunto de pontos $\bar{y}$, tais que:

$$
c_{i}=y_{i}, i=1, \ldots, d-\alpha
$$

$\mathrm{e}$

$$
r^{p} \geq \sum_{i=d-\alpha+1}^{d}\left(c_{i}-y_{i}\right)^{p}
$$

$\mathrm{Na}$ Figura 13a, por exemplo, D2 tem a primeira dimensão inativa e a segunda ativa. Apenas a primeira dimensão de D1 está ativa. A dimensionalidade de Dl é 1 (apenas a primeira dimensão foi levada em consideração para determinar D1) e a dimensionalidade de D2 é 2 (as duas dimensões foram consideradas). 
a)

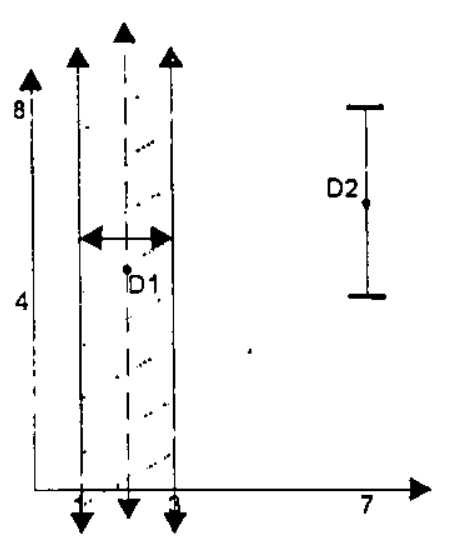

D1: centro (2), raio 1 D2: cantro $(7,6)$, raio 2

Número de dimensōes ativas: 1 b)

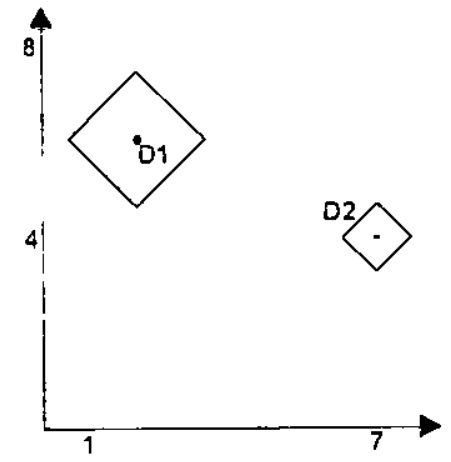

D1: centro $(2,6)$, raio 2

D2: centro $(7,4)$, raio 1

Número de dimensöes ativas: 2 c)

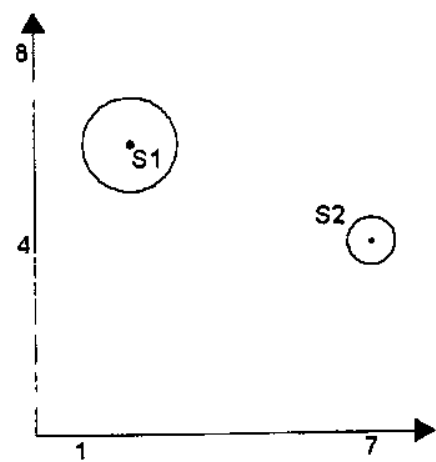

D1: centro $(2,6)$. raio 2

D2: centro $(7,4)$. raio 1

Número de dimensóes ativas: 2

- Centro do TMBR

$\longleftrightarrow$ Indica que se extende ao infinito ao longo de tal dimensão

Figura 13: Exemplos de TMBRs (em forma de Diamantes e Esferas). a) $\alpha=1$; b) $\alpha=2$; $c$ ) $\alpha=2$.

O conceito de dimensões inativas tem como base a seguinte idéia:

- na medida em que a árvore aumentar em altura, algumas folhas serão compostas por pontos que possuem, eventualmente, as mesmas $k$ primeiras coordenadas. Caso isto ocorra, os $T M B R$ s iniciais consideram que as $k$ primeiras dimensões destes pontos são inativas, pois não trazem nenhuma contribuição no sentido de discriminá-los.

Como conseqüência, os algoritmos são definidos de forma que as dimensões ativas sejam sempre as últimas. Além disso, o valor de $\alpha$ pode ser ajustado garantindo que todos os primeiros TMBRs de uma árvore possuam este mesmo valor. $\mathrm{O}$ valor de $\alpha$ é, na verdade, um parâmetro da TV-Tree. Logo, o número de dimensões ativas $(\alpha)$ de uma TV-Tree é o número de dimensões ativas de todos os seus $T M B R \mathrm{~s}$.

A notação $T V$-1 indica uma $T V$-Tree com $\alpha=1$. A Figura 13 exemplifica uma TV-1 (Figura 13a) e uma TV-2 (Figura 13b, c). O valor de $\alpha$ pode ser visto como o poder discriminatório da árvore. À medida que um maior poder discriminatório se faz necessário, novas dimensões são introduzidas. 
A estrutura de dados de um $T M B R$ é composta por: um vetor telescópico, contendo o número de dimensões (quantidade de coordenadas) e uma lista de coordenadas; e o valor do raio. A árvore gerada é semelhante à da $R$-Tree, e apresenta as seguintes características:

- cada nó contém um conjunto de entradas que correspondem aos TMBRs;

- todos os descendentes de uma entrada estão englobados por seu $T M B R$;

- os TMBRs podem ser sobrepostos;

- cada nó equivale a uma página de disco.

- como o tamanho de uma entrada varia de acordo com a dimensionalidade do vetor telescópico, a quantidade total de entradas que um nó pode ter também varia. Esta quantidade é definida pelo tamanho (em bytes) de um nó e pelo tamanho dos objetos (pontos e $T M B R$ s) nele inseridos.

A Figura 14 apresenta uma $T V-1$ e a Figura 15 apresenta uma $T V-2$. A faixa A-I corresponde a pontos e as faixas D1-D4, SS1-SS2 e S1S4 correspondem a nós internos. Apenas as duas primeiras dimensões são mostradas.

\subsubsection{Consulta}

A consulta na $T V$-Tree é similar à feita na $R-$ Tree. A partir da raiz, cada uma das radas é examinada e a subárvore referente àquelas cujo $T M B R$ faz interseção com a região de busca é percorrida recursivamente. Pode ser necessário percorrer mais do que uma subárvore de um determinado nó, pois os $T M B R$ s não são, necessariamente, disjuntos.

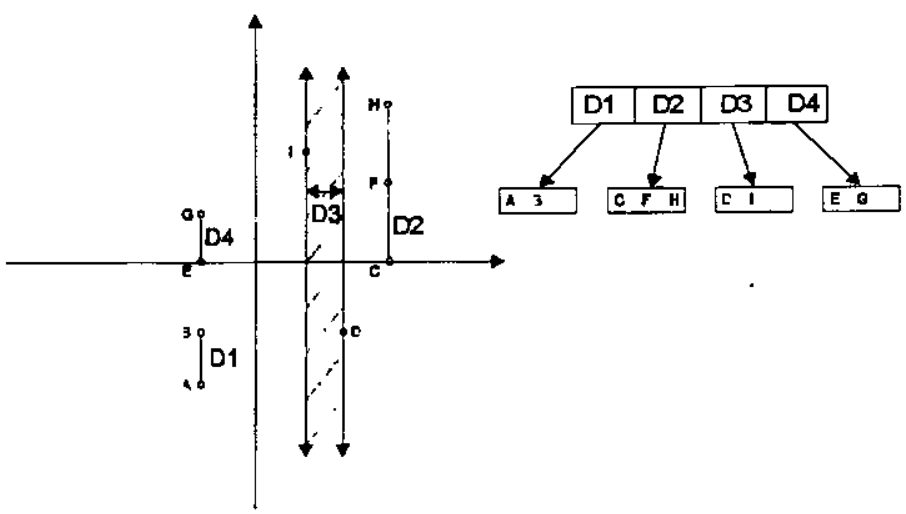

Figura 14: Exemplo de uma $T V-1$ (MBRs em forma de diamantes).

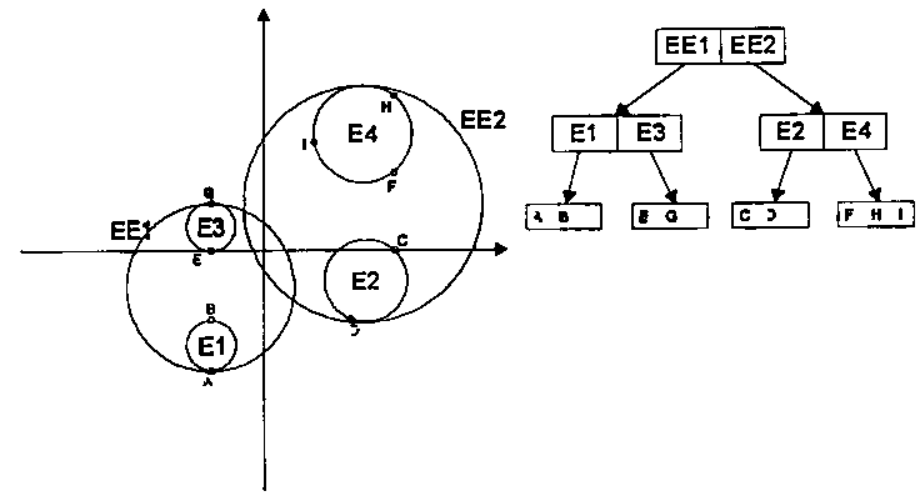

Figura 15: Exemplo de uma TV-2 (MBRs em forma de esferas). 


\subsubsection{Inserção}

A inserção é iniciada por uma busca percorrendo as subárvores mais adequadas a receberem o novo ponto. Os critérios para indicar esta adequação são apresentados adiante. Ao alcançar uma folha, a inserção é feita. Se a quantidade máxima de entradas de um nó foi superada, ou ele é particionado, ou algumas de suas entradas são reinseridas. Após a inserção, os ajustes necessários nos $T M B R$ s são propagados árvore acima.

Um $T M B R$ pode ser ajustado de duas formas: aumentando o seu raio ou reduzindo sua dimensionalidade (contraindo o vetor telescópico do seu centro) de forma a acomodar o novo jonto. A Figura 16 ilustra o ajuste no $T M B R D 1$, de uma $T V-1$, para incluir o ponto $P$.

A escolha da subárvore a ser percorrida para incluir um elemento $e$ (ponto ou $T M B R$ ), baseia-se nos seguintes critérios:

- Aquela em que o ajuste no $T M B R$ gera a menor quantidade de regiões sobrepostas;

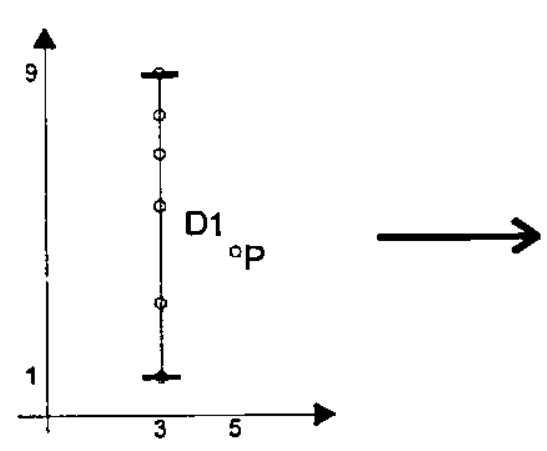

D1: Centro(3,5), raio 4

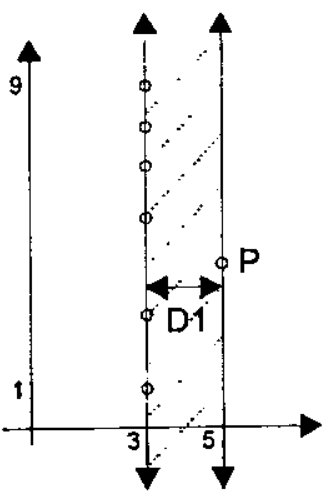

D1: Centro(4), raio 1

- Aquela cujo $T M B R$ necessita de menor ajuste quanto à sua

Figura 16: Exemplo de inserção. O TMBR D1 é ajustado para incluir o ponto $P$. dimensionalidade. Ou seja, se há a necessidade de diminuir a dimensionalidade do $T M B R$, escolha aquele que sofrerá a menor redução;

- Aquela cujo TMBR necessita de menor aumento em seu raio;

- Aquela onde a distância entre o ponto a ser inserido e o centro do seu TMBR é mínima.

Durante a inserção, duas situações podem levar um nó a ter sua quantidade máxima de entradas ultrapassada: ou por estar recebendo mais uma entrada, ou porque alguma das entradas já existentes teve o seu TMBR modificado (uma tentativa de estender o vetor telescópico aumentaria o espaço necessário para armazená-lo, por exemplo). A solução mais simples seria particionar o nó.Porém, outra opção apresentada pela $T V$-Tree é inserir novamente alguns elementos a partir da 
raiz. A vantagem com esta última opção é que se aumenta a chance de colocar em um mesmo nó elementos que se encontram mais próximos.

Quando o número de entradas em um nó é superado, os seguintes critérios são utilizados para decidir o que deve ser feito:

- se for uma folha, uma porcentagem $\left(p_{r i}\right)$ predeterminada de suas entradas serão reinseridas se esta for a primeira vez que o espaço do nó é esgotado durante a inserção corrente. Caso contrário, a folha será particionada. Políticas diferentes podem ser utilizadas para decidir que entradas devem ser reinseridas. Uma opção é escolher a que se encontra mais distante do centro da região;

- se o nó for interno será sempre particionado e o resultado será propagado árvore acima.

Algoritmo 12: Inserção

Inserir o elemento $e$ na árvore cuja raiz é indicada por $N$ :

1. Use EscolherEntrada para determinar-a subárvore a ser percorrida, até uma folha ser alcançada. Faça $L$ conter o endereço desta folha;

2. Insira $e$ em $L$;

3. se o número de entradas de $L$ foi superado:

3.1. então, se esta é a primeira vez durante a inserção:

3.1.1. então, obtenha os $p_{r i}$ elementos mais distantes do centro de $L$ e reinsira-os desde a raiz;

3.2. Senão, particione $L$;

4. Atualize os TMBRs necessários. Particione os nós internos que superarem a quantidade máxima de entradas.

\subsubsection{Particionamento}

O particionamento da TV-Tree pode ser feito de várias formas. Em [LinK et al., 94], duas são destacadas: 
- pelo uso de alguma técnica de agrupamento visando manter em um nó os objetos (pontos e TMBRs) que se encontram mais próximos entre si, por exemplo: dois objetos, os que apresentam a maior distância entre si, são escolhidos como sementes para encabeçar os dois grupos que serão gerados; a partir dai, os outros objetos são inseridos de forma a manter os mais próximos no mesmo grupo. Ou seja, cada objeto é comparado com as sementes e inserido no grupo encabeçado por aquela de menor distância ao mesmo.

- pelo uso de alguma técnica de ordenação (space-filling curves [Samet, 90] [Gaede \& Günther, 98], por exemplo). Os vetores são ordenados e em seguida o nó é particionado segundo algum critério, por exemplo: manter em um mesmo nó os objetos que, juntos, somam o menor raio.

\subsubsection{Remoção}

A remoção é semelhante à feita na $R$-Tree. A árvore é percorrida até que a folha onde se encontra o objeto a ser removido seja atingida. Em seguida, o mesmo é removido e as alterações necessárias (ajustes nos TMBRs dos nós superiores) são propagadas árvore acima. No caso de um nó ficar com menos do que a quantidade mínima de entradas, o mesmo é removido e suas entradas são reinseridas.

A seguir, alguns exemplos encontrados na literatura de áreas que utilizam os conceitos de dados naciais serão apresentados, com o intuito de mostrar quão vasta é sua aplicabilidade.

\subsection{Exemplos de Aplicação e Trabalhos Relacionados}

Atualmente diversas áreas do conhecimento têm usado BD espaciais. A seguir, estão relacionados alguns exemplos de aplicações que as utilizam e alguns trabalhos recentes envolvendo MIEs:

1. Medicina [Smith \& Chang, 94] [Traina et al., 98]: esta talvez seja a área de maior motivação, tendo diversos trabalhos já desenvolvidos. São exemplos de aplicações: armazenamento e recuperação de imagens e auxílio no estudo de casos através da identificação de imagens com algum tipo de semelhança. Petrakis e Faloutsos, em 
[Petrakis \& Faloutsos, 97], propõem um método para facilitar consultas por similaridade a BDs de imagens utilizando Grafos Relacionais Rotulados (Attributed Relational Graphs) para representar o conteúdo das imagens.

2. Base de dados Temporais e de Seqüências Amostrais [White \& Jain, 96a] [Kuman et al., 98]: MIEs são usados para responder perguntas como "encontre ações da bolsa de valores que apresentam uma flutuação de mercado com o seguinte padrão..." e "encontre uma seqüência de DNA com padrões semelhantes à desta...". Nascimento e Silva em [Nascimento \& Silva, 98] apresentam uma extensão do MIE R-Tree [Guttman, 84], chamada Historical R-Tree, usada para auxiliar consultas em BDs temporais.

3. Processamento de dados Geográficos (ou "Sistema de Informações Geográficas") [Günther \& Buchmann, 90] [Schneider, 97]: BDs espaciais auxiliam na elaboração de mapas e no armazenamento e recuperação de dados como: distribuição populacional, relevo, acidentes geográficos, planta de uma cidade, etc. Auxiliam, também, no registro da evolução destes dados no decorrer do tempo. As operações mais comuns são: Containment Query, Nearest Neighbors Query, Adjacency Query, e Spatial Joins.

4. Sensoriamento remoto [Schneider, 97]: imagens e outros tipos de dados provenientes de sensores em satélites ao redor da Terra têm sido intensamente utilizados para fazer previsões meteorológicas, detecção de queimadas, detecção de plantações para produzir matéria prima usada na fabricação de drogas como a cocaina e a maconha, dentre outras. $\mathrm{BD}$ espaciais são utilizadas para auxiliar na análise e armazenamento destes dados.

5. BDs do tipo Multimídia (Multimedia Databases) [LinK et al., 94] [Smith \& Chang, 94]: que armazenam áudio (sons, vozes, músicas, etc.), vídeo, etc. Consultas típicas são: "obter uma música que apresenta uma seqüência de sons como...", "encontrar em um filme uma imagem com determinadas características ou semelhantes a uma imagem dada...", etc.

6. Tratamento de cadeias de caracteres [Kukich, 92]: envolvendo correção ortográfica, correção de erros em textos obtidos por reconhecimento óptico de caracteres (Optical Character Recognition - $O C R$ ), busca de seqüências de cadeias de caracteres em textos 
muito grandes, etc. Com relação a este último exemplo. uma aplicação interessante é a busca de cadeias de caracteres parecidas (ou com erro): procurar em uma agenda eletrônica o endereço "Rua Major Alberto, no. 1234" quando o endereço correto é "Rua Major Carlos Alberto, no. 4321".

7. Computação móvel [Tayeb et al., 98]: com o crescente uso de computadores portáteis (notebook) e agendas eletrônicas de bolso (palmtop) por pessoas que estão a todo tempo se deslocando entre cidades e até países diferentes, MIEs estão sendo estudados para responder perguntas que levam em consideração, automaticamente, a posição atual do usuário, ou seja: "qual o hotel mais próximo de onde estou...".

\subsection{Conclusão}

Neste capítulo foram introduzidos os conceitos em torno de dados espaciais: o que são, como são representados em meio computacional, propriedades, dificuldades que apresentam em termos de armazenamento e recuperação, os operadores espaciais mais comuns encontrados na literatura e como o desempenho de uma consulta espacial pode ser melhorada se feita em duas etapas. Dois dos MIEs foram resumidos com a intenção de exemplificar e complementar os conceitos apresentados ao inicio do capítulo. Por fim, foram exemplificadas algumas aplicações que utilizam dados espaciais.

Durante a elaboração deste trabalho observou-se que o conceito em torno de alta ou baixa dimensionalidade não é padronizado. Ou seja, alguns autores colocam que alta dimensão corresponde a algo em torno de 5 a 10 [Beckmann et al., 90], ou 20-30 [Petrakis \& Faloutsos, 97], já outros consideram que as dimensões de nível mediano estão abaixo de 20 [White \& Jain, 96a]. Outros consideram alta dimensão algo em torno de 100 [LinK et al., 94] [White \& Jain, 96a], sendo que alguns sequer especificam o que corresponde a alta dimensão.

Ocorre que este conceito está diretamente relacionado com a aplicação dada aos MIEs, e não à sua estrutura. Esta falta de consenso gera um problema com relação à avaliação dos mesmos, pois, por não existir um parâmetro formalizado que indique a ordem da dimensão, torna-se 
necessário o entendimento completo das estruturas para avaliar se são adequadas ou não ao problema. 
4. Avaliando os MIEs R-TReE E TV-TREe 


\section{AVALIANDo os MIEs R-TREe E TV-TREE}

\subsection{Introdução}

O objetivo deste trabalho, como já foi dito, é avaliar os diversos métodos de indexação voltados para dados espaciais pontuais, procurando identificar aquele que melhor se adapte aos requisitos colocados ao final da seção 2.3. Os métodos apresentados nas seções 3.4 .2 (R-Tree) e 3.4 .3 (TV. Tree) já revelam soluções que atendem aos dois últimos requisitos, ou seja: suportam armazenamento secundário e são dinâmicos. Trata-se, portanto, de avaliar estes métodos em relação ao primeiro requisito: adaptabilidade a dimensões variadas e altas.

Visto que os sumarizadores das imagens (ver seção 2.3) só são especificados quando o metaesquema de uma aplicação é definido, a estrutura dos parâmetros que serão retornados só é conhecida após esta definição. Como diferentes sumarizadores podem gerar conjuntos distintos de parâmetros, o método de indexação a ser utilizado deve ser projetado de forma a se adaptar, em tempo de execução, a diferentes dimensões (definidas pela quantidade de elementos que compõem os parâmetros de um determinado conjunto). Ou seja, o código desenvolvido não pode ser recompilado cada vez que um novo sumarizador é incluído no meta-esquema de uma aplicação.

A solução para este problema está mais relacionada com a fase de implementação. O método pode ser desenvolvido como um TAD, onde as dimensões são passadas como parâmetros e as estruturas de dados são instanciadas em tempo de execução. Porém, como a aplicação alvo do MIE é o gerenciador de objetos SIRIUS/GO, a possibilidade de trabalhar com dimensões distintas leva a um problema que envolve a segunda parte do requisito mencionado (dimensões altas) e será retomado mais adiante.

A questão da indexação de pontos em dimensões muito elevadas tem sido alvo de inúmeros estudos. Esta questão, também conhecida por problema da dimensionalidade [LinK et al., 94] [Berchtold et al., 96] [Chakrabarti \& Mehrotra, 99], pode gerar conseqüências de diferentes tipos: diminuição da eficiência de armazenamento, diminuição da eficiência temporal, maior 
incidência de regiões sobrepostas (aumentando a quantidade de nós a serem visitados em uma consulta) e outras.

Para exemplificar a sua importância, observa-se que o MIE Point-Quadtree (uma descrição deste MIE pode ser obtida em [Samet, 90]) apresenta uma complexidade computacional que varia exponencialmente em função da dimensão: $2^{d}$, onde $d$ é a dimensão em uso. Isto ocorre, pois, cada ponto inserido divide a região onde se encontra em $2^{d}$ novas (hiper) regiões (quadrantes para o caso bidimensional e octantes para o tridimensional), necessitando do mesmo número de variáveis nos nós que armazenam os pontos, uma para cada subárvore definida pela divisão.

Outro exemplo é o MIE $k$ - $d$-Tree (uma descrição deste MIE pode ser obtida em [Samet, 90]), o qual pode ser adaptado para apresentar uma complexidade computacional constante quanto ao número de variáveis armazenadas por nó, mas não suporta armazenamento secundário e não é balanceado. Para tratar o problema do armazenamento secundário, o MIE $k$ - $d$ - $B$-Tree foi proposto em [Robinson, 81]. No entanto, possui problemas com o algoritmo de particionamento (o particionamento de um nó pode vir a ser propagado, obrigatoriamente, tanto árvore acima como abaixo), tem problemas de reorganização quando ocorrem muitas remoções e não garante uma taxa mínima de ocupação. Uma análise do comportamento desta estrutura em função da variação da dimensão foi apresentada em [Santos Filho et al., 99b], complementando este trabalho.

A dimensão dos vetores retornados pelos sumarizadores pode assumir valores que atingem as centenas, tornando necessário analisar o comportamento dos MIEs em função destes valores. Dentre as conseqüências da dimensionalidade comentadas anteriormente, a que está relacionada ao SIRIUS/GO é a eficiência de armazenamento: dados espaciais em dimensões mais altas necessitam de maior espaço de armazenamento para suas coordenadas.

Este gerenciador, assim como outros [Elmasri \& Navathe, 94], acessam o disco através de blocos (ou páginas) de tamanho (quantidade de bytes) fixo. Como alguns MIEs apresentam uma dimensionalidade tal que o espaço necessário para armazenar os dados espaciais cresce em função da dimensão, é necessário projetar o método de indexação de forma a se adequar à dimensão dos 
dados que irá indexar. Se o método não for bem projetado, o gerenciador poderá ficar instável e até "abortar", pois os dados podem não "caber" em um nó, estourando sua capacidade máxima.

Analisando o requisito como um todo, dimensões variadas e altas, tem-se que um dos problemas a ser avaliado neste trabalho refere-se ao comportamento dos MIEs em função da variação da dimensão, considerando que pode assumir valores muito altos e que a aplicação alvo apresenta a restrição de acessar o disco através de blocos de tamanho fixo. Vale ressaltar, ainda, que o tamanho máximo dos vetores a serem indexados é indeterminado, pois novos sumarizadores podem ser definidos ao longo do uso da base de imagens, justificando ainda mais a necessidade desta avaliação.

$\mathrm{O}$ restante deste capítulo apresenta um conjunto de testes feitos com os MIEs $R$-Tree e TV-Tree para dimensões variadas e com nós de tamanho fixo. Inicialmente estes testes serão descritos, envolvendo: os dados utilizados, suas etapas e o sistema computacional utilizado. Por fim, serão apresentados os resultados e seus comentários, comparações entre os métodos testados e as conclusões desta fase do trabalho.

\subsection{Descrição das Simulações}

O universo de estudo das simulações constituiu-se de 10.000 vetores de 256 elementos representando pontos no espaço de dimensão 256. Para variar as dimensões foram considerados os $k$ (sendo $k$ a dimensão em teste) primeiros elementos destes vetores. $O$ procedimento utilizado para a obtenção dos vetores é descrito a seguir.

A intenção inicial era testar os métodos em dimensões variadas indexando vetores de características gerados a partir de imagens médicas. Um número razoável de vetores seria em torno de 10.000 , tornando necessário o mesmo número de imagens em meio digital. Como esta quantidade é muito alta e no projeto CAMS/SIRIUS não foram processadas, ainda, um número suficiente de imagens de um mesmo domínio, optou-se por usar um arquivo com dados binários (não textuais) para gerar os vetores. A seguir, será descrito como este arquivo foi gerado e como os vetores foram extraídos. 
$\mathrm{Na}$ literatura, diversas idéias têm sido aplicadas para gerar artificialmente dados amostrais: indexar retângulos obtidos no esquema de um circuito integrado de computador [Guttman, 84], processar palavras de um dicionário extraindo vetores de características [LinK et al., 94], gerar dados aleatoriamente [Berchtold et al., 96], etc. Com o intuito de estar próximo ao que seria feito com as imagens médicas, propõe-se, neste trabalho, simular a extração dos vetores a partir de trilhas de músicas gravadas digitalmente.

O sumarizador escolhido para extrair as características corresponde ao histograma de tons de cinza para imagens de 8 bits de profundidade, as quais possuem até 256 tons diferentes. Ou seja, para cada tom da escala de cinza seriam contados os pontos (pixels) com aquele tom, armazenando o resuitado em vetores com 256 elementos.

Desta forma, trilhas de um CD foram copiadas em formato digital para o disco rígido e concatenadas, produzindo um arquivo grande o suficiente para que 10.000 vetores, com 256 elementos cada, fossem extraídos. Já que a idéia era utilizar imagens do tipo $220 \times 220 \times 8$ (linhas $\mathrm{X}$ colunas $\mathrm{X}$ profundidade em bits) totalizando 48.400 bytes, o arquivo foi criado com 484.000.000 bytes. Em seguida, os vetores foram montados a partir de blocos de 48.400 bytes e armazenados em outro arquivo. Cada registro contém os 256 valores encontrados e a posição, no arquivo de trilhas musicais, do primeiro byte de cada bloco.

Os vetores assim formados possuem uma dependência linear entre seus elementos, onde 0 somatório destes, para qualquer vetor, é igual a 48.400. Com isto, os pontos representados pelos vetores estarão distribuídos no espaço ao longo de uma "hiper-superficie". Observa-se, ainda, que os dados gerados podem ser coincidentes. Ou seja, não é garantida a unicidade destes vetores (podem existir vários vetores com os mesmos elementos, indicando o mesmo ponto no espaço).

As simulações envolveram as seguintes dimensões: $2,4,8,16,32,64,128$ e 255 . Foram usadas páginas de acesso a disco com 4.096 bytes de tamanho. A dimensão 255 substituiu a de 256, pois na $R$-Tree só seria possível armazenar um único $M B R$ com 256 intervalos (um para cada dimensão) em nós com este tamanho de página. Ao passo que com a dimensão 255 , foi possível armazenar $2 M B R$ s. 
Cada simulação foi composta por 2 etapas: inserção dos pontos e consultas por coincidência exata (exact match query). Foram inseridos 10.000 vetores, um a um, na mesma ordem em que foram gerados, sendo que apenas os 1.000 últimos foram contabilizados para efeito de análise de desempenho. $\mathrm{E}$ foram feitas 1.000 consultas da seguinte forma: considerando o conjunto dos 10.000 registros já inseridos, foi feito um programa que escolhia, aleatoriamente, 1.000 registros deste conjunto, montando uma seqüência de busca. O programa foi feito de forma a garantir que o mesmo registro só seria consultado uma vez. A seqüência gerada foi percorrida e cada ponto obtido era submetido para consulta. Vale ressaltar que o mesmo conjunto de dados e a mesma ordem de inserção e consulta foram usados em todos os testes.

Para as simulações foi utilizado o seguinte sistema computacional: microcomputador Pentiun II $300 \mathrm{MHz}$ com $256 \mathrm{MB}$ de memória principal, $6 \mathrm{~GB}$ de disco rígido e sistema operacional Linux Kernel 2.0.35 distribuição Red Hat.

Como os resultados apresentados a seguir apresentam medidas de tempo, vale observar que esta medida depende muito do sistema computacional usado e de aspectos diretamente relacionados ao código utilizado (linguagem de programação, estilo e experiência do programador, etc.), não podendo ser utilizado para comparação entre os métodos. Como será visto adiante, existe uma limitação na estrutura de dados dos métodos onde só é possível armazenar uma quantidade sỉecífica de informações por nó, levando a erros em tempo de execução caso este limite venha a ... )assado.

Em outras palavras, se o número de informações necessárias para armazenar um ponto ou região do espaço ( $M B R$ ou $T M B R$, a depender do método) for grande (em bytes) ao ponto de não "caber" em um nó, o programa passa a apresentar erros. Neste sentido, os testes apresentados neste trabalho visam identificar e comparar os limites individuais de cada método.

\section{$4.3 \quad$ R-Tree}

As simulações feitas com o MIE R-Tree envolveram os três algoritmos de particionamento descritos na seção 3.4.2.6. A quantidade máxima de entradas por nó foi determinada pela dimensão em teste e pelo tamanho da página de disco, sendo a quantidade mínima definida como 
metade da máxima. A Tabela 1 apresenta as quantidades máxima e mínima de entradas por nó vs. a dimensão. Observa-se que a quantidade máxima de entradas por nó decresce linearmente na medida em que a dimensão aumenta, o que irá aumentar a altura da árvore.

Tabela 1: Quantidades máxima e mínima de entradas por nó da R-Tree em função da dimensão em teste.

\begin{tabular}{|c|c|c|c|c|c|c|c|c|}
\hline 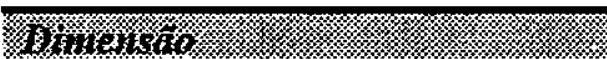 & 8. & 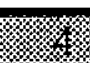 & (1) & 16 & 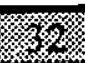 & (6) & 28. & 235 \\
\hline Quantidade Máxima de E & 254 & 127 & 63 & 31 & 15 & 7 & 3 & 2 \\
\hline Quantidade Minima de Entradas & 102 & 56 & 30 & 15 & 7 & 3 & 1 & 1 \\
\hline
\end{tabular}

O código usado nas simulações referentes a este método, corresponde ao original desenvolvido 、 autor e foi obtido via FTP em "http://emerald.ucsc.edu/ tonig/rtrees/scr.tar". Algumas adaptações foram feitas para atender às necessidades geradas pela simulação: tamanho do nó, dimensão em uso, etapas de simulação, dentre outras. Vale ressaltar que a árvore gerada por esse código reside totalmente em memória principal, portanto os valores de tempo resultantes das simulações não contabilizam o tempo de acesso a disco.

Foram realizadas 21 simulações combinando as diferentes dimensões com os 3 algoritmos de particionamento descritos na seção 3.4.2.6. Destas, duas apresentaram problemas de segmentação de memória e foram descartadas dos resultados, a saber: dimensões 128 e 255 usando o algoritmo Quadrático. Não foram feitas simulações com o algoritmo Exaustivo nas dimensões 2, 4 e 8, pois, além do tempo de execução ser muito grande (ver seção 3.4.2.6, sobre quantidade de combinações possíveis), não traria contribuições significativas para a análise efetuada. A Tabela 2 mostra com um " $\mathrm{X}$ " as combinações que finalizaram com sucesso. Portanto, por razões intrínsecas aos algoritmos de particionamento utilizados, foram analisados os resultados de 19 simulações no total.

Tabela 2: Simulações utilizando a $R$-Tree terminadas com sucesso.

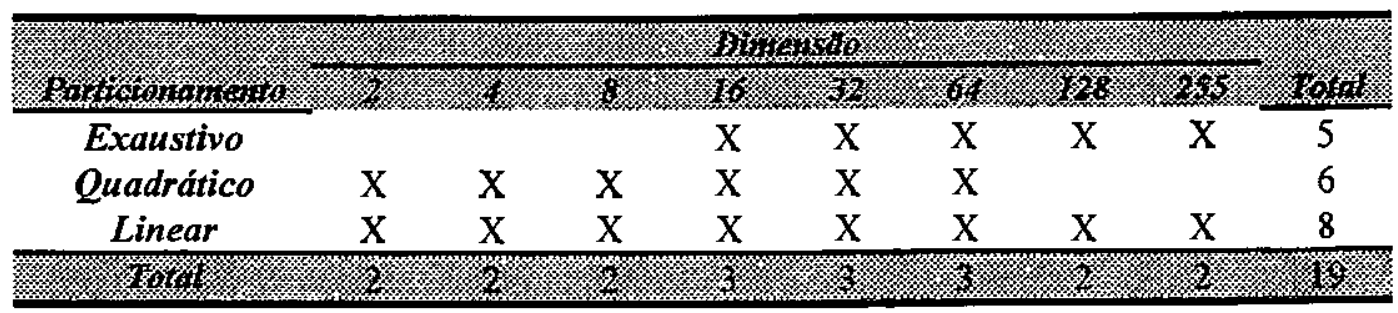




\subsubsection{Resultados}

\section{Inserçāo}

A Tabela 3 apresenta a configuração das árvores após a fase de Inserção. Confirmando o que foi dito anteriormente, a altura da árvore (item I) cresce linearmente com o aumento da

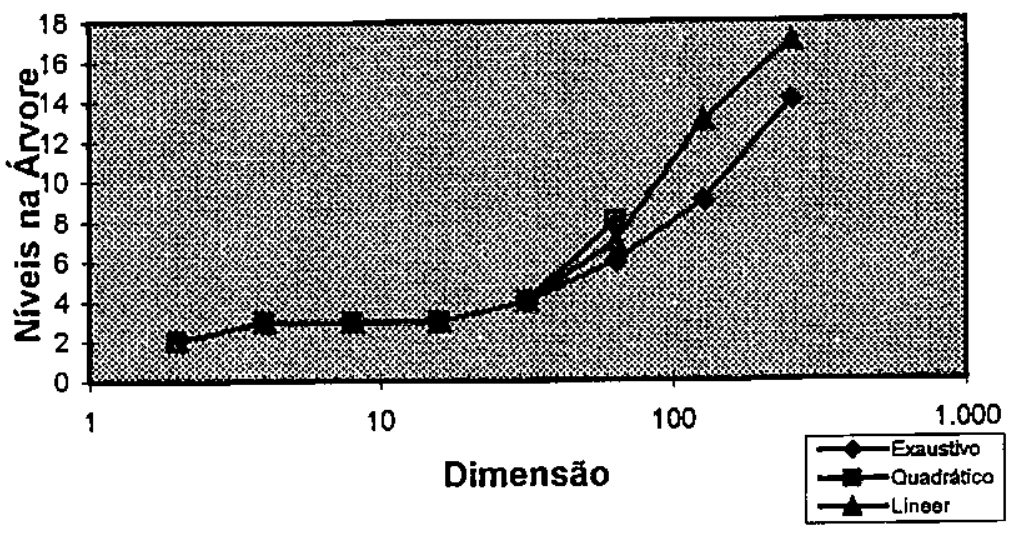

Figura 17: R-Tree - Altura após 10.000 inserçöes. dimensão devido à diminuição da quantidade máxima de entradas por nó (Tabela 1). $O$ comportamento deste indicador é indesejável, pois degrada as consultas. Esta degradação se dá porque aumenta o "caminho" para se atingir os pontos indexados (que estão nas folhas).

O gráfico da Figura 17 mostra que a altura das árvores geradas pelos diferentes algoritmos de particionamento começa a ser diferenciada por volta da dimensão 64 , sendo que o algoritmo exaustivo apresenta o melhor resultado. Observa-se, ainda, que a partir da dimensão 32 a altura da árvore aumenta mais rapidamente.

A quantidade total de nós (ver Figura 18) e o tamanho do índice (itens II e III da Tabela 3 ,

Tabela 3: R-Tree - Configuração após a inserção de 10.000 pontos.

\begin{tabular}{|c|c|c|c|c|c|c|c|c|}
\hline 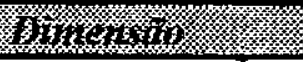 & 奴 & 聯 & 8 & 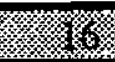 & 3 & 26 & 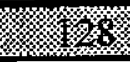 & 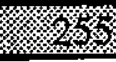 \\
\hline \multicolumn{9}{|c|}{ I. Altura da Arvore } \\
\hline i. Exaustivo & & & & 3 & 4 & 6 & 9 & 14 \\
\hline ii. Quadrático & 2 & 3 & 3 & 3 & 4 & 8 & & \\
\hline iii. Linear & 2 & 3 & 3 & 3 & 4 & 7 & 13 & 17 \\
\hline \multicolumn{9}{|c|}{ II. Quantidade Total de Nós } \\
\hline i. Exaustivo & & & & 469 & 1.038 & 2.499 & 5.005 & 10.005 \\
\hline ii. Quadrático & 71 & 139 & 238 & 467 & 1.025 & 4.131 & & \\
\hline iii. Linear & 77 & 140 & 239 & 470 & 1.010 & 3.320 & 9.995 & 14.328 \\
\hline \multicolumn{9}{|c|}{ III.Tamanho do Indice $(k B)$} \\
\hline i. Exaustivo & & & & 1.876 & 4.152 & 9.996 & 20.020 & 40.020 \\
\hline ii. Quadrático & 284 & 556 & 952 & 1.868 & 4.100 & 16.524 & & \\
\hline iii. Linear & 308 & 560 & 956 & 1.880 & 4.040 & 13.280 & 39.980 & 57.312 \\
\hline \multicolumn{9}{|c|}{ IV.Taxa de Ocupação } \\
\hline i. Exaustivo & & & & $74 \%$ & $70 \%$ & $71 \%$ & $99 \%$ & $99 \%$ \\
\hline ii. Quadrático & $69 \%$ & $64 \%$ & $71 \%$ & $74 \%$ & $71 \%$ & $48 \%$ & & \\
\hline iii. Linear & $64 \%$ & $64 \%$ & $71 \%$ & $74 \%$ & $72 \%$ & $57 \%$ & $66 \%$ & $84 \%$ \\
\hline
\end{tabular}




respectivamente) também
crescem linearmente em função
da dimensão, sendo o algoritmo
Exaustivo o que apresenta melhor
resultado.

$\mathrm{Na}$ verdade, o item III depende linearmente do II, pois o tamanho do índice pode ser obtido a partir

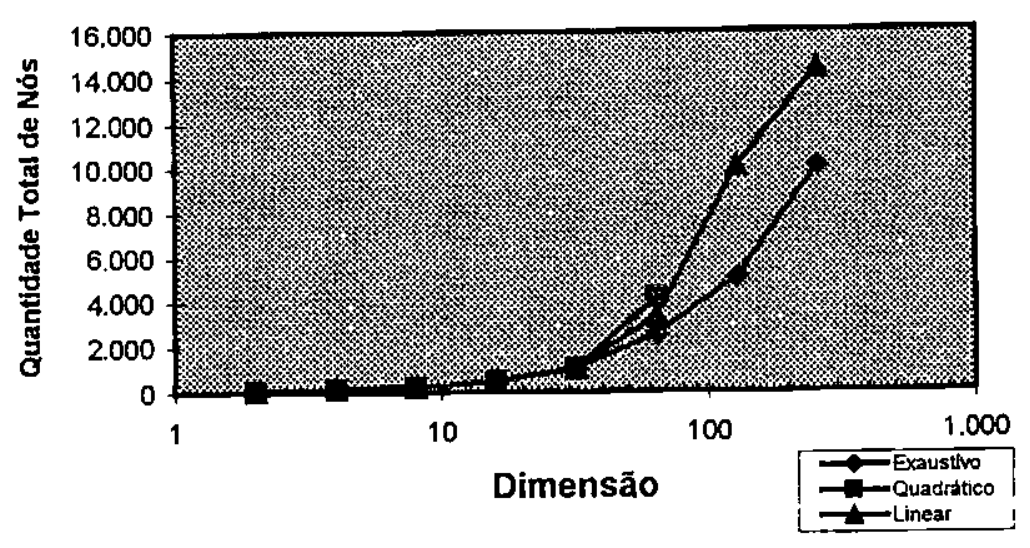

Figura 18: R-Tree - Quantidade total de nós. da multiplicação da quantidade total de nós pelo tamanho da página de disco. Novamente, observa-se nos dois itens uma diferenciação nos resultados para os diferentes algoritmos por volta da dimensão 64. Além disto, a curva apresenta um crescimento mais acentuado a partir da dimensão 32 .

Cabe, neste ponto, uma observação: sabe-se que em decorrência de como foram gerados, os pontos utilizados nas simulações não estão uniformemente distribuídos no espaço; e, como a cada dimensão apenas uma parte das coordenadas é utilizada, a distribuição varia para cada caso. Acredita-se, portanto, que a distribuição dos dados possa estar provocando diferentes índices de desempenho.

Procurando visualizar de forma simplificada a correlação entre a distribuição dos dados, para as dimensões diferentes, e os resultados, um programa que calcula a variância de cada coordenada foi feito e os resultados obtidos são apresentados na Figura 19. Em virtude de as variâncias se encontrarem em um intervalo muito extenso (entre 100 e 16 milhões), foi usada a escala logarítmica para representar estes valores.

O gráfico mostra que a variância decresce bruscamente até a dimensão 30 , aproximadamente, permanecendo entre 100 e 1.000 até uma dimensão próxima à 232. Como as primeiras coordenadas apresentam altos valores de variância, acredita-se que os pontos estejam muito dispersos. Enquanto isso, na medida em que se aumenta a dimensão de teste e se adicionam as coordenadas entre 30 e 235 (com valores mais amenos), os pontos devem ficar relativamente mais concentrados em uma região do espaço. 


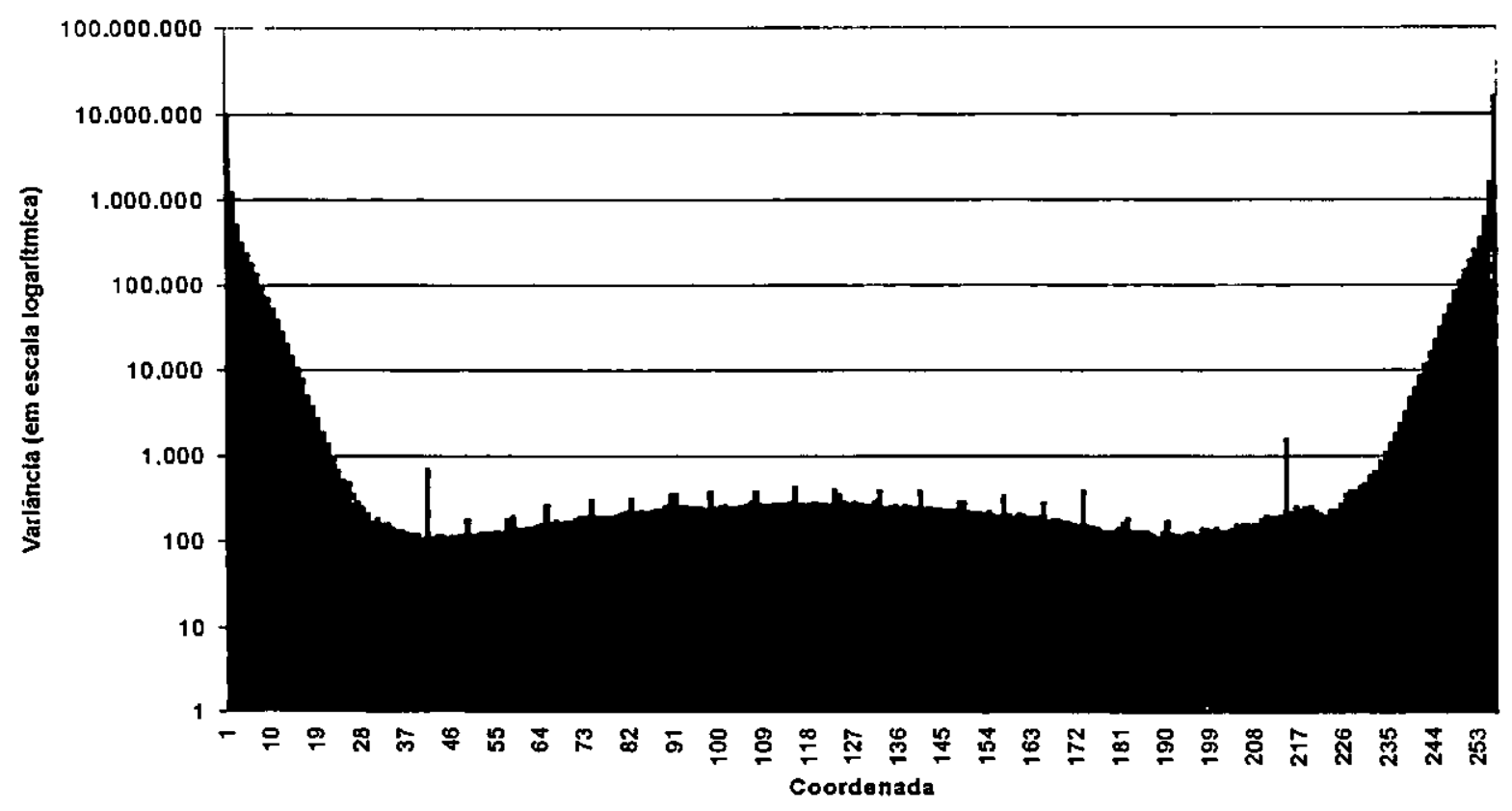

Figura 19: Variância (em escala logarítmica) das 256 coordenadas dos 10.000 pontos inseridos.

Esta medida (variância das coordenadas) não é muito precisa para mensurar a distribuição dos pontos no espaço e não reflete inteiramente os resultados obtidos. Portanto, não é possível usá-la como estimativa de desempenho para $R$-Trees. Porém, este cálculo foi feito para se ter uma aproximação, ou noção, da influência da distribuição sobre os resultados. Além disso, como a maior parte dos indicadores apresentados nesta seção revela uma diferenciação por volta da dimensão 32 , torna-se útil a definição de algum parâmetro que justifique este comportamento.

Vale ressaltar que não faz parte do escopo deste trabalho desenvolver formas de estimar o desempenho dos MIEs a partir dos dados de entrada. Faloutsos e Kamel em [Faloutsos \& Kamel, 94] apresentam um estudo nesta linha, onde é proposto que a dimensão fractal do conjunto de dados pode ser usada para estimar o comportamento de $R$-Trees.

Retornando aos resultados das simulações, tem-se que a taxa de ocupação se manteve entre $64 \%$ e $84 \%$ nas dimensões abaixo de 32 , inclusive. A faixa obtida se encontra dentro do esperado para árvores semelhantes à B-Tree [Langsam et al, 96]. Os algoritmos Quadrático e Linear apresentam uma queda brusca nos valores da taxa de ocupação entre as dimensões 32 e 64 (de $71 \%$ para $48 \%$ e de $72 \%$ para $57 \%$, respectivamente). Novamente, observa-se que a distribuição espacial dos pontos possa ter influenciado estes resultados. 
Ainda sobre o algoritmo Quadrático, o valor encontrado na dimensão 64 é inferior á ocupação mínima por nó (50\%). Isso pode ser explicado da seguinte forma: como não são feitas restrições quanto à ocupação mínima da raiz, este valor indica que todos nós internos e folhas estão próximos a $50 \%$ de ocupação, ao passo que a raiz apresenta um valor inferior a este.

As taxas de ocupação encontradas para as dimensões 128 e 255 são, respectivamente: $66 \%$ e $84 \%$ para o algoritmo Linear e $99 \%$, nos dois casos, para o algoritmo Exaustivo. Como o número mínimo e máximo nestas dimensões são bastante próximos, a árvore tende a apresentar uma taxa de ocupação mais próxima dos $100 \%$.

Os resultados da Tabela 4 mostram o comportamento da $R$-Tree durante a inserção dos últimos 1.000 pontos, dentre os 10.000 inseridos. O número de nós particionados por inserção se comporta de forma semelhante ao itens II e III da Tabela 3, já discutidos. Se há um número maior de particionamentos, obtém-se uma quantidade maior de nós e, conseqüentemente, um índice de tamanho maior. O crescimento deste item é suave até a dimensão 32 , tornando-se mais acentuado a partir deste ponto (ver gráfico da Figura 20). Para enfatizar o seu significado, observa-se que com o algoritmo Exaustivo ocorre um particionamento a cada duas inserções para a dimensão 128 e um a cada uma inserção para a dimensão 255; e para o Linear ocorre um a cada uma inserção para a 128 e três a cada duas inserções para a 255 .

A dimensão 64 da Tabela 4 mostra um aumento considerável

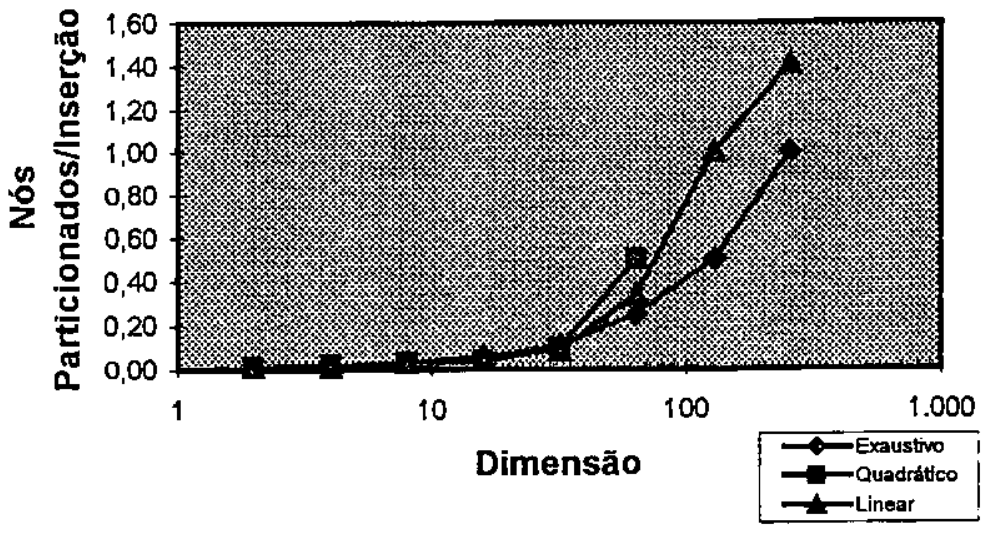

Figura 20: $R$-Tree-Nós particionados por ponto inserido, considerando as 1.000 últimas inserções. particionados por inserção) para os três algoritmos: de 0,11 para 0,25 com o Exaustivo; de 0,10 para 0,50 com o Quadrático; e de 0,09 para 0,34 com o Linear. Este salto pode confirmar a suspeita da heterogeneidade na distribuição dos pontos. A diminuição da quantidade de entradas por nó, por si só, não explica o aumento brusco do número de particionamentos, principalmente por ser este aumento comum a todos os algoritmos. 
Tabela 4: R-Tree - Desempenho da inserção. Foram considerados apenas os últimos 1.000 pontos.

\begin{tabular}{|c|c|c|c|c|c|c|c|c|}
\hline 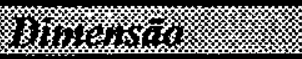 & 烟 & 4 & 3. & 媓 & 俭 & 64. & $\left(\frac{1}{3}\right.$ & 28. \\
\hline \multicolumn{9}{|c|}{ I. Nós Particionados//nserção } \\
\hline i. Exaustivo & & & & 0,05 & 0,11 & 0,25 & 0,50 & 1,00 \\
\hline ii. Quadrático & 0,01 & 0,02 & 0,03 & 0,04 & 0,10 & 0,50 & & \\
\hline iii. Linear & 0,01 & 0,01 & 0,03 & 0,06 & 0,09 & 0,34 & 1,00 & 1,41 \\
\hline \multicolumn{9}{|c|}{ II. Nós Acessados/Inserçäo } \\
\hline i. Exaustivo & & & & 3,05 & 4,11 & 6,25 & 9,50 & 15.00 \\
\hline ii. Quadrático & 2,01 & 3,02 & 3.03 & 3,04 & 4,10 & 8,50 & & \\
\hline iii. Linear & 2,01 & 3,02 & 3,02 & 3,06 & 4,09 & 7,33 & 14,00 & 18,41 \\
\hline \multicolumn{9}{|c|}{ III.Tempo Total de Inserção (s) } \\
\hline i. Exaustivo & & & & 0,33 & 0,50 & 0,77 & 1,85 & 4,18 \\
\hline ii. Quadrático & 0,65 & 0,62 & 0,65 & 0,63 & 0,80 & 2,02 & & \\
\hline iii. Linear & 0,08 & 0,22 & 0,23 & 0,32 & 0,50 & 1,12 & 2,78 & 5,58 \\
\hline
\end{tabular}

Ora, supondo uma maior concentração de pontos em determinada região, é de se esperar que tendam a ocupar o mesmo nó da $R$-Tree, para que seja gerado, assim, um $M B R$ de área menor. Conseqüentemente, este nó passa a ser particionado mais vezes, elevando a quantidade de particionamentos por ponto inserido.

A etapa de inserção envolve uma fase de consulta onde a árvore é percorrida para se identificar o nó onde o objeto será armazenado. $O$ item II da Tabela 4 apresenta o número de nós acessados por inserção nesta fase. Observa-se que seus resultados estão próximos aos da altura da árvore (item I da Tabela 3), como era esperado.

O tempo total de inserção (item III da Tabela 4) apresenta uma dependência em função da 'ensão, como pode ser visto pelo gráfico da Figura 21. A partir deste gráfico, conclui-se que o algoritmo Exaustivo apresenta melhor desempenho para dimensões acima de 32 . Isto ocorre, pois, como o número de entradas por nó diminui, o número de combinações possíveis para este tipo de particionamento também diminui. Entre as dimensões 16 e 32 , os algoritmos

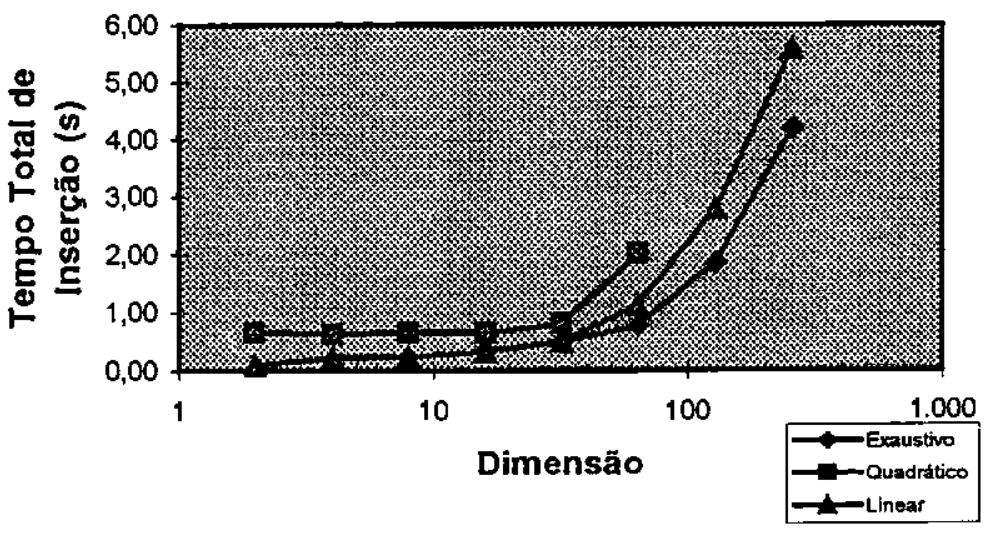

Figura 21: $R$-Tree - Tempo total de inserçăo para os últimos 1.000 pontos. 
Tabela 5: $R$-Tree - Desempenho obtido com 1.000 consultas por coincidência exata.

\begin{tabular}{|c|c|c|c|c|c|c|c|c|}
\hline Shim & 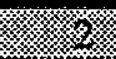 & $8 \%$ & 8 & 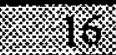 & (3) & 6 & 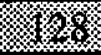 & 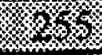 \\
\hline \multicolumn{9}{|l|}{ I. Pontos Encontrados } \\
\hline i. Exaustivo & & & & 1.018 & 1.018 & 1.018 & 1.018 & 1.018 \\
\hline ii. Quadrático & 1.025 & 1.018 & 1.018 & 1.018 & 990 & 1.013 & & \\
\hline iii. Linear & 1.025 & 1.018 & 1.018 & 1.018 & 1.018 & 1.018 & 1.018 & 1.018 \\
\hline \multicolumn{9}{|l|}{ II. Nós Acessados/Consulta } \\
\hline i. Exaustivo & & & & 225.67 & 157.59 & 43.36 & 43.60 & 49.27 \\
\hline ii. Quadrático & 3.58 & 129.12 & 187,10 & 225.33 & 159.50 & 84,57 & & \\
\hline iii. Linear & 8.22 & 130.16 & 188,03 & 224,97 & 161.48 & 74.26 & 98.77 & 91,78 \\
\hline \multicolumn{9}{|l|}{ III.Tempo Total de Consulta (s) } \\
\hline i. Exaustivo & & & & 4,60 & 2,07 & 0,40 & 0,60 & 1,17 \\
\hline ii. Quadrático & 0,10 & 5.47 & 7.45 & 4,73 & 2.05 & 0,75 & & \\
\hline iii. Linear & 0,38 & 5,53 & 7,53 & 4.75 & 2.15 & 0.78 & 1.37 & 2.33 \\
\hline \multicolumn{9}{|l|}{$\begin{array}{l}\text { IV. Tempo TotalNós Acessados/ } \\
\text { Consulta }\end{array}$} \\
\hline i. Exaustivo & & & & 0,020 & 0,013 & 0,009 & 0,014 & 0,024 \\
\hline ii. Quadrático & 0,028 & 0,042 & 0,040 & 0,021 & 0,013 & 0,009 & & \\
\hline iii. Linear & 0,047 & 0,043 & 0,040 & 0.021 & 0,013 & 0,011 & 0,014 & 0,025 \\
\hline
\end{tabular}

Exaustivo e Linear apresentam o mesmo desempenho. Abaixo de 16, o Linear apresenta um desempenho melhor.

\section{Consulta}

Os resultados da Tabela 5 mostram o comportamento da $R$-Tree durante 1.000 consultas do tipo coincidência exata. Foram encontrados 1.018 pontos para todas as simulações com o algoritmo Fxaustivo; com o algoritmo Quadrático foram encontrados 1.018 pontos para as simulações nas dimensões 4,8 e 16 e, respectivamente, $1.025,990$ e 1.013 nas dimensões 2, 32 e 64; e com o algoritmo Linear, 1.025 pontos para a simulação na dimensão 2 e 1.018 nas demais dimensões.

Destes resultados conclui-se que, dos vetores gerados como descrito na seção 4.2 e dentre os 1.000 selecionados para consulta por coincidência exata, $5 \%$ são coincidentes na dimensão 2 e apenas $3,6 \%$ nas demais dimensões, apresentando uma baixa taxa de colisões apesar da * andência linear entre as coordenadas.

Para as dimensões 32 e 64 do algoritmo Quadrático era esperado o mesmo resultado obtido com os demais algoritmos. Fica, portanto, a suspeita de que este algoritmo gere os chamados falsos descartes (false dismissals), ao menos para dimensões muito altas. 
O item II da Tabela 5 apresenta o número de nós acessados por consulta. De forma geral, considerando que se trata de busca de pontos por coincidência exata era esperado que os resultados ficassem próximos à altura da árvore, com uma pequena variação devido à ocorrência de $M B R$ s sobrepostos. Porém, os resultados mostram um desempenho muito inferior ao esperado, pois em $50 \%$ dos casos o número de nós acessados é em torno de 35 vezes a altura da árvore e no restante uma média de 5 vezes o respectivo valor.

Este resultado indica que existe uma quantidade realmente grande de $M B R$ s sobrepostos em nós internos da árvore, apesar do baixo índice de colisões. Porém, ao contrário do que se imaginava, não foi identificada nenhuma dependência destes resultados com a variação da dimensão. Em outras palavras, para este conjunto de dados não pode ser dito que, com o aumento da dimensão, o número de $M B R$ s sobrepostos aumenta.

Após a dimensão 16, como pode ser visto na Figura 22, o número de nós acessados por consulta diminui, apresentando poucas alterações a partir da dimensão 64. Acredita-se que a distribuição espacial dos dados esteja afetando, também, este resultado. Como ocorreram mais particionamentos nestas dimensões (acima da 64), é provável que os $M B R$ s resultantes se encontrem menos sobrepostos.

O tempo total de consulta reflete, em parte, o comportamento do número de nós acessados por "Isulta. No entanto, uma observação deve ser feita: o número de nós acessados por consulta wita entre as dimensões 8 e 16 (de 187,1 para 225,33 com o algoritmo Quadrático e de 188,03 para 161,48 para 0 algoritmo Linear), enquanto que o tempo total de consulta diminui neste mesmo intervalo (de 7,45 para 4,73 com o algoritmo Quadrático e de 7,53 para 4,75 para o algoritmo Linear), contrariando a tendência esperada

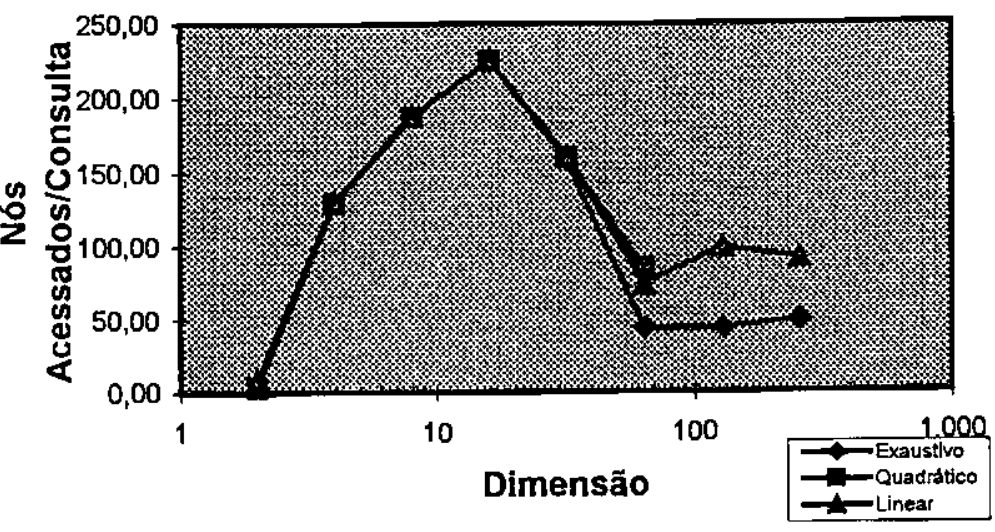

Figura 22: R-Tree - Número de nós acessados por ponto consultado vs. dimensão. 
de que estes valores tivessem a mesma evolução.

Para entender este comportamento, foi calculado o tempo médio gasto em cada nó consultado (tempo total / nós acessados / consulta) e os resultados se encontram no item

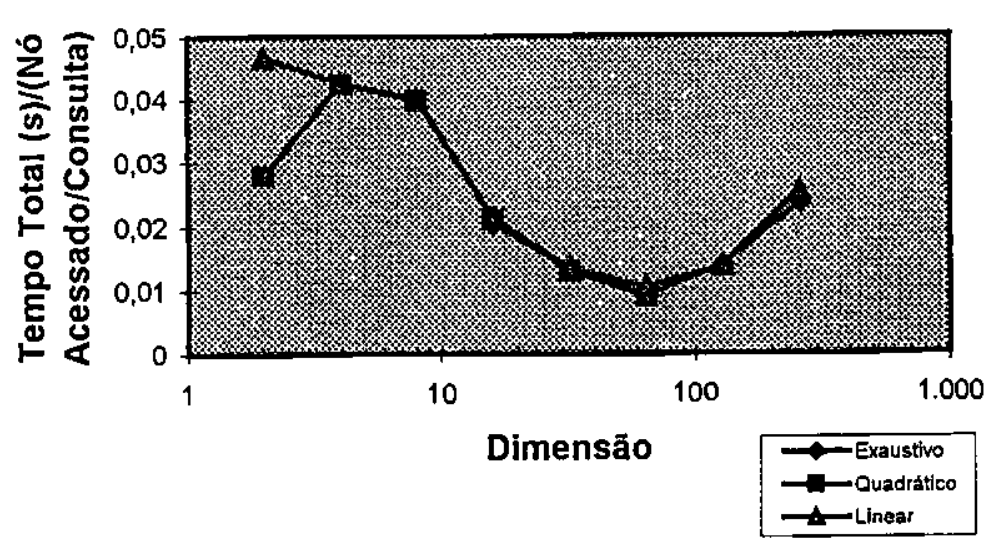

Figura 23: $R$-Tree - Tempo médio de processamento de um nó em função da dimensão, durante a fase de consulta.

\section{IV da Tabela 5. Observa-se que o}

tempo médio de processamento dos nós durante uma consulta decresce até a dimensão 64 (ver gráfico na Figura 23). Isto ocorre porque a quantidade de entradas foi diminuindo, reduzindo o número de comparações feitas a cada passo. O posterior aumento deve ser resultante do grande número de dimensões, indicando que deva existir um valor ótimo de entradas entre as dimensões 64 e 128.

Por fim, em relação à consulta, o algoritmo Exaustivo apresenta melhor desempenho para dimensões acima de 32, praticamente empatando com o algoritmo Linear entre as dimensões $16 \mathrm{e}$ 32. Abaixo de 16, os algoritmos Linear e Quadrático apresentam desempenhos iguais.

\subsubsection{Discussão}

A estrutura de dados da $R$-Tree exige duas variáveis para cada dimensão que compõe o objeto a ser indexado. Para dimensões maiores, um maior número de variáveis é necessário, diminuindo o número de entradas por nó. A princípio, esta característica já constitui um problema, pois, além de diminuir a quantidade de entradas por nó, causando perdas em quase todos os indicadores de desempenho apresentados na seção anterior, é dificil definir um tamanho de nó adequado. Por maior que seja o nó, um novo sumarizador pode vir a ser definido de tal forma que não será possível armazenar sequer um objeto.

Vale lembrar que este estudo visa o uso do método de indexação em gerenciadores de objetos, o qual, por sua vez, define o tamanho do bloco de acesso a disco. Neste sentido, aumentar o 
tamanho do nó não é uma solução aceitável, pois implicaria em alterar todo o gerenciador. Por outro lado, "quebrar" o objeto de forma a caber em vários blocos também não é uma solução desejável, pois implicaria em um aumento do número de acessos a disco.

Uma conseqüência direta da diminuição do número de entradas por nó é o aumento da altura da árvore. Utilizando a mesma quantidade de dados, a árvore gerada para 255 dimensões possui, aproximadamente, 8 vezes a altura da que foi gerada para 2 dimensões (considerando o algoritmo Linear). Aumentar este valor implica aumentar o número de acessos a disco durante as consultas.

Além da quantidade de entradas, a quantidade total de nós e o tamanho do índice também aumentam razoavelmente como resultado da alteração na estrutura de dados para incluir novas dimensões. A taxa de ocupação, por sua vez, apesar de permanecer em uma faixa aceitável para a maioria dos casos (em torno de $65 \%$ com o algoritmo Linear), indica uma forte tendência a aumentar o número de particionamentos para dimensões mais críticas (com poucas entradas por nó). Esta observação é comprovada com as médias de particionamentos por inserção apresentadas na Tabela 4, comentadas anteriormente.

Dentre os resultados, o mais significativo é o número de nós acessados por consulta. Como já foi dito, esperava-se que este número fosse próximo à altura da árvore, visto que todas as consultas foram por coincidência exata. No entanto, os testes mostraram valores razoavelmente maiores (em torno de 35 vezes a altura das árvores). Apesar de não demonstrar a existência de uma correlação com a variação da dimensão, este resultado indica que a $R$-Tree não é adequada para a aplicação desejada, principalmente por se tratar estritamente de dados pontuais.

Enfim, por ser mais versátil, o algoritmo Linear seria o mais indicado. Apesar de apresentar resultados inferiores ao Exaustivo, este algoritmo pôde se aplicado a todas as dimensões testadas sem apresentar problemas. Além disso, de forma geral os resultados indicam 0 mesmo comportamento para os três algoritmos em função da dimensão, realçando a importância desta versatilidade. 


\subsection{TV-Tree}

O código da TV-Tree usado nas simulações corresponde ao original baseado no trabalho apresentado em [LinK et al., 94], tendo sido gentilmente cedido pelos próprios autores $\mathrm{K}$. Lin, $\mathrm{H}$. V. Jagadish e C. Faloutsos.

Algumas adaptações foram feitas da mesma forma que descrito na seção 4.3, envolvendo: tamanho do nó, dimensão em uso, etc. Para tornar a simulação com este método compatível com aquela elaborada com a $R$-Tree, outra mudança foi feita passando a se considerar os acessos ao nó raiz nas contagens. A árvore gerada foi, também, mantida residente em memória principal.

Como foi dito na seção 3.4.3.2, o tamanho de uma entrada varia de acordo com a dimensionalidade do vetor telescópico e, conseqüentemente, a quantidade total de entradas que um nó pode ter também varia. Esta variação ocorre, inclusive, em níveis diferentes de um mesmo índice. A ocupação mínima é definida, não em função do número de entradas, mas sim, em função da proporção de bytes em uso do nó. Para os testes apresentados a seguir, foi utilizada uma taxa de ocupação mínima de $40 \%$ do tamanho total (em bytes). A função telescópica utilizada para contrair e expandir os vetores é a que trunca os elementos dos vetores (ver seção 3.4.3.1)

A Tabela 6 apresenta a faixa de valores correspondente ao número máximo de entradas por nó em função das dimensões de teste. Esta faixa indica o menor e o maior valores encontrados entre os diferentes níveis dos índices e é determinada pelo número de dimensões em uso pelo vetor telescópico. O menor número indica o máximo de entradas nas folhas e o maior indica o máximo am níveis intermediários. A raiz apresenta um valor intermediário entre estes limites. Foram feitas 16 simulações, das quais 15 foram encerradas com sucesso.

Tabela 6: Faixa de valores correspondente ao número máximo de entradas por nó em função das dimensões de teste da TV-Tree. Esta faixa corresponde ao Intervalo encontrado nos diferentes níveis dos respectivos índices.

\begin{tabular}{|c|c|c|c|c|c|c|c|c|}
\hline 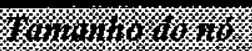 & & & 16. & 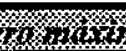 & 要(5) & 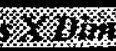 & 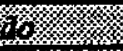 & \\
\hline (K) & 䇾 & $4 \%$ & 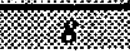 & m & 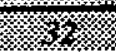 & 新 & $x$ & 等 \\
\hline $2 k B$ & $60-136$ & $60-120$ & $60-120$ & $34-120$ & $17-120$ & $\begin{array}{l}17-120 \\
17-240\end{array}$ & $\begin{array}{l}17-120 \\
17-240\end{array}$ & $17-240$ \\
\hline
\end{tabular}


O tamanho das páginas de acesso a disco foi definido em 4.098 bytes. Porém, como a TV-Tree trabalha com subconjuntos das coordenadas dos pontos, o número máximo de entradas por nó foi razoavelmente elevado, mantendo-se quase o mesmo para as diferentes dimensões de teste (Tabela 6). Para avaliar este método em situações mais críticas, um segundo conjunto de testes foi feito utilizando nós com 2.048 bytes. Como conseqüência, a dimensão 255 apresentou problemas de espaço levando o programa a "abortar" (este fato será comentado novamente na discussão dos resultados).

A seguir, serão apresentados os resultados das simulações. Os diferentes conjuntos de testes serão agrupados e tratados em função do tamanho de seus nós, portanto: grupo TV2kB (árvores com nós de 2.048 bytes) e grupo TV4kB (árvores com nós de 4.096 bytes).

\subsubsection{Resultados}

r.t. $\quad x+2$

a aoela 7 apresenta a

configuração das árvores após a fase de inserção. A altura da árvore se manteve praticamente constante com valor 3 (ver rráfico da Figura 24). A

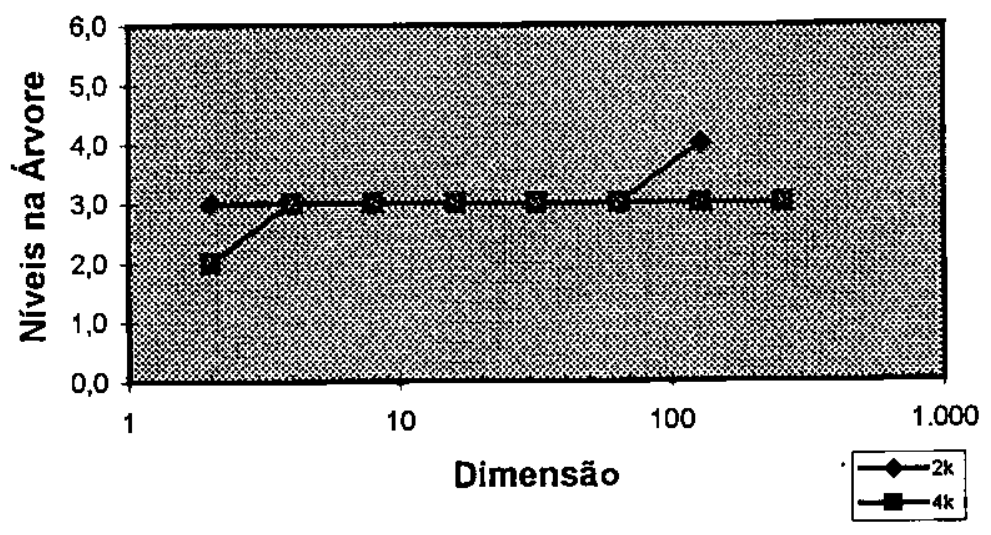

Figura 24: TV-Tree - Altura da árvore após 10.000 inserçōes.

úmensão 2 do grupo TV4kB teve valor 2 , visto o baixo número de dimensões. A dimensão 128

Tabela 7: TV-Tree - Configuração após a inserção de 10.000 pontos.

\begin{tabular}{|c|c|c|c|c|c|c|c|c|}
\hline 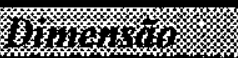 & 约 & 4 & 6 & 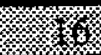 & 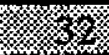 & 6 & 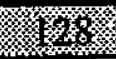 & 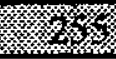 \\
\hline \multicolumn{9}{|c|}{ I. Altura da Arvore } \\
\hline i. $T V 2 k B$ & 3 & 3 & 3 & 3 & 3 & 3 & 4 & \\
\hline ii. $T V 4 k B$ & 2 & 3 & 3 & 3 & 3 & 3 & 3 & 3 \\
\hline \multicolumn{9}{|c|}{ II. Quantidade Total de Nos } \\
\hline i TV2kB & 207 & 259 & $37 I$ & $61 \mathrm{I}$ & I. 129 & 2.080 & 4.396 & \\
\hline ii. $T V 4 k B$ & 99 & 133 & 186 & 306 & 528 & 1.032 & 2.083 & 4.364 \\
\hline \multicolumn{9}{|c|}{ III. Tamanho do Indice (kB) } \\
\hline i. $T V 2 k B$ & 414 & 518 & 742 & 1.222 & 2.258 & 4.160 & 8.792 & \\
\hline ii. $T V 4 k B$ & 396 & 532 & 744 & 1.224 & 2.112 & 4.128 & 8.332 & 17.456 \\
\hline \multicolumn{9}{|c|}{ IV.Taxa de Ocupação } \\
\hline i. $T V 2 k B$ & $68 \%$ & $70 \%$ & $70 \%$ & $69 \%$ & $66 \%$ & $67 \%$ & $61 \%$ & \\
\hline ii. $T V 4 \mathrm{kB}$ & $70 \%$ & $67 \%$ & $69 \%$ & $68 \%$ & $69 \%$ & $66 \%$ & $63 \%$ & $59 \%$ \\
\hline
\end{tabular}


do grupo TV2kB teve valor 4 como conseqüência do aumento do número de coordenadas em um nó de tamanho reduzido. Como esperado, a influência do aumento da dimensão começa a ficar evidente mais "cedo", para nós de tamanho menor.

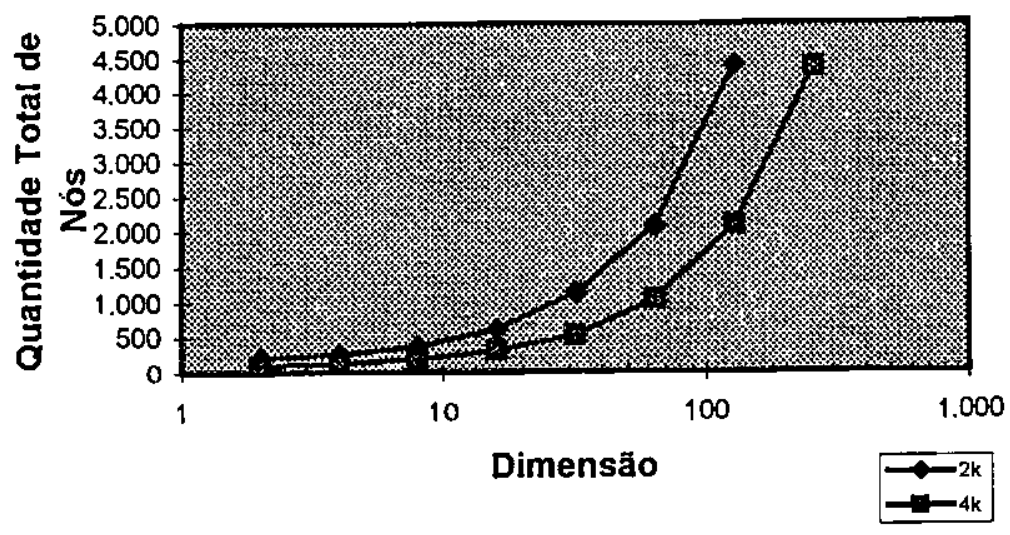

Figura 25: TV-Tree - Quantidade total de nós após 10.000 inserçöes.

A quantidade total de nós (item

II) cresce linearmente em função da dimensão, praticamente dobrando de valor na medida em que a dimensão aumenta. Observa-se que os valores dos índices do grupo TV2kB são quase o dobro daqueles do TV4kB (ver Figura 25). Acreditava-se que a diminuição do tamanho do nó causaria um aumento na quantidade de coordenadas nos vetores telescópicos dos níveis internos agravando o desempenho de armazenamento de forma acentuada. Porém, os resultados mostram que as conseqüências não são tão graves. O item III (tamanho do índice) reforça ainda mais esta observação, visto que, para os dois tipos de nós, o tamanho total do índice é o mesmo.

A taxa de ocupação se manteve entre $66 \%$ e $70 \%$ nos dois grupos para as dimensões abaixo de 64, inclusive, estando em uma faixa bem aceitável. Para as demais dimensões os valores estiveram entre $59 \%$ e $63 \%$. Apesar de mais baixos que na faixa anterior não têm um significado muito . im, pois foi definida uma taxa mínima de ocupação de $40 \%$. No entanto, curiosamente, ao zráfico deste item (ver Figura 26) observa-se uma tendência de queda progressiva em função do aumento da dimensão para os dois grupos.

A Tabela 8 apresenta os resultados das últimas 1.000 inserções feitas com a TV-Tree.

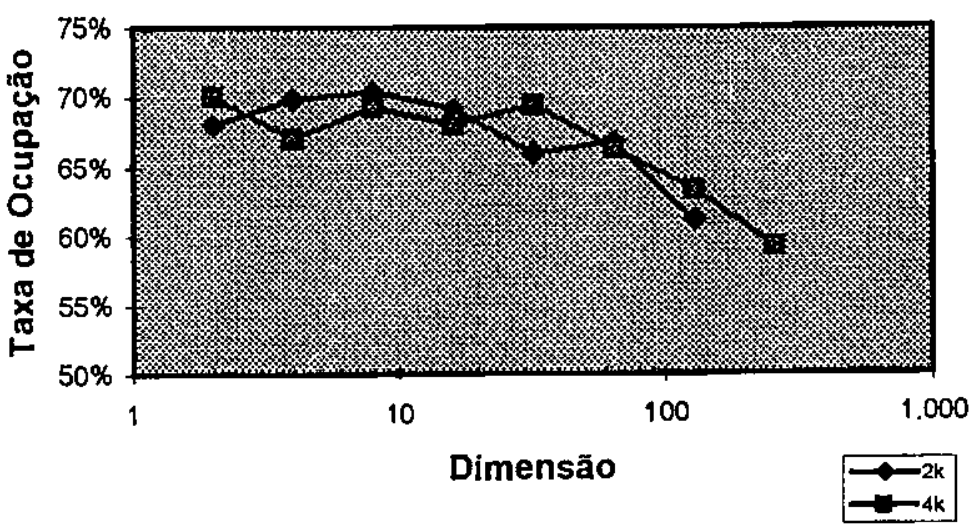

Figura 26: TV-Tree - Taxa de ocupaçăo após 10.000 inserções. 
Tabela 8: TV-Tree - Desempenho da inserçāo. Foram considerados apenas os últimos 1.000 pontos.

\begin{tabular}{|c|c|c|c|c|c|c|c|c|}
\hline 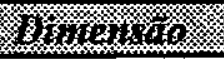 & 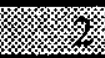 & 諭 & 8 & 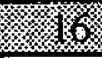 & 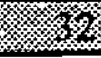 & 8 & rys & 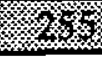 \\
\hline \multicolumn{9}{|c|}{ I. Nós Particionados/Inserção } \\
\hline i. $T V 2 k B$ & 0,02 & 0,03 & 0,04 & 0,07 & 0,11 & 0,20 & 0,43 & \\
\hline ii. $T V 4 k B$ & 0,01 & 0,02 & 0,02 & 0,03 & 0,05 & 0,11 & 0,21 & 0,44 \\
\hline \multicolumn{9}{|c|}{ II. Nós Acessados/Inserção } \\
\hline i. $T V 2 k B$ & 5,70 & 6,60 & 6,47 & 5,70 & 5,63 & 5,87 & 7,60 & \\
\hline ii. $T V 4 k B$ & 4,04 & 4,82 & 6,17 & 6,06 & 5,73 & 6,00 & 6,01 & 5,77 \\
\hline \multicolumn{9}{|c|}{ III.Tempo Total de Inserçäo (s) } \\
\hline i. $T V 2 k B$ & 23,37 & 23,37 & 25,53 & 25,35 & 29,05 & 38,95 & 39,97 & \\
\hline ii. $T V A k B$ & 41,65 & 52,38 & 40,92 & 38,27 & 38,78 & 46,42 & 49,97 & 59,52 \\
\hline
\end{tabular}

Assim como na $R$-Tree, o número de nós particionados por ponto inserido apresenta um comportamento semelhante ao dos itens II e III da Tabela 7, devido à já comentada relação existente entre estes itens. Observa-se que a quantidade de inserções necessárias para provocar um particionamento decresce linearmente em função da dimensão e, somente ao atingir a dimensão 128 do grupo TV $2 \mathrm{kB}$ e a 255 do grupo TV4kB, os particionamentos passam a ocorrer a cada duas inserções.

O número de nós acessados por inserção (item II da Tabela 8) está em torno de duas vezes a altura da árvore (item I da Tabela 7). Apesar de não ser uma média alta, era esperado que este valor se mantivesse próximo à altura, e não ao dobro. Observa-se que o aumento da dimensão não gera

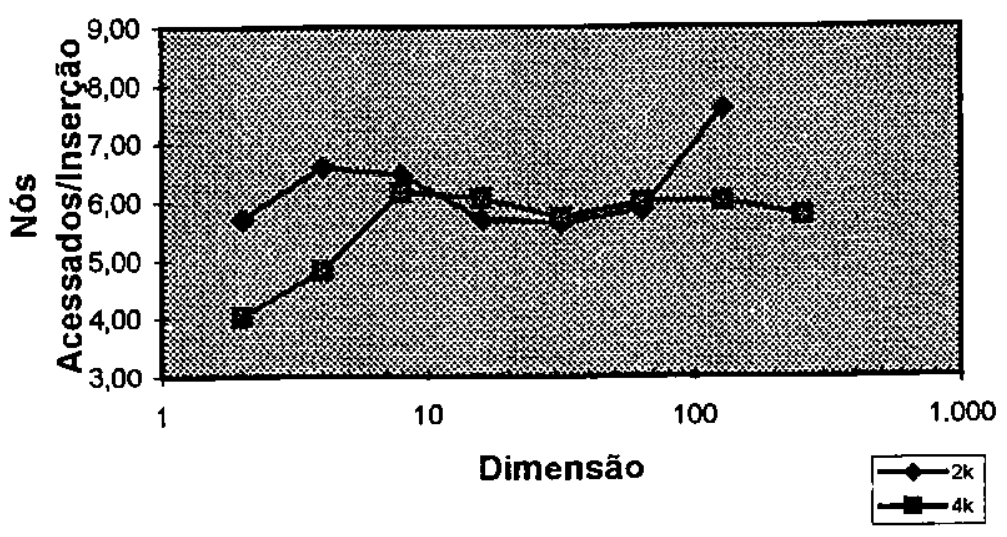

Figura 27: TV-Tree - Nós acessados por inserção para os últimos 1.000 pontos. grandes perdas de desempenho neste quesito (ver gráfico da Figura 27).

O tempo de inserção dos últimos 1.000 pontos (item III da Tabela 4) apresenta um crescimento suave em função da dimensão, indicando uma pequena dependência (Figura 28). $O$ resultado encontrado para a dimensão 4 do grupo TV4kB está bem fora do esperado, pois não acompanha a tendência dos outros. 
Este teste foi refeito algumas vezes e resultados semelhantes foram obtidos, dificultando a identificação de algum fator que pudesse estar provocando tal variação. Exceto nesta dimensão, os dois grupos apresentam comportamento razoavelmente semelhantes. O grupo TV2kB

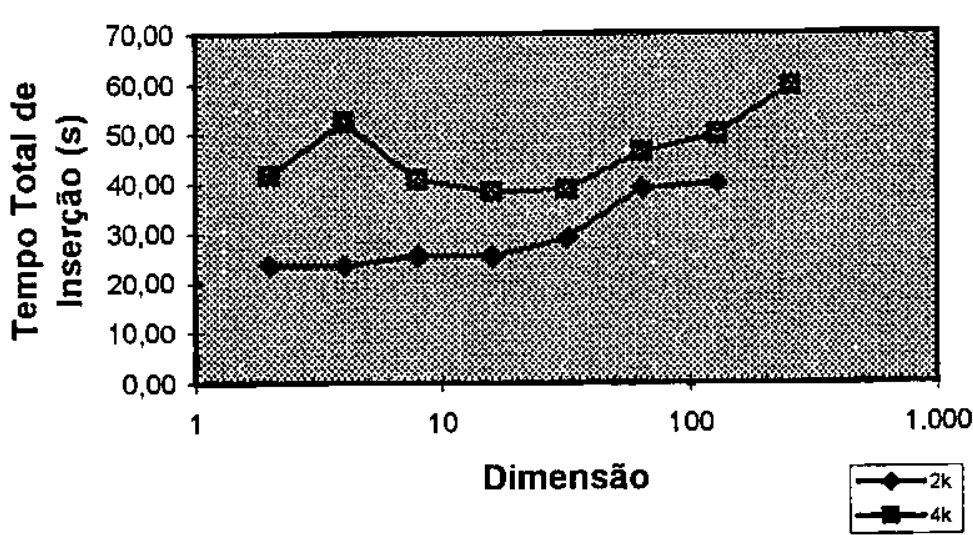

Figura 28: TV-Tree - Tempo total de inserçäo dos últimos 1.000 pontos. indica os melhores tempos de inserção, sendo que isto ocorre por necessitar uma menor quantidade de cálculos, visto que possui menos entradas por nó.

\section{Consulta}

A Tabela 9 apresenta o comportamento da TV-Tree durante 1.000 consultas do tipo coincidência exata. Foram obtidos os mesmos resultados com os dois grupos, a saber: 1.025 pontos para a dimensão 2 e 1.018 pontos para as demais dimensões. Estes resultados são os mesmos encontrados com o método R-Tree nos algoritmos Linear e Exaustivo (seção 4.3.1), valendo os mesmos comentários sobre as colisões. $\mathrm{O}$ item II (número de nós acessados por consulta), como era esperado, está bem próximo da altura da árvore, sendo um pouco maior no grupo TV2kB. Portanto, não há uma grande dependência em função da dimensão (ver Figura 29).

Tabela 9: TV-Tree - Desempenho obtido com 1.000 consultas por coincidência exata.

\begin{tabular}{|c|c|c|c|c|c|c|c|c|}
\hline 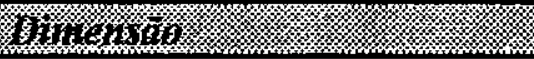 & 榤 & 搐 & 然 & 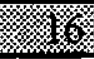 & 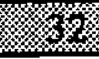 & 縈新 & 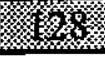 & 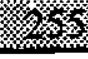 \\
\hline \multicolumn{9}{|l|}{ I. Pontos Encontrados } \\
\hline i. $T V 2 k B$ & 1.025 & 1.018 & 1.018 & 1.018 & 1.018 & 1.018 & 1.018 & \\
\hline ii. $T V 4 k B$ & 1.025 & 1.018 & 1.018 & 1.018 & 1.018 & 1.018 & 1.018 & 1.018 \\
\hline \multicolumn{9}{|l|}{ II. Nos Acessados/Consulta } \\
\hline i. $T V 2 k B$ & 3,48 & 3,60 & 3,76 & 3,94 & 4,03 & 4,07 & 4,55 & \\
\hline ii. $T V 4 k B$ & 2,27 & 3,38 & 3,39 & 3,31 & 3,50 & 3,51 & 3,48 & 3,42 \\
\hline \multicolumn{9}{|l|}{ III.Tempo Total de Consulta (s) } \\
\hline i $T V 2 k B$ & 1,85 & 1,88 & 1,97 & 2,00 & 2,30 & 2,93 & 2,67 & \\
\hline ii. $T V 4 k B$ & 3.45 & 2,60 & 2,95 & 2,45 & 2,73 & 2,80 & 3,27 & 3,95 \\
\hline \multicolumn{9}{|l|}{$\begin{array}{l}\text { IV.Tempo Total/Nós Acessados } \\
\text { Consulta }\end{array}$} \\
\hline i. $T V 2 k B$ & 0,532 & 0,523 & 0,523 & 0,508 & 0,570 & 0,721 & 0,586 & \\
\hline ii. $T V 4 k B$ & 1,521 & 0,770 & 0,871 & 0,740 & 0,781 & 0,797 & 0,940 & 1,154 \\
\hline
\end{tabular}


O item III da Tabela 9 mostra o tempo total das 1.000 consultas. Neste item, o grupo TV2kB possui um crescimento suave em função da dimensão (Figura 30). Já o tempo do grupo TV4kB praticamente decresce até a dimensão 16 , passando a ascender daí em diante. Não é possivel

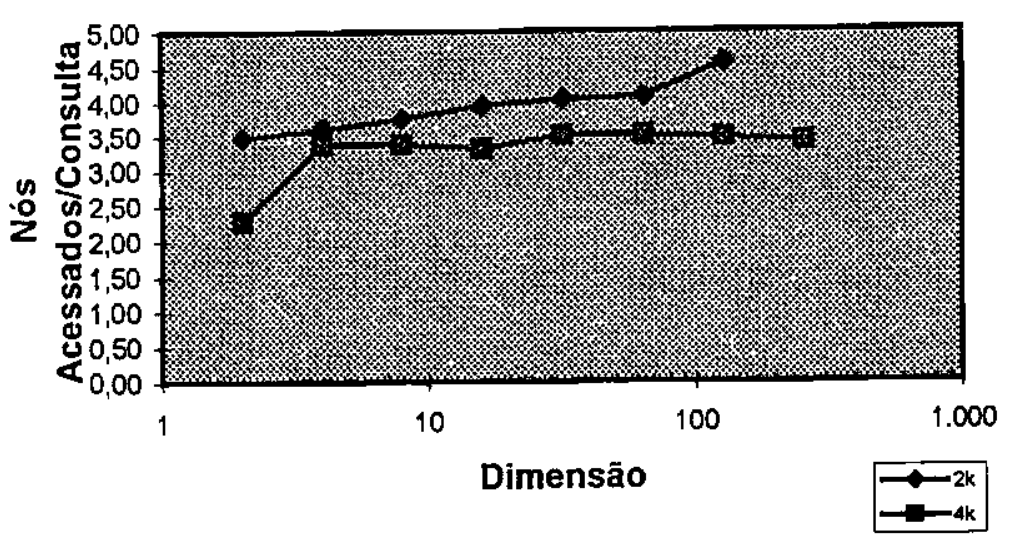

Figura 29: TV-Tree - Número de nós acessados por ponto consultado vs. dimensão.

determinar uma correlação entre o número de nós acessados (item II) e o tempo total de inserção (item III), pois os mesmos apresentam comportamentos bem distintos: a dimensão 2 do grupo TV4kB apresenta a menor quantidade de nós acessados por consulta $(2,27)$, porém o segundo maior tempo $(3,45)$; o grupo TV2kB apresenta um grande aumento na quantidade de nós acessado entre as dimensões 64 e 128 (de 4,07 para 4,55), ao passo que o tempo de consulta decresce neste mesmo intervalo (de 2,93 para 2,67).

Observa-se que a quantidade de nós acessados por consulta (Figura 29) para o grupo TV2kB é maior que a do grupo TV4kB em todas as dimensōes, ao passo que o tempo total de consulta (Figura 30) é menor (em quase todas as dimensões). Novamente, este resultado não.pode ser considerado isoladamente, pois o tempo de acesso a disco não foi considerado. Porém, seu resultado é interessante por indicar o comportamento que a TV-Tree apresenta com relação ao tempo de processamento gasto em um único nó. Ou seja, como o grupo TV4kB suporta uma quantidade maior de entradas por nó (ver Tabela 6), torna-se necessário um número maior de cálculos, levando a um aumento no tempo total de consulta.

O item IV da Tabela 9 apresenta - tempo médio gasto em um

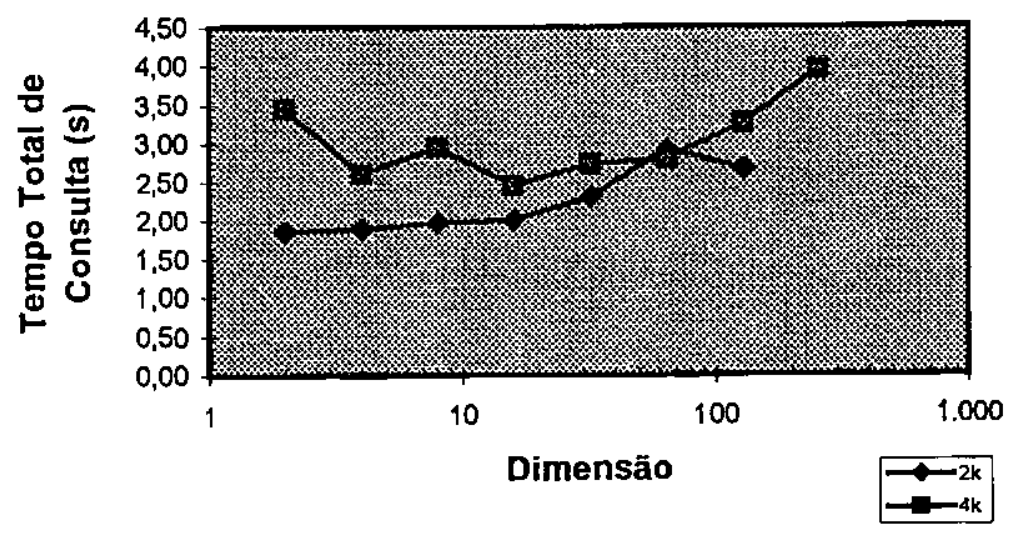
único nó durante a fase de

Figura 30: TV-Tree - Tempo total de 1.000 consultas vs. dimensão. 
consulta. O gráfico da Figura 31 mostra mais claramente as diferenças entre os dois grupos. Observa-se, ainda, que o grupo TV $2 \mathrm{kB}$ se coloca de forma mais estável diante da variação da dimensão.

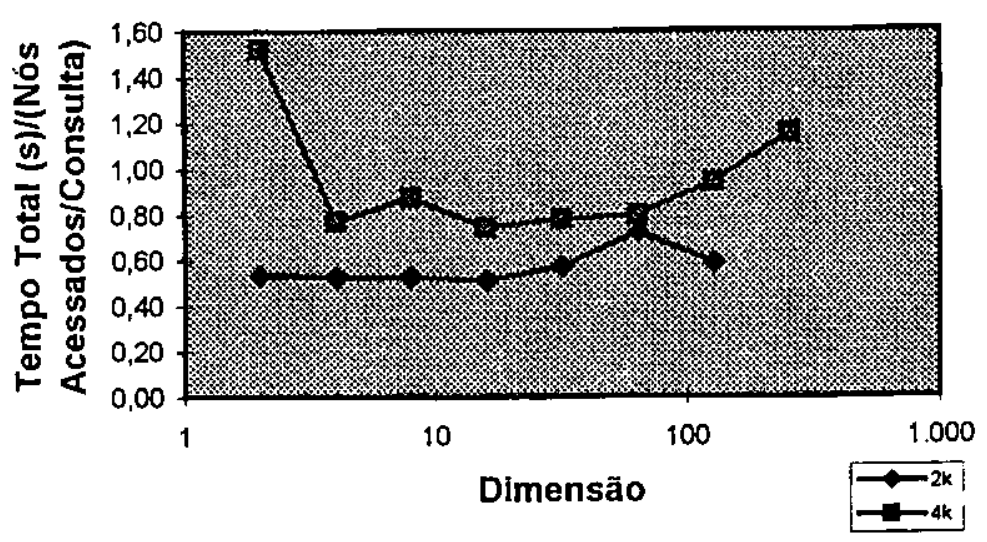

\subsubsection{Discussão}

Figura 31: TV-Tree - Tempo médio de processamento de um nó em função da dimensão, durante a fase de consulta.

A quantidade de entradas por nó

da $T V$-Tree é definida a partir do número de dimensões em uso pelos vetores telescópicos, que, por sua vez, depende do conjunto de dados que estão sendo armazenados (tamanho, distribuição, número de coordenadas, etc). Portanto, não existe uma dependência direta entre esta quantidade e a dimensão dos objetos. Como conseqüência, a altura das árvores obtidas nos testes se manteve com valor quase constante. Apesar disto, foi observado que existe uma dimensão limite, considerando o nó com tamanho fixo.

Foi dito que este método usa o conceito de taxa mínima de ocupação (porção do nó - número de bytes - em uso) e não com quantidade mínima de entradas. No entanto, existe um critério próprio à implementação, que força um número mínimo de entradas mesmo que a taxa mínima tenha sido atendida. Isto é feito para evitar que a estrutura seja degenerada para uma lista encadeada. Procurando analisar o desempenho em uma situação mais próxima do limite, foram realizados testes com nós de 2.048 bytes (grupo TV2kB). Como conseqüência, o teste com a dimensão 255 apresentou erro por não ser possível armazenar o número mínimo de entradas, levando o programa a "abortar". Valem aqui, portanto, os mesmo comentários feitos na seção 4.3 .2 sobre os inconvenientes de se aumentar o tamanho do nó, visto as imposições relativas ao gerenciador de objetos, bem como os comentários sobre "quebrar" o objeto, por aumentar o número de acessos a disco.

Uma observação deve ser feita: é claro que não existe uma forma de gerar uma estrutura com tamanho fixo de nó que se adapte a qualquer dimensão sem a necessidade de quebrar.o objeto a 
ser indexado. Para entender esta afirmação, deve ser levado em consideração que é possível tratar o problema do limite de espaço em nós intermediários (a TV-Tree tenta resolver isso). Porém, é impossivel tratar este problema nas folhas, pois este nível deve, necessariamente, apresentar todos os atributos espaciais do objeto (mesmo que aproximados por um $M B R$ ), no caso as coordenadas do ponto.

Um método que se coloca armazenando esses atributos fora do indice está, na verdade, apresentando uma solução de implementação para facilitar a construção do mesmo, tornando o tamanho do nó homogêneo. Porém, não apresenta uma melhoria funcional significativa, pois, de qualquer forma, serão necessários vários acessos a disco para se recuperar todos os atributos espaciais do objeto.

Esta questão pode ser vista da seguinte forma: não é correto comparar um método que armazena os atributos espaciais do objeto no próprio indice com outro que não o faz, sem considerar os acessos para recuperar estes atributos. Pois, armazenar os atributos espaciais fora do índice é uma solução de implementação e não funcional. E, de qualquer forma, os atributos terão que ser recuperados para serem comparados, quer seja na fase de inclusão, consulta ou remoção.

Ou seja, para avaliar o desempenho de um método de indexação espacial, deve ser levado em consideração o acesso completo aos atributos espaciais dos objetos indexados. Portanto, como "quebrar" os objetos é inevitável para dimensões altas (e limitações de tamanho de nó), os métodos devem ser avaliados levando em consideração, também, onde é necessário este procedimento. Ou seja, se em todos os niveis, ou se em apenas alguns (de preferência apenas nas folhas).

Retomando a discussão sobre a TV-Tree, observa-se que o estouro apresentado com a dimensão 255 não foi provocado em um nó folha, mas sim em um nó interno. Se o problema tivesse ocorrido em uma folha, uma solução de implementação bastaria. Entretanto, o que se tem é um problema estrutural, cuja solução pode levar a um aumento no número de acessos a disco mesmo em níveis intermediários. Em todo caso, o resultado obtido com este método é muito satisfatório, pois suportou uma faixa de valores relativamente alta para dimensão, considerando que as árvores geradas nos testes tinham poucos níveis. 
Os demais resultados da etapa de inserção apresentam aspectos que necessitam de parâmetros (de comparação) para serem mensurados e serão detalhados na próxima seção em conjunto com os do MIE $R$-Tree. Com relação à etapa de consulta, deve-se destacar que o número de nós acessados por ponto consultado esteve próximo à altura da árvore em todas as dimensões, correspondendo às expectativas.

Finalizando, sob aspectos gerais, o tamanho do nó não significou grandes alterações nos indicadores. Houve um aumento no número total de nós para as árvores do grupo com nó de menor tamanho (TV2kB). Mas, como a altura não foi muito afetada, não surgiram maiores conseqüências. Na próxima seção, as duas estruturas testadas serão comparadas.

\subsection{R-Tree X TV-Tree}

Apesar dos resultados da $R$-Tree não terem sido muito satisfatórios, serão muito úteis como referencia para avaliar o desempenho da $T V$-Tree. Como será visto adiante, alguns dos resultados não revelam muita importância quando vistos isoladamente. Nesta seção, por simplicidade e por apresentarem os resultados mais completos, considere-se que os comentários feitos correspondem aos testes com o algoritmo Linear, para a $R$-Tree, e aos testes do grupo TV4kB, para a TV-Tree, dispensando qualquer indicação sobre este assunto, novamente.

Considerando, inicialmente, a configuração das árvores após a etapa de inserção, observa-se que além de a $T V$-Tree gerar árvores com quantidades menores de níveis, sua eficiência de armazenamento é bem superior à da $R$-Tree, principalmente para as dimensões acima de 32 . Nestes casos, o primeiro método apresenta, em média, um terço do tamanho do segundo. Nas demais dimensões, os valores são bem mais próximos, sendo quase iguais em alguns casos. Vale observar que este ganho de eficiência ocorre apesar da $T V$-Tree apresentar um decréscimo na taxa de ocupação ao longo do aumento da dimensão.

Para dimensões 128 e 255 , a $R$-Tree sofre praticamente um particionamento para cada inserção. Ao passo que a $T V$-Tree necessita de algo em torno de três a cinco inserções. Pelo gráfico da Figura 32 é evidente que a $T V$-Tree apresenta resultados muito melhores para este indicador. 
Na etapa de inserção é necessário acessar um número de nós próximo a duas vezes a altura da árvore para a $T V$-Tree, ao passo que estes valores são praticamente equivalentes para a R-Tree. Apesar disto, como a aitura das árvores geradas pelo primeiro método é praticamente

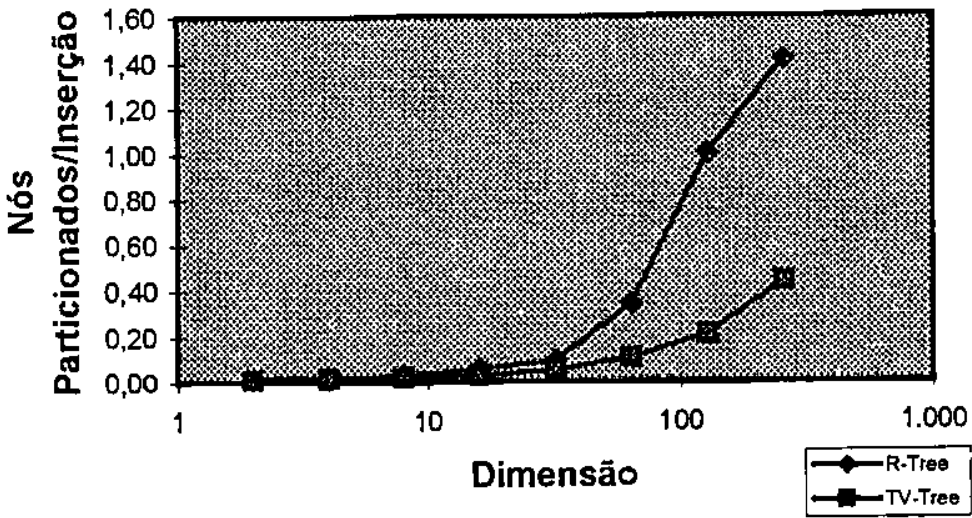

Figura 32: R-Tree X TV-Tree - Nós particionados por inserção, considerando os últimos 1.000 pontos. constante (em torno de 3, ver

Tabela 8) e com relativamente poucos níveis, este resultado não vem a ter grande significado.

Os dois métodos encontraram o mesmo número de pontos na etapa de consulta por coincidência exata. Supõe-se, portanto, que não houve falsos descartes em nenhum dos casos. Quanto ao número de nós acessados, a $R$-Tree apresenta resultados realmente inaceitáveis, principalmente se comparados aos da $T V$-Tree, pois em média encerra a consulta em um número de acessos que é 36 vezes o valor do outro método. O resultado em questão tem importância crucial na comparação dos métodos, diante do significado das operações de consulta. Porém, nenhum dos dois apresentou um comportamento que indicasse perda de desempenho levạndo em consideração, apenas, a variação da dimensão.

Finalizando, em relação aos aspectos gerais, a TV-Tree se encontra melhor configurada para trabalhar em dimensões elevadas e variadas, sendo, portanto, mais indicada para tratar o problema proposto neste trabalho.

\subsection{Conclusão}

Esta seção dedicou-se a simulações com os MIEs $R$-Tree e TV-Tree. Inicialmente discutiu-se como os dados foram obtidos, as etapas que fizeram parte das simulações e o sistema computacional utilizado (sistema operacional, processador, memória disponível, etc.). Os métodos foram analisados separadamente e em seguida comparados, um com o outro. A 
conclusão final foi de que a TV-Tree se comportou de maneira mais satisfatória, sendo o método mais indicado para aplicação ao problema proposto. 
5. CONCLUSÕES 


\section{Conclusões}

\subsection{Considerações Iniciais}

Imagens, em geral, têm sido armazenadas e recuperadas em Sistema Gerenciadores de Banco de Dados com o auxilio de métodos de indexação aplicados a vetores de características, os quais são obtidos através de algum procedimento computacional aplicado às imagens que representam. Desta forma, os vetores são tratados como coordenadas de pontos situados no espaço, cuja dimensão é determinada pela quantidade de elementos que possuem. Esses métodos são conhecidos como Métodos de Indexação Espacial.

Para apoiar o desenvolvimento de aplicações médicas que utilizam imagens gráficas, o Modelo de Dados SIRIUS define um tipo abstrato de dados Imagem que pode ser associado a atributos de objetos. Para tanto, três dos principais conceitos são apresentados: Constante-Imagem, Sumarizadores e Parâmetros-da-Imagem.

Uma Constante-Imagem é aquela que, definida por um especialista no domínio de certa aplicação (o radiologista em aplicações médicas, por exemplo), possui informações relevantes para a descrição de determinada patologia, de região do corpo humano, ou de outro objeto de estudo. As consultas são feitas utilizando as constantes-imagem como ponto de referência. Os Sumarizadores são algoritmos de extração de características aplicados às imagens para obter os vetores a serem indexados. Tais algoritmos são especificados pelo especialista em processamento de imagens que, em conjunto com o gerente de aplicação, indicará quais são os parâmetros da imagem a serem indexados pelo sistema. Dessa forma, os Parâmetros-da-Imagem correspondem ao resultado retornado pelos sumarizadores, ou seja, os vetores de características extraídos das imagens.

O relacionamento entre estes conceitos é especificado por um meta-esquema (ver Figura 1 na seção 2.3) onde os pares constituídos por <sumarizador, constante-imagem> definem domínios, ou conjuntos, de vetores que são armazenados em índices espaciais. 
O presente trabalho mostra que um método para indexar estes vetores deve ser dinâmico, suportar armazenamento secundário e ser capaz de trabalhar com domínios de dimensões diferentes e elevadas. Visto que este método será implementado no gerenciador de objetos SIRIUS/GO, o mesmo deve ser implementado de forma genérica com relação à quantidade de dados a serem indexados e o tamanho máximo dos vetores.

Diversos métodos foram estudados procurando identificar aquele que melhor se aplica ao problema proposto. Testes feitos com dois destes métodos, $R$-Tree e $T V$-Tree, usando conjuntos de vetores com dimensões entre 2 e 255 são descritos e comentados, visando sua aplicação no gerenciador de objetos SIRIUS/GO.

A principal conclusão obtida a partir destes testes corresponde à identificação da $T V$-Tree como sendo o método que deverá ser implementado no SIRIUS/GO, pois apresenta resultados muito melhores que a $R$-Tree. Isto ocorre principalmente com relação ao número de acessos a disco em operações de consulta e na capacidade de trabalhar com dimensões elevadas sem implicar em grandes perdas de desempenho, quando comparada com a $R$-Tree.

Concluiu-se, também, que os maiores problemas encontrado pela $R$-Tree foram: o número máximo de entradas por nó e a quantidade de regiões sobrepostas. Visto que o SIRIUS/GO trabalha com tamanho fixo de registros, uma quantidade maior de coordenadas leva a um aumento no número de variáveis necessárias para armazenar um ponto, impedindo que um nó tenha o mesmo número de entradas para dimensões diferentes. Conseqüentemente, o aumento da dimensão resulta em redução do número máximo de entradas, deteriorando o comportamento do método rapidamente. Ou seja, há uma grande elevação na altura da árvore, a quantidade de particionamentos aumenta, o índice cresce em tamanho e o desempenho em consultas diminui. Como a $T V$-Tree trabalha, em niveis intermediários, com regiões definidas por subconjuntos de coordenadas da dimensão total, esta deterioração é mais amena. Neste caso, ocorre apenas uma diminuição na taxa de ocupação, principalmente em nós internos.

Observa-se que, quanto maior a quantidade de regiões sobrepostas, maior será o número de nós acessados nas operações de consulta. Neste sentido, a $R$-Tree não é indicada para conjuntos compostos apenas por dados pontuais, visto o grande número de nós acessados em consultas por 
coincidência exata. Em alguns testes, chegou a ser acessado um número de nós correspondente a 35 vezes, ou mais, a altura da árvore. Vale ressaltar que este comportamento independe da dimensão, ao contrário do que se esperava. $\mathrm{Na}$ dimensão 4 a árvore apresentou 3 níveis para 10.000 pontos indexados e uma média de 130 nós acessados em 1.000 consultas por coincidência exata. Ao passo que na dimensão 255, com 17 niveis, 91 nós foram acessados para o mesmo numero de pontos inseridos e consultados.

\subsection{Principais Contribuições}

Como contribuições resultantes do presente trabalho, cabe mencionar:

- a identificação e descrição dos requisitos, impostos pelo tipo de dados Imagem do Modelo SIRIUS, que devem ser atendidos pelo método de indexação a ser implementado no gerenciador SIRIUS/GO. Ao início deste trabalho existia apenas a definição do meta-esquema com a indicação da necessidade de se utilizarem métodos de indexação espaciais, porém não havia um estudo aprofundado de seus requisitos: o uso de $S A M$ ou $P A M$, a necessidade de trabalhar com dimensões variadas (problema da dimensionalidade), a dimensão máxima que um sumarizador pode assumir, dentre outros;

- a identificação dos principais fatores que degradam um método de indexação, considerando a variação da dimensão: quantidade máxima de entradas por nó e sobreposição de regiões espaciais. Com isto, será possivel gerar modificações nos métodos existentes no sentido de minimizar sua degradação;

- a obtenção de um conjunto de resultados de simulações feitas com dois dos mais importantes métodos de indexação encontrados na literatura, visando dimensões variadas e elevadas. Estes resultados podem ser bastante úteis como parâmetro de comparação de desempenho com novos métodos que possam vir a ser estudados;

- a criação de uma base de 10.000 vetores com 256 elementos que pode ser usada como conjunto de dados de controle no desenvolvimento e aprimoramento de novos métodos. Apesar da dependência entre os elementos que compõem os vetores desta 
base, vale ressaltar que os testes encontrados na literatura estão, geralmente, limitados a vetores de até 64 elementos;

- por fim, por ser este o primeiro trabalho dentro do Grupo de Base de Dados e Imagens do ICMC-USP em torno de dados espaciais, envolvendo conceitos, definiçōes, métodos de indexação, etc., passa a ter real valor como material de referência para estudos futuros dentro do grupo.

\subsection{Propostas de Trabalhos Futuros}

Durante a elaboração deste trabalho algumas propostas para linhas de estudo surgiram, dentre as quais destacam-se:

- por definição, o método $T V$-Tree trabalha com regiões do espaço não disjuntas. Portanto, existe o risco de, para um determinado conjunto de vetores, o número de regiões sobrepostas vir a ser alto a ponto de tornar as operações de consulta muito ineficientes. Por outro lado, o método $K-D-B-$ Tree, que trabalha com regiōes disjuntas, apresenta problemas semelhantes aos da $R$-Tree em relação à quantidade máxima de entradas por nó. Em [Santos Filho et al., 99b] é feita uma análise do método $K-D-B$ Tree visando sua aplicação ao SIRIUS/GO. Uma fusão entre estes dois métodos pode ser estudada, procurando-se gerar uma estrutura que trabalhe com subconjuntos de coordenadas das regiões indexadas em níveis internos, aumentando a quantidade de entradas por nó; e com regiões disjuntas, diminuindo o risco de aumentar o número de acessos a disco em operações de consulta;

- observou-se, durante os testes, que a TV-Tree apresentava uma dimensão limite a partir da qual se tornava instável. Isto ocorria porque o vetor telescópico aumentava a quantidade de coordenadas na medida em que era necessário discriminar melhor os pontos inseridos. Com isto, em uma escala bem menor do que na $R$-Tree, a quantidade máxima de entradas por nó diminuía. Propõe-se estudar funções telescópicas que trabalhem com subconjuntos de tamanho fixo, evitando esta instabilidade. $O$ preço desta função pode ser um aumento na altura da árvore. Porém, acredita-se que este aumento não será muito maior que dois níveis (considerando o caso original); 
- como a função telescópica usada nos testes é definida de forma a truncar as coordenadas dos pontos, usando apenas as primeiras (a depender do poder discriminatório necessário), deve-se estudar critérios de ordenação para serem aplicados a estas coordenadas visando melhorar o desempenho da TV-Tree;

- os resultados dos testes com a $R$-Tree mostraram que, para o conjunto de dados usado, houve uma mudança no comportamento da estrutura em determinadas dimensões. Observou-se que a distribuição dos pontos poderia estar afetando este comportamento. Procurando identificar como esta distribuição poderia estar agindo foi calculada a variância individual de cada coordenada, levando à identificação de uma grandẹ quantidade de coordenadas com baixa variância nestas dimensões. Deve ser feito um estudo mais detalhado da influência deste indicador no comportamento da $R$-Tree, podendo com isto obter-se uma forma de estimar o desempenho da estrutura;

- é necessário refazer os testes descritos neste trabalho simulando um caso real. Ou seja, gerar uma base de vetores a partir de características extraidas de imagens médicas. Esta base deve ter um número razoável de vetores (10.000, por exemplo), os quais devem ser compostos por, no mínimo, 200 elementos, tornando possivel a avaliação dos métodos em dimensões elevadas;

- por fim, enquanto que os métodos aqui estudados trabalham apenas com a posição absoluta dos objetos no espaço, novos métodos têm sido propostos onde a indexação é feita sobre a distância relativa entre eles, segundo uma métrica predefinida. Estes métodos são conhecidos por Metric Trees, ou Árvores Métricas, e como exemplo pode-se citar a $M$-Tree [Ciaccia et al., 1997]. Será interessante estudar estes métodos visando sua aplicação ao meta-esquema proposto pelo SIRIUS. 
Referências Bibliográficas 


\section{REFERÊNCIAS BIBLIOGRÁFICAS}

[Alcocer et al., 96] ALCOCER, P.R.C.; MELO, C.P.; FURUIE, S.S.; BERTOZZO JR., N.; PARZIANELLO, L.C.; REBELO, M.S. O Projeto PACS: um sistema para visualisação dinâmica e armazenamento de imagens de angiografia digital no INCOR. In: FÓRUM NACIONAL DE CIÊNCIA E TÉCNOLOGIA EM SAÚdE, 3. Anais. Campos do Jordão, 1996, v. 2. p. 695-696.

[Aref \& Samet, 97] AREF, W.G.; SAMET, H. Efficient Window Block Retrieval in QuadtreeBased Spatial Databases. GeoInformatica. v. 1, n. 1, p. 59-91, 1997.

[Beck, 97] BECK, M. F. Representação de Áudio em Banco de Dados. São Carlos, 1997. Dissertação (Mestrado) - Instituto de Ciências Matemáticas e de Computação, Universidade de São Paulo.

[Beckmann et al,, 90] BECKMANN, N.; KRIEGEL, H.-P.; SCHNEIDER, R.; SEEGER, B. $\mathrm{R}^{*}$-tree: an efficient and robust access method for points and rectangles. In: $A C M$ SIGMOD INTERNATIONAL CONFERENCE ON THE MANAGEMENT OF DATA. Proceedings. Atlantic City, 1990. p. 322-331.

[Berchtold et al., 96] BERCHTOLD, S.; KEIM, D.A.; KRIEGEL, H.-P. The X-tree: an index structure for high-dimensional data. In: INTERNATIONAL CONFERENCE ON VERY LARGE DATA BASES, 22. Proceedings. Mumbai (Bombay), 1996. p. 28-39.

[Biajiz, 96] BIAЛZ, M. Representação de Modelos de Dados Orientados a Objetos Através da Parametrização de Abstrações de Dados. São Carlos, 1996. Tese (Doutorado) - Instituto de Física de São Carlos, Universidade de São Paulo.

[Brinkhoff et al., 94] BRINKHOFF, T.; KRIEGEL, H.-P.; SCHNEIDER, R.; SEEGER, B. Multi-Step Processing of Spatial Joins. In: ACM SIGMOD INTERNATIONAL CONFERENCE ON MANAGEMENT OF DATA. Proceedings. Minneapolis, 1994. p. 197-208.

[Brown, 92] BROWN, L.G. A Survey of Image Registration Techniques. ACM Computing Surveys. v. 24, n. 4, p. 325-376, 1992.

[Cardenas et al., 93] CARDENAS, A.F.; IEONG, I.T.; TAIRA, R.K.; BARKER, R.; BREANT, C.M. The Knowledge-Based Object-Oriented PICQUERY+ Language. IEEE Transactions on Knowledge and Data Engineering. v. 5, n. 4, p. 644-657, 1993.

[Chakrabarti \& Mehrotra, 99] CHAKRABARTI, K.; MEHROTRA, S. The Hybrid Tree: an index structure for high dimensional feature spaces. In: INTERNATIONAL CONFERENCE ON DATA ENGINEERING, 15. Proceedings. Sydney, 1999. p. 440447. 
[Ciaccia et al., 1997] CIACCIA, P.; PATELLA, M.; ZEZULA, P. M-Tree: an efficient access method for similarity search in metric spaces. In: INTERNATIONAL CONFERENCE ON VERY LARGE DATA BASES, 23. Proceedings. Athens, 1997. p. 426-435.

[Comer, 79] COMER, D. The ubiquitous B-tree. ACM Computing Surveys. v. 11, n. 2, p. 121-137, 1979.

[Crudele et al., 97] CRUDELE, M.; CLAPWORTHY, G.J.; KROKOS, M.A.; SALCITO, G.; VASILONOKOLIDAKIS, N. A Distributed Database on the INTERNET of 3D Models of Human Pathological Organs. In: IEEE SYMPOSIUM ON CBMS, 10. Anais. Maribor, 1997. p. 256-260.

[Dutton, 90] DUTTON, G.F. The Current State of PACS. Applied Radiology. v. 19, p. 15$19,1990$.

[Elmasri \& Navathe, 94] ELMASRI, R; NAVATHE, S.B. Fundamentals of Database Systems. 2.ed. Redwood City, Addison-Wesley, 1994.

[Faloutsos \& Kamel, 94] FALOUTSOS, C.; KAMEL, I. Beyond Uniformity and Independence: analysis of R-Trees using the concept of fractal dimension. In: ACM SIGACT-SIGMODSIGART SYMPOSIUM ON PRINCIPLES OF DATABASE SYSTEMS, 30. Proceedings. Minneapolis, 1994. p. 4-13.

[Flickner et al., 95] FLICKNER, M.; SAWHNEY, H.S.; ASHLEY, J.; HUANG, Q.; DOM, B.; GORKANI, M.; HAFNER, J.; LEE, D.; PETKOVIC, D.; STEELE, D.; YANKER, P. Query by Image and Video Content: the QBIC system. IEEE Computer. v. 28, n. 9, p. 23-32, 1995.

[Folk et al., 98] FOLK, M.J.; ZOELLICK, B.; RICCARDI, G. File Structures, An Object Oriented Approach Using C++. 3.ed. Addison-Wesley, 1998.

[Freeston, 87] FREESTON, M. The BANG File: a new kind of Grid File. In: ACM SIGMOD INTERNATIONAL CONFERENCE ON MANAGEMENT OF DATA. Proceedings. San Franciso, 1987. p. 260-269.

[Friedman et al., 77] FRIEDMAN, J.H.; BENTLEY, J.H.; FINKEL, R.A. An Algorithm for Finding Best Matches in Logarithmic Expected Time. ACM Transactions on Mathematical Software. v. 3, n. 3, p. 209-226, 1977.

[Gaede \& Günther, 98] GAEDE, V.; GÜNTHER, O. Multidimensional Access Methods. $A C M$ Computing Surveys. v. 30, n. 2, p. 170-231, 1998.

[Gennip et al., 92] VAN GENNIP, E.M.S.J.; BAKKER, A.R.; GREBERMAN, M. Do the Benefits outweigh the costs of PACS? The results of an International Workshop on Technology Assessment of PACS. Computer Methods and Programs in Biomedicine. v. 37, p. 265-271, 1992.

[Grosky \& Mehrotra, 89] GROSKY, W.I.; MEHROTRA, R. Image DataBase Management. IEEE Computer. v. 22, n. 12, p. 7-8, 1989. 
[Gudivada \& Raghavan, 95] GUDIVADA, V.N.; RAGHAVAN, V.V. Content-Based Image Retrieval Systems. IEEE Computer. v. 28, n. 9, p. 18-22, 1995.

[Günther \& Buchmann, 90] GÜNTHER, O.; BUCHMANN, A. Research Issues in Spatial Databases. ACM SIGMOD Record. v. 19, n. 4, p. 69-74, 1990.

[Guttman, 84] GUTTMAN, A. R-Trees: a dynamic index structure for spacial searching. In: ANNUAL MEETING ACM SIGMOD. Proceedings. Boston, 1984. p. 47-57.

[Jagadish, 90] JAGADISH, H.V. Linear Clustering of Objects with Multiple Attributes. In: ACM SIGMOD INTERNATIONAL CONFERENCE ON MANAGEMENT OF DATA. Proceedings. Atlantic City, 1990. p. 332-342.

[Jagadish, 91] JAGADISH, H.V. A Retrieval Technique for Similar Shapes. In: ACM SIGMOD INTERNATIONAL CONFERENCE ON THE MANAGEMENT OF DATA. Proceedings. Denver, 1991. p. 208-217.

[Knuth, 73] KNUTH, D. The Art of Computer Programming: sorting and searching. Reading, Addison-Wesley, 1973. v. 3.

[Kriegel et al., 90] KRIEGEL, H.-P.; SCHIWIETZ, M.; SCHNEIDER, R.; SEEGER, B. A Performance Comparison of Multidimensional Point and Spatial Access Methods. Berlim, Springer, 1990. (Lecture Notes in Computer Science, n. 409)

[Kriegel et al., 92] KRIEGEL, H.-P.; HORN, H.; SCHIWIETS, M. The Performance of Object Decomposition Techiniques for Spatial Query Processing. In: MONIEN, B.; OTTMMAN, TH., eds. Data Structures and Efficient Algorithms. Berlim, Springer, $1992 . \quad$ p. 104123. (Lecture Notes in Computer Science, n. 594)

[Kukich, 92] KUKICH, K. Techniques for Automatically Correcting Words in Text. ACM Computing Surveys. v. 24, n. 4, p. 377-440, 1992.

[Kuman et al., 98] KUMAN, A;; TSOSTRAS, U.J.; FALOUTSOS, C. Desining Access Methods for Bitemporal Databases. IEEE Transactions on Knowledge and Data Engineering. v. 10, n. 1, p. 1-20, 1998.

[Langsam et al, 96] LANGSAM, Y.; AUGENSTEIN, M.J.; TENEMBAUM, A.M. Data Structures Using C And C++. 2.ed. New Jersey, Prentice Hall, 1996.

[LinK et al., 94] LIN, K.-I; JAGADISH, H.V.; FALOUTSOS, C. The TV-tree - An Index Structure for High-Dimensional Data. Very Large Data Bases Journal. v. 3, n. 4, p. 517 $542,1994$.

[Marsh, 97] MARSH, A. EUROMED - The Creation of a Telemedical Information Society. In: IEEE SYMPOSIUM ON CBMS, 10. Anais. Maribor, 1997. p. 86-91.

[Nascimento \& Silva, 98] NASCIMENTO, M.A.; SILVA, J.R.O. Towards Historical R-Trees. In: ACM SYMPOSIUM ON APPLIED COMPUTING. Proceedings. Atlanta, 1998 . p. 235-240. 
[Nievergelt et al., 84] NIEVERGELT, J.; HINTERBERGER, H.; SEVCIK, K.C. The Grid File: an adaptable, symmetric multikey file structure. In: ACM TRANSACTIONS ON DATABASE SYSTEMS. Proceedings. v. 9, n. 1, 1984. p. 38-71.

[Orenstein, 86] ORENSTEIN, J.A. Spatial Query Processing in an Object-Oriented Database System. In: ACM SIGMOD INTERNATIONAL CONFERENCE ON MANAGEMENT OF DATA. Proceedings. Washington D.C., 1986. p. 326-336.

[Patel \& DeWitt, 96] PATEL, J.M.; DEWITT, D. J. Partition Based Spatial-Merge Join. In: ACM SIGMOD INTERNATIONAL CONFERENCE ON MANAGEMENT OF DATA. Proceedings. Montreal, 1996. p. 259-270.

[Petrakis \& Faloutsos, 97] PETRAKIS, E.G.M.; FALOUTSOS, C. Similarity Searching in Medical Image Databases. IEEE Transactions on Knowledge and Data Engineering. v. 9, n. 3, p. $435-447,1997$.

[Ratib, 92] RATIB, O. Current Views on the Funcionalities of PACS. International Journal of Biomedicine Computing. v. 30, p. 193-199, 1992.

[Robinson, 81] ROBINSON, J.T. The K-D-B Tree: a search structure for large multidimensional dynamic indexes. In: ACM SIGMOD INTERNATIONAL CONFERENCE ON THE MANAGEMENT OF DATA. Proceedings. Ann Arbor, 1981. p. 10-18.

[Roussopoulus et al., 95] ROUSSOPOULUS, N.; KELLEY, S.; VINCENT, F. Nearest Neighbor Queries. In: ACM SIGMOD INTERNATIONAL CONFERENCE ON MANAGEMENT OF DATA Proceedings. San Jose, 1995. p. 71-79.

[Samet, 90] SAMET, H. The Design and Analysis of Spatial Data Structures. Reading, Addison-Wesley, 1990.

[Samet, 95] SAMET, H. Spatial Data Structures. In: KIM, W., ed. Modern Database Systems. Reading, Addison-Wesley/ACM, 1995. p. 361-385.

[Santos et al., 96] SANTOS, R. R.; TRAINA, A.J.M.; TRAINA JR., C. Uma Linguagem de Definição e Recuperação de Imagens Baseada em Conteúdo em uma Base de Dados Orientada a Objetos. In: SIMPÓSIO BRASILEIRO DE BANCO DE DADOS, 11. Anais. São Carlos, 1996. p. 127-142.

[Santos Filho et al., 99a] SANTOS FILHO, R.F.; TRAINA, A.J.M.; TRAINA JR., C. Algoritmos Para Indexação em Bases de Dados Através de Estruturas Multidimensionais. São Carlos, ICMC-USP, Abril 1999. (Relatório Técnico $n^{0}$ 85). [ Disponível via FTP em <ftp.icmc.sc.usp.br/pub/BIBLIOTECA/rel_tec/Rt_85.ps.zip> ]

[Santos Filho et al., 99b] SANTOS FILHO, R.F.; TRAINA, A.J.M.; TRAINA JR., C. Indexando Pontos em Espaços com Altas Dimensões Através dos Métodos de Indexação Espacial K-D-B-Tree, R-Tree e TV-Tree: uma breve comparação analítica. São Carlos, ICMC-USP, Abril 1999. (Relatório Técnico no 86). [ Disponível via FTP em <ftp.icmc.sc.usp.br/pub/BIBLIOTECA/rel_tec/Rt_85.ps.zip> ] 
[Santos, 97] SANTOS, R. R. Incorporação do Tipo de Dado Imagem em um Banco de Dados Orientado a Objetos. São Carlos, 1997. Tese (Doutorado) - Instituto de Física de São Carlos, Universidade de São Paulo.

[Schneider, 97] SCHNEIDER, M. Spatial Data Types for Database Systems: finite resolution geometry for geographic information systems. Berlim, Springer, 1997. (Lecture Notes in Computer Science, n. 1288).

[Sclabassi et al., 96] SCLABASSI, R.J.; KRIEGER, D.; SIMON, R.; LOFINK, R.; GROSS, G.; DELLAUDER, D.M. NeuroNet: collaborative itraoperative guidance and control. IEEE Computer Graphics and Applications. v. 16, n. 1, p. 39-45, 1996.

[Sellis et al., 97] SELLIS, T.K.; Roussopoulos, N.; Faloutsos, C. Multidimensional Access Methods: trees have grown everywhere. In: INTERNATIONAL CONFERENCE ON VERY LARGE DATA BASES. Proceedings. Athens, 1997. p. 13-14.

[Smith \& Chang, 94] SMITH, J.R.; CHANG, S.-F. Quad-Tree Segmentation for Texture-Based Image Query. In: ANNUAL ACM MULTIMEDIA CONFERENCE, 2. Proceedings. San Francisco, p. 279-286, 1994.

[Tamura \& Yokoya, 84] TAMURA, H.; YOKOYA, N. Image Database Systems: a survey. Pattern Recognition. v. 17, n. 1, p. 29-49, 1984.

[Tayeb et al., 98] TAYEB, J.; ULUSOY, Ö; WOLFSON, O. A Quadtree-base Dynamic Attribute Indexing Method. The Computer Journal. v. 41, n. 3, 1998.

[Tchounikine et al., 97] TCHOUNIKINE, A.; AMGHAR, Y.; FLORY, A. Semantic Interrogation for a Radiological Documentary Record. In: IEEE SYMPOSIUM ON CBMS, 10. Anais. Maribor, 1997. p. 98-102.

[Traina et al., 98] TRAINA JR., C.; TRAINA, A.J.M.; SANTOS, R. R.; SENZAKO, E. Y. A Tool for Content-Based Medical Image Retrieval Object Oriented Databases. In: BIENAL WORLD CONFERENCE ON INTEGRATED DESIGNS AND PROCESS TECNOLOGY - ISSUES AND APPLICATIONS OF DATABASE TECHNOLOGY, 3. Proceedings. Berlim, 1998. p. 344-351.

[Traina, 86] TRAINA JR., C. Máquina e Modelo de Dados Dedicados para Aplicações de Engenharia. São Carlos, 1986. Tese (Doutorado), Instituto de Física de São Carlos, Universidade de São Paulo.

[White \& Jain, 96a] WHITE, D.A.; JAIN, R. Algorithms and Strategies for Similarity Retrieval. San Diego, University of California, Visual Computing Lab., Junho 1996. (Technical Report VCL-96-101). [ Disponível via FTP em $<$ http://vision.ucsd.edu/papers/simret/journ1.ps.gz> ]

[White \& Jain, 96b] WHITE, D.A.; JAIN, R. Similarity Indexing with the SS-tree. In: INTERNATIONAL CONFERENCE ON DATA ENGINEERING, 22. Proceedings. New Orleans, 1996 . p. 516-523. 
[Zaniolo et al., 97] ZANIOLO, C.; CERI, S.; FALOUTSOS, C.; SNODGRASS, R.T.; SUBRAHMANIAN, V.S.; ZICARI, R. Advanced Database Systems. Morgan Kaufmann Publishers, 1997.

[Zhou et al., 97] ZHOU, X.; ABEL, D.J.; TRUFFET, D. Data Partitioning for Parallel Spatial Join Processing. Berlim, Springer, 1997. (Lecture Notes in Computer Science, n. 1262) 